\title{
Divine discrimination: gender harassment and Christian justification
}

Abigail L. Muldoon

DePaul University, abigailmuldoon@gmail.com

Follow this and additional works at: https://via.library.depaul.edu/etd

\section{Recommended Citation}

Muldoon, Abigail L., "Divine discrimination: gender harassment and Christian justification" (2015). College of Liberal Arts \& Social Sciences Theses and Dissertations. 190.

https://via.library.depaul.edu/etd/190

This Thesis is brought to you for free and open access by the College of Liberal Arts and Social Sciences at Digital Commons@DePaul. It has been accepted for inclusion in College of Liberal Arts \& Social Sciences Theses and Dissertations by an authorized administrator of Digital Commons@DePaul. For more information, please contact digitalservices@depaul.edu. 


\title{
DIVINE DISCRIMINATION: GENDER HARASSMENT AND CHRISTIAN
} JUSTIFICATION

\author{
A Thesis \\ Presented in \\ Partial Fulfillment of the \\ Requirements for the Degree of \\ Master of Arts
}

June 2015

BY

Abigail L. Muldoon

Department of Women's and Gender Studies

College of Liberal Arts and Social Sciences

DePaul University

Chicago, Illinois 


\title{
THESIS COMMITTEE
}

Midge Wilson, Ph. D.

Committee Chair

\author{
Beth Catlett, Ph. D.
}

Frida Furman, Ph. D. 


\section{ACKNOWLEDGMENTS}

I would like to express my sincere appreciation to my committee chair, Dr. Midge Wilson. Her guidance has been instrumental in developing this thesis. I would like to thank Dr. Beth Catlett for always keeping me grounded in feminist frameworks and Dr. Frida Furman for her input in shaping the sections of this project regarding religion. Many thanks to Dr. Kimberly Quinn for her invaluable support during the IRB process of this study and for providing feedback

for the methods and results section of this thesis. I would also like to thank my friends and colleagues at the Division of Adolescent Medicine of Ann \& Robert H. Lurie Children's Hospital of Chicago for their emotional support and insightful feedback. Last but certainly not least, I would like to thank my husband, Patrick, for his continued support throughout this project. Whether it was making dinner almost every night for the past three years or being a sounding board for my thoughts regarding this project, he has been the best partner a graduate student or wife could ask for. 


\section{TABLE OF CONTENTS}

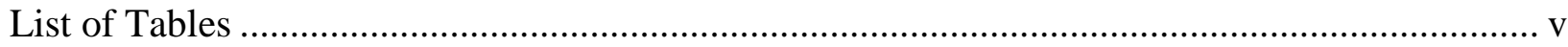

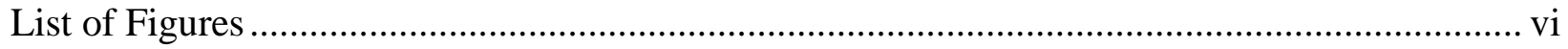

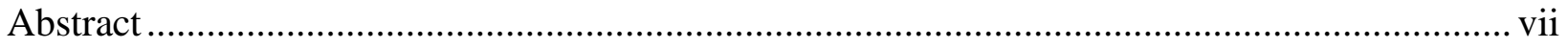

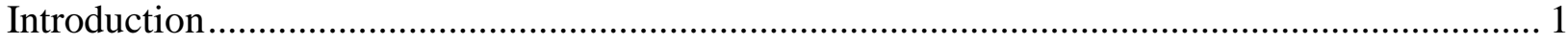

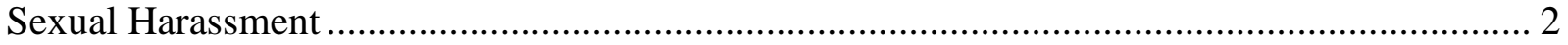

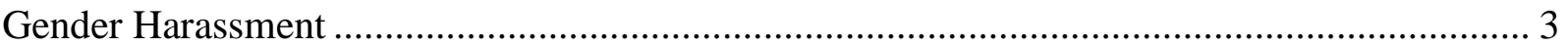

Contemporary conceptualizations ……………………………………………………..... 3

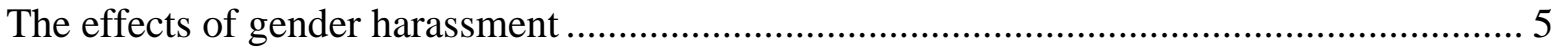

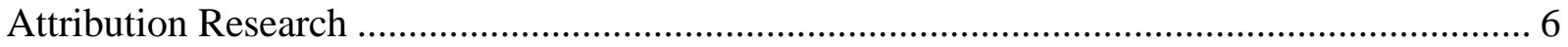

Christian Belief and Gender Ideology .......................................................................... 10

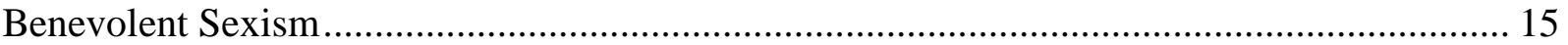

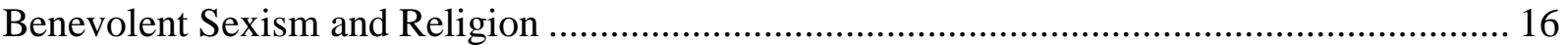

Religious-Based Harassment........................................................................................ 17

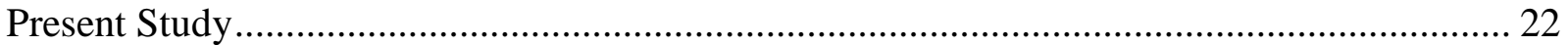

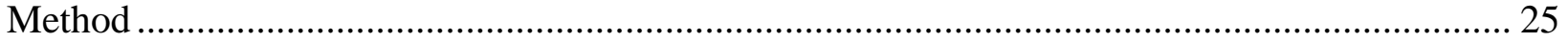

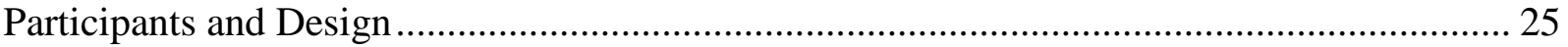

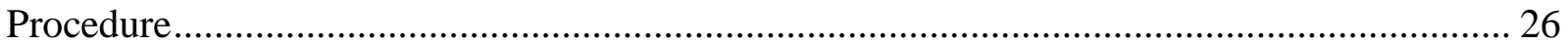

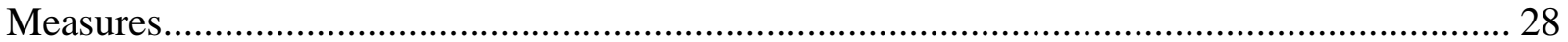

Gender harassment ………………………………............................................. 29

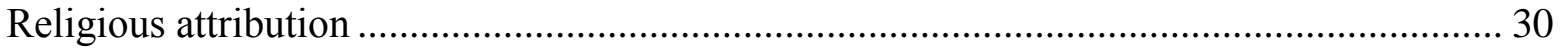

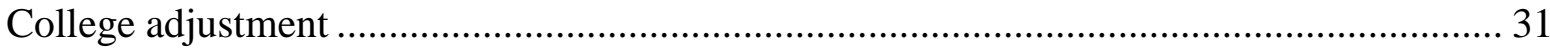

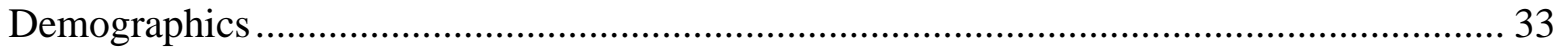

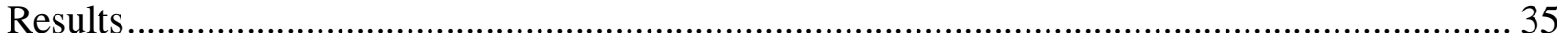

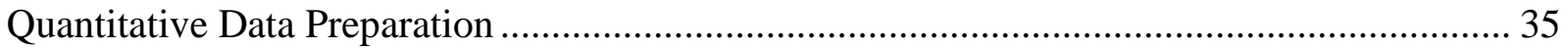

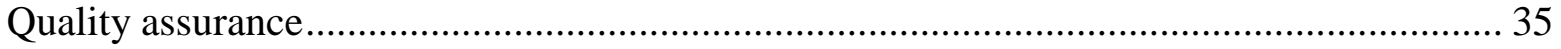

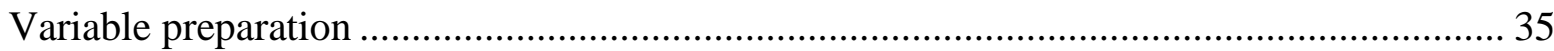

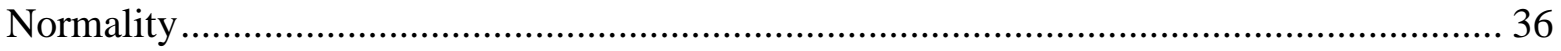

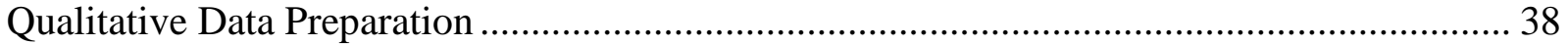

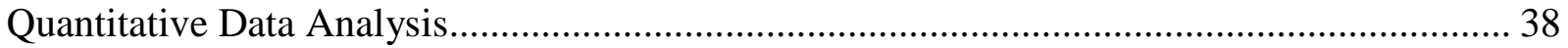

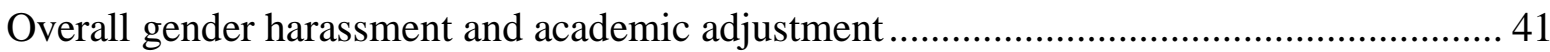

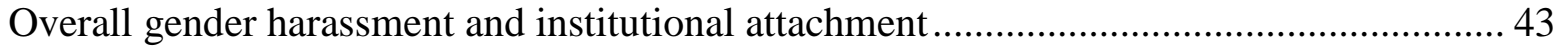

Overall gender harassment and personal-emotional adjustment ........................................... 44 


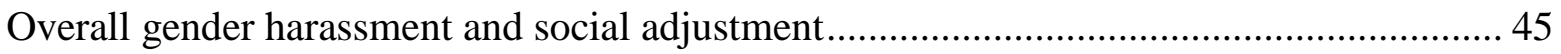

Overall gender harassment and overall college adjustment ............................................... 46

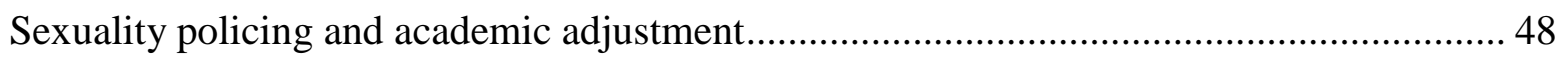

Sexuality policing and institutional attachment............................................................... 49

Sexuality policing and personal-emotional adjustment ....................................................... 50

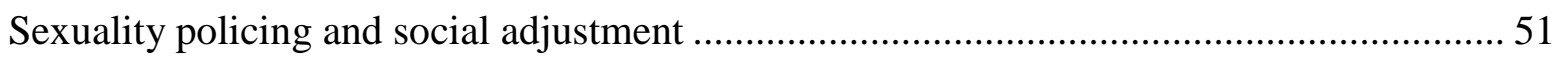

Sexuality policing and overall college adjustment ………….......................................... 52

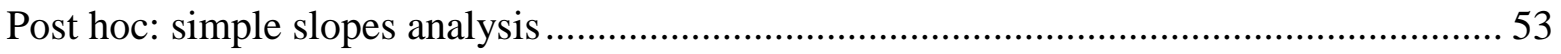

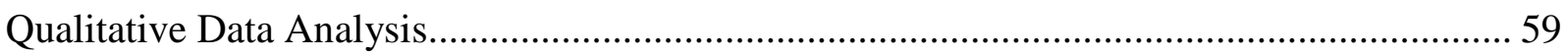

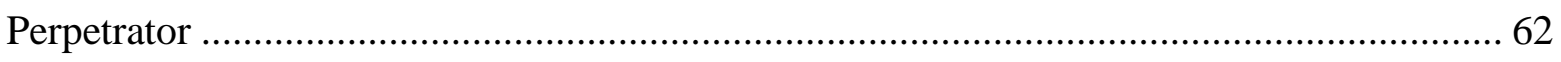

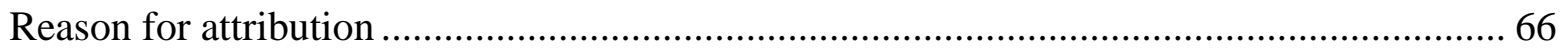

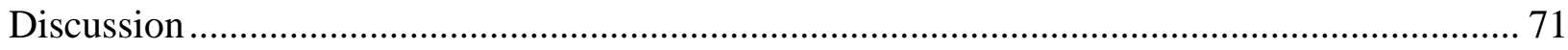

Normative Behavior and Perceived Injustice.................................................................... 74

Sexuality Policing: Adolescent Development and Christian Control …….............................. 82

Social Adjustment: Potential Protection ............................................................................ 90

Limitations and Future Directions ..................................................................................... 92

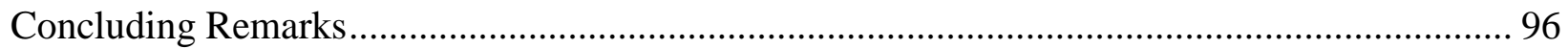

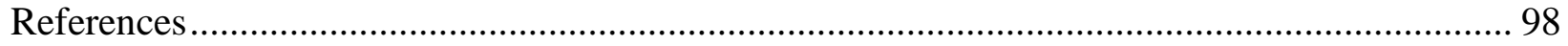

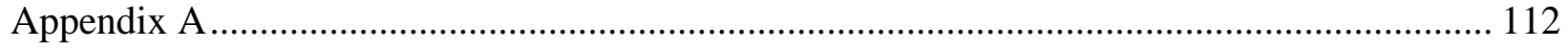

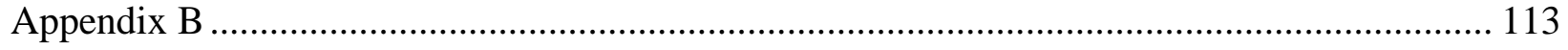

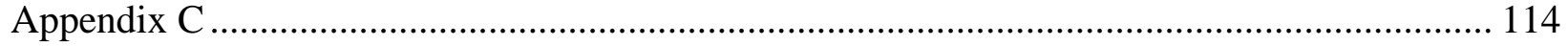

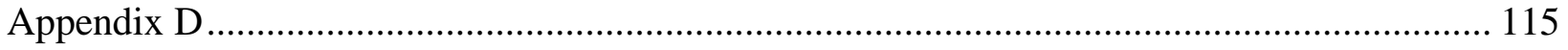




\section{$\underline{\text { LIST OF TABLES }}$}

Table 1. Intercorrelations Among Gender Harassment Subscales and Sexuality Policing Scale 30

Table 2. Intercorrelations Among Student Adaptation to College Questionnaire Subscales....... 32

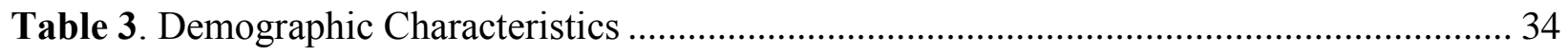

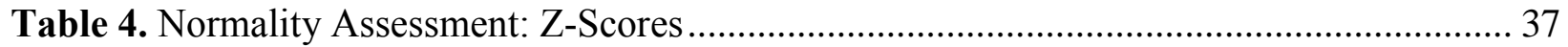

Table 5. Correlations for Overall GEQ Regression Variables................................................ 41

Table 6. Correlations for Sexuality Policing Regression Variables...................................... 41

Table 7: Hierarchical Regression Analysis: Gender Harassment and Academic Adjustment..... 42

Table 8: Hierarchical Regression Analysis: Gender Harassment and Institutional Attachment.. 43

Table 9: Hierarchical Regression Analysis: Gender Harassment and Personal-Emotional

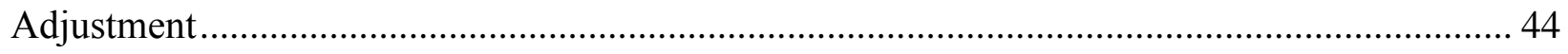

Table 10: Hierarchical Regression Analysis: Gender Harassment and Social Adjustment......... 45

Table 11: Hierarchical Regression Analysis: Gender Harassment and Overall College

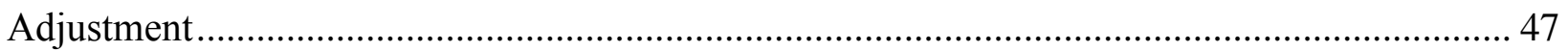

Table 12: Hierarchical Regression Analysis: Sexuality Policing and Academic Adjustment..... 49

Table 13: Hierarchical Regression Analysis: Sexuality Policing and Institutional Attachment.. 50

Table 14: Hierarchical Regression Analysis: Sexuality Policing and Personal-Emotional

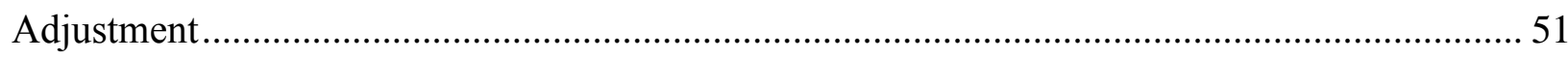

Table 15: Hierarchical Regression Analysis: Sexuality Policing and Social Adjustment ........... 52

Table 16: Hierarchical Regression Analysis: Sexuality Policing and Overall College

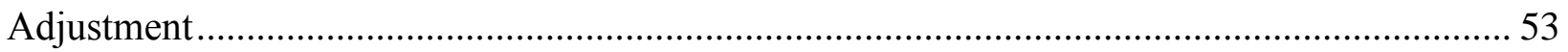

Table 17: Post Hoc Simple Slopes T-Tests for Sexuality Policing and College Adjustment...... 54

Table 18: Word Frequency Chart Generated by NVivo (Exact Match Only) .......................... 59 


\section{LIST OF FIGURES}

Figure 1. Simple slopes of sexuality policing predicting levels of academic adjustment for low

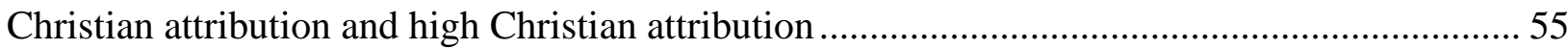

Figure 2. Simple slopes of sexuality policing predicting levels of institutional attachment for low Christian attribution and high Christian attribution ........................................................ 56

Figure 3. Simple slopes of sexuality policing predicting levels of personal-emotional adjustment

for low Christian attribution and high Christian attribution 57

Figure 4. Simple slopes of sexuality policing predicting levels of overall college adjustment for low Christian attribution and high Christian attribution 58 


\begin{abstract}
$\underline{\text { ABSTRACT }}$
Gender harassment (i.e., derogatory comments or actions that express stereotypical attitudes regarding someone's gender) is often times the most prominent form of sex-based harassment directed towards women in both workplace and academic settings. This study explored the moderating effect of Christian attribution on gender harassment predicting college adjustment for college women using a mixed-methods approach rooted in feminist theoretical perspectives. Two hundred twenty-three female-identified students attending a Catholic university in a large, urban city completed the Gender Experiences Questionnaire (GEQ), a measure designed to capture instances of sexuality policing, indicated whether they believed reported harassment was motivated by the Christian/Catholic belief of the perpetrator, and completed the Student Adaptation to College Questionnaire (SACQ). Additionally, participants were asked to write about their experiences of reported Christian-motivated gender harassment. Overall gender harassment negatively predicted college adjustment. Additionally, Christian attribution was found to moderate the impact of sexuality policing on college adjustment. A qualitative analysis of participants' own descriptions of Christian-motivated gender harassment revealed that participants identified their classmates/peers as the most common perpetrator(s) of harassment and the most common cited reason for making a Christian attribution was knowing the perpetrator's Christian/Catholic religious affiliation. Conclusions, limitations of the study, and future directions for research are discussed.
\end{abstract}

Keywords: gender harassment, sex-based harassment, divine discrimination, Christianmotivated harassment, college adjustment 


\section{Introduction}

My own college experience was marked by two seemingly opposing transitions: my Christian faith was solidifying and my identity as a feminist was intensifying. Perhaps not surprisingly, the campus Christian organization in which I was heavily invested opposed my feminist gender ideologies while my growing circle of feminist friends seriously questioned any devotion to Christianity. The Christian group eventually revealed itself to be entrenched in conservative Evangelicalism and thus actively advocated anti-gay and anti-feminist ideologies. Tensions grew to a boiling point when the leader's wife and I got into a heated discussion about the role of women in marriage. She believed a wife should be a subservient helper to the husband, who is head of the household, and I had come to strongly disagree with that position. As our debate turned into an argument, she finally exclaimed in frustration, "Well, if that's how you feel about Christian marriage, then don’t get married!" I remember feeling very jarred by this response. People had disagreed with me before because of my feminist politics but never had I been left quite so stunned by this declaration. There was something harshly different about a fellow Christian not just disagreeing with me, but being of the conviction that I was wrong and she was right because God was on her side. I felt defeated and belittled, while she seemed to feel totally justified in her divine discrimination.

The dual-identity of being both a Christian and a feminist has since led to a number of other similar incidents in my life: someone deploying a conservative Christian narrative to belittle my feminist-informed beliefs about gender. Each time it happened, I felt not just gender harassed but also silenced by having been put into a non-negotiable corner. 
These types of occurrences have led me to develop an interest in the emotional effects of gender harassment. More specifically, I am interested in how religious attributions used to justify gender harassment can intensify resulting negative feelings, sometimes referred to as "sanctified sexism" (Hall, Christerson, \& Cunningham, 2010). The following thesis is an investigation of the current traditional gender ideologies produced by Catholicism and Christian Protestant denominations, and of the feminist-inspired responses to these traditional beliefs. After a review of traditional gender ideologies prescribed by hegemonic Christian institutions, I further explore the potential negative effects of using these Christian-based gender ideologies to justify gender harassment. This Christian-motivated gender harassment is a form of "divine discrimination," a term I am using to describe the phenomenon of using a Christian belief or ideology to motivate and justify minority discrimination. Utilizing a mixed-methods approach, this thesis uses both quantitative and qualitative methods to further detect the moderating effect of Christian attribution of gender harassment on levels of college adjustment in female university students. ${ }^{1}$ This study aims to provide evidence that gender harassment is associated with impaired college adjustment, but especially when the harassment is believed to be motivated by the Christian belief of the perpetrator.

\section{Sexual Harassment}

Historically, gender harassment has been theorized as a subdomain of sexual harassment. As noted by Fitzgerald, Gelfand, and Drasgow (1995), the first attempt to comprehensively classify the experiences of sexual harassment among students was issued by the National Advisory Council on Women's Educational Program in a publication entitled Sexual harassment:

\footnotetext{
${ }^{1}$ In the context of quantitative research, moderating refers to the extent that the impact of an independent variable (i.e., gender harassment) on a dependent variable (i.e., college adjustment) is being influenced either by minimizing or maximizing the effect, by a third variable (i.e., Christian attribution).
} 
A report on the sexual harassment of students (Till, 1980). Given the myriad of scholars who were proposing their own conceptualizations of sexual harassment, some of which were legally based ones occurring in workplace settings, the Council was hesitant to establish its own definition of sexual harassment in the academy. However, the Council's report did emphasize a "victim-based" approach, stating that academic sexual harassment "is the use of authority to emphasize the sexuality or sexual identity of a student in a manner which prevents or impairs that student's full employment of educational benefits, climate, or opportunities" (Till, 1980, pp. 6-7). The report identified five dimensions of sexual harassment ranked in order of severity from least offensive to most: 1) Generalized sexist remarks or behavior, 2) Inappropriate and offensive, but essentially sanction-free sexual advances, 3) Solicitation of sexual activity or other sex-linked behavior by promise of rewards, 4) Coercion of sexual activity by threat of punishment, and 5) Sexual assaults (Till, 1980, pp. 7-8). Drawing on the same categorization schema, Fitzgerald et al. (1988) developed the Sexual Experiences Questionnaire (SEQ) to capture the five dimensions of sexual harassment which they identified as: 1) gender harassment, 2) seductive behavior, 3) sexual bribery, 4) sexual coercion, and 5) sexual assault, respectively. Fitzgerald, Gelfand, and Drasgow (1995) remodeled the SEQ based on theoretical advances in measuring sexual harassment to narrowly define only three dimensions: 1) gender harassment, 2) sexual coercion and 3) unwanted sexual attention.

\section{Gender Harassment}

Contemporary conceptualizations. As defined by Fitzgerald, Gelfand, and Drasgow (1995), gender harassment refers to "a broad range of verbal and nonverbal behaviors not aimed at sexual cooperation but that convey insulting, hostile, and degrading attitudes about women" (p. 430). Unlike sexual harassment, gender harassment stems from stereotypical attitudes about and 
prejudice towards gender and gender roles. Such harassment in the form of comments or actions that express these stereotypical attitudes (e.g., "you cannot lead, you are a woman") are experienced as derogatory, belittling, and/or demeaning.

Contemporary conceptualizations of gender harassment posit that it is its own construct distinct from sexual harassment (Leskinen \& Cortina, 2014; Leskinen, Cortina, \& Kabat, 2011; Lim \& Cortina, 2005). While sexual coercion and unwanted sexual attention both address a range of behaviors that force or express unwanted interest in a sexual relationship, gender harassment does not require the presence of a sexual desire (Lim \& Cortina, 2005). As Lim and Cortina (2005) conclude, "gender harassment, being hostile but nonsexual, should remain a separate construct that is correlated" with unwanted sexual attention and sexual coercion (p. 484). In fact, gender harassment has been found to be more common than sexual coercion and unwanted sexual attention in both workplace and academic populations (Eliason, Hall, \& Anderson, 2012; Fitzgerald, et al., 1988; Huerta, Cortina, Pang, Torges, \& Magely, 2006; Leskinen, Cortina, \& Kabat, 2011; Lim \& Cortina, 2005; van Roosmalen \& McDaniel, 1999). Gender harassment, along with sexual coercion and unwanted sexual attention (i.e., a dichotomous conceptualization) are better understood as subdomains of sex-based harassment, any behavior that "derogates, demeans, or humiliates an individual based on that individuals' sex" (Berdahl, 2007, p. 644). Recently, Leskinen and Cortina (2014) developed the Gender Experiences Questionnaire (GEQ) which measures five dimensions of gender harassment: 1) sexist remarks, 2) sexually crude/offensive behavior, 3) infantilization, 4) work/family policing, and 5) gender policing.

The conceptualization of gender harassment as distinct from sexual harassment is fairly new. Given the longstanding conflation of these two constructs, research focusing on sexual 
harassment will be used to inform the understanding of gender harassment, and thus is included in this thesis. While these two concepts are separate from one another, gender harassment has been studied as a dimension of sexual harassment for so long it would be amiss to omit research focusing on the latter. For the remainder of this thesis, I use the term "sexual harassment" as necessary to stay consistent with the terminology used in prior literature although it refers to the confounding measurements of both constructs. I do, however, make a point to mention the specific concept of "gender harassment" when authors have also made the necessary distinction.

The effects of gender harassment. The study of gender harassment distinct from sexual harassment is often neglected in research. Perhaps this is to be expected as gender harassment, compared to the unwanted sexual attention and coercive elements of sexual harassment, is often considered a less important and legitimate negative behavior (Tang, Yik, Cheung, Choi, \& Au, 1995). When gender harassment has been studied, its typical focus is the harmful consequences for women in the workplace. For example, Leskinen, Cortina, and Kabat (2011) found that women in the military who experienced gender harassment not associated with sexual harassment reported "lower psychological well-being, job performance, job commitment, and satisfaction with their employment and health" while female attorneys experiencing the same harassment reported "lower satisfaction with professional relationships and higher job stress" (p. 36). Raver and Nishii (2010) found that gender harassment was associated with reduced job satisfaction, organizational commitment, psychological outcomes, and increased turnover intentions. Lim and Cortina (2005) found that gender harassment and workplace incivility (rude and antisocial behaviors towards others at work) were associated with more negative job-related outcomes (defined as job satisfaction, withdrawal, and stress) and psychological health (defined as psychological distress, well-being, life satisfaction, and health satisfaction). One major study 
focusing on the gender harassment of women in academia found that for participants experiencing gender harassment (defined as a sexual insult/invitation and disparaging jokes and comments made at the expense of women), almost $44 \%$ stated a loss of trust in men, over $22 \%$ reported a decrease in confidence, and over $2 \%$ reported negative health outcomes (van Roosmalen \& McDaniel, 1999, p. 43).

Given the dearth of research that focuses on the unique experiences of gender harassment isolated from sexual harassment and its ubiquitous nature in society, more research should be devoted to understanding this form of sex-based harassment in a variety of settings. One such example is college campuses. Sexual harassment is prominent in university settings with one in five women reporting they have been sexually assaulted while in college (The White House Council on Women and Girls, 2014). With most measures of sexual harassment also gauging dimensions of gender harassment, the latter may be just as pervasive in this setting. More attention should be paid to parsing out the specific effects of gender harassment on college students, given its particular negative consequences.

\section{Attribution Research}

Harold Kelley developed a model of attribution in the 1960s. His goal was to identify the factors that observers, including the self, use when assigning responsibility to events (Kelley, 1967). His contribution to research has spawned decades of scholarship and given birth to new terminology and theory, including self-aggrandizement effect, self-perception theory, and the attribution-of-blame model of judgements of injustice. Kelley posits that when observers make attributions for an actor's response to a behavior, three factors come into play: consensus, consistency and distinctiveness. As cited in Klein, Apple, and Kahn (2011), consensus means 
that others react to a stimulus in a similar manner as the actor did; there is high consensus among a comparison group in how actors should respond to a certain situation. Consistency is defined as whether the actor responds to a stimulus in the same manner over time; there is high consistency when the actor responds to a stimulus in a similar manner longitudinally. Distinctiveness is defined as whether the actor only has the response in the presence of the stimuli; if an actor's response is unique to the stimulus then it is high in distinctiveness. Each of these three factors can present at high or low in a given situation (Kelley, 1967).

Depending upon the combination of the these factors and what level they are endorsed, one of three kinds of attributions are made: 1) High consensus is indicative of a situational attributional pattern meaning that if others are known to respond to a stimulus in a similar manner as the actor, an observer will attribute the actor's response not to something unique about the actor, but to the situation, i.e., something about the situation encourages all actors to respond in a specific way; 2) Low distinctiveness is associated with the dispositional attributional template, meaning if the actor reacts to a stimulus in the same manner as other stimuli, it is something unique to the actor (i.e., she/he is responsible) as to why she/he is having the reaction she/he is; and 3) Low consistency is associated with the circumstantial attributional pattern, meaning if the actor's response is known to be inconsistent with her/his typical response to a stimulus, observers conclude the actor's response must be related to something about the specific circumstance (Kelley, 1967).

Less investigated have been the emotional experiences of the self as a function of the perceived causes of an event directed at oneself. There has been research, however, on the role of attributional thinking as an important cognitive activity that takes place after experiencing an unjust situation. 
Mikula (1993) developed a model of perceiving injustice (later deemed the "attributionof-blame model of judgements of injustice") which is composed of several factors: 1) the observation that someone has experienced a violation of entitlement, or outcomes that people consider themselves or others deserving of based on "who they are and what they have done" (Mikula, 2003, p. 793); 2) responsibility for the violation is attributed to someone (not the victim of the violation of entitlement); and 3) there is insufficient support for justifying the violation of entitlement. As such "judgments of injustice are conceived as a particular instance of blaming: blaming an agent who is seen as responsible for the violation of entitlement of somebody else without sufficient justification” (Mikula, 2003, p. 795). Additionally, Mikula (2003) found evidence that beyond perceiving that someone has experienced a violation of entitlement, judgments regarding justice also depend upon attributions of causality, intention, and whether or not there is specific justification for the violation.

Someone experiencing an injustice within an interpersonal relationship often responds by making attributional assessments in an attempt to search for potential causes of the injustice (Mikula \& Schlamberger, 1985). Attributions of responsibility and blame can operate as moderators of people's reactions to violations of entitlement. Mikula (2003) argues that when someone experiences a violation of entitlement, a person engages in attributional thinking in order to understand the cause of the violation and determine who is responsible for causing it. The attributions of cause and responsibility affect the emotional and psychological reactions to the violations (Mikula, 2003; Miller, 2001). With regards to the present study, people experiencing gender harassment (i.e., an unjust situation that is a violation of their entitlement to transgress traditional gender roles without consequence) may engage in attributional thinking in 
order to understand who and/or what caused the behavior, including any potential religiousbased justifications.

Studies show there are gendered differences in the attributions men and women make when it comes to harassment. One study revealed that men are more likely to blame victims for their harassment (Kenig \& Ryan, 1986). This may play a role in religious-motivated harassment as Christian men may believe the harassment is warranted by the transgressive behavior of the victim. Christian men who witness women disobeying traditional gender role prescriptions may believe the harassing behavior is a divinely mandated correction.

Additionally, Kenig and Ryan (1986) found women were more likely to see mild sexual harassment (defined as "sex-stereotyped jokes or depictions, teasing remarks of a sexual nature, and unwanted suggestive looks or gestures") as an organizational problem rather than simply just an interpersonal issue (p. 542). This offers evidence for women seeing that gender harassment should not be dealt with solely within the context of interpersonal relationships, but should also be of concern to the Church and Christian institutions that allow this kind of behavior to manifest and perpetuate. Additionally, women's ability to recognize the role organizations play in harassment may mean they are more likely to attribute the cause of gender harassment to a belief endorsed by an institution such as the Christian church.

Jensen and Gutek (1982) found that women who held traditional gender ideologies were more likely to blame victims (including themselves) for occurrences of sexual harassment. Christian women who hold more conservative gender ideologies may be less likely to report harassing behavior as such, or attribute cause to the perpetrator. When researchers are collecting data to assess harassment they may want to avoid using questions that specifically references the 
phrase "gender harassment" as participants may not be labeling their own experiences as harassment, even though those experiences may qualify as such.

Attribution theory helps to explain how women may interpret and attribute responsibility for harassment. Given the negative nature of gender harassment, victims experiencing these injustices are more likely to be engaging in attributional thinking in order to determine the causal source of harassment. These causal sources or instances of blaming can moderate women's reactions to harassment and their outcomes. Specific and unique emotional and psychological reactions of the harassment can occur when religious motivation is perceived to be the root cause - or the excuse used to justify the harassing behavior.

\section{Christian Belief and Gender Ideology}

Many Christian denominations endorse a traditional gender ideology which states that women and men are equal in worth but designed by God for different roles. These role differences are intended to complement one another and apply to family life, religious leadership, and sometimes society (Butler, 2007; Driscoll \& Driscoll, 2012; Francis, 2013; Grudem, 1994; MacArthur, 2011; Piper \& Grudem, 1991; St. Pierre, 1994). Referred to as complementarianism, this ideology is rooted in scripture from both the Old and New Testaments of the Bible, which were written in a time when gendered-based divisions of labor were necessary for survival. Complementarianism assigns leadership positions to men and support roles to women: men are to be the heads of their family and church, while women should provide loving support to help enable male leadership (Grudem, 1994, pp. 459 - 465; MacArthur, 2011; Piper \& Grudem, 1991). Public sphere leadership is thus delegated to men (who are expected to provide for the family and lead church congregations) and private sphere leadership is delegated 
to women (who are expected to be primary caregiver to the children and maintain the home front). While supporters of complementarianism insist that although men and women are designed for different roles and spaces, there is "firm conviction that men and women are equal in dignity" (Francis, 2013).

While supporters of complementarianism might proclaim the worth of men and women as being equal, in reality the nature of the assigned roles favors one sex over the other. With men having access to public spaces of leadership, including the priesthood and other top clergy positions, a hierarchy is created that clearly privileges men. Meanwhile women are lauded for their traditional femininity and ability to bear and raise children, but the private sphere, in which women dwell and have some influence, is bound to be subordinate. Women's designation as leaders of the private sphere limit their impact on their community, the responsibilities they can take on in and outside of the Church, and the authority they have in the spaces where they do assume leadership (St. Pierre, 1994, pp. 112-116). Under the guise of being complementary and equal, the different roles assigned to men and women actually serve to establish male dominance and to ensure a system of patriarchy, both within the church and outside of it.

Many critics of complementarianism point out that the subordination of "women's roles" cannot logically coexist with genuine gender equality (Pierce \& Groothuis, 2004). Women's existence as female, not their skill set or experience is in and of itself what requires them to be submissive to public male leadership. It is not the roles women take on which dictate their position as private sphere supporters of public male leadership; it is their fundamentally ontological nature of being female (Pierce \& Groothuis, 2004). As writer Rebecca Merrill Groothuis states, "Women's inferior 'role' cannot be defended by the claim that it is ontologically distinct from woman's equal being... being determines role and role defines 
being..." (Pierce \& Groothuis, 2004, p. 333). In other words, claiming women are equal to men in worth but designed by God to have different roles makes no logical sense when those roles are inherent to one's biological sex, and positioned in a hierarchy that privileges public male leadership over private female support.

Catholic teachings have long endorsed a complementarian gender ideology ${ }^{2}$ (D'Emilio, 2014; Francis, 2013; John Paul II, 1988; Sacred Congregation for the Doctrine of the Faith, 1976). Women have continuously been denied the right to priesthood (Butler, 2007; John Paul II, 1994; Ruether, 2008; Sacred Congregation for the Doctrine of the Faith, 1976), even while Catholic teachings praise women for their unique contributions to the Church as wives, mothers, and daughters (John Paul II, 1988). Catholic officials also laud women for their feminine qualities and the work they do in providing necessary support for church leaders (Francis, 2013; John Paul II, 1988). This behind-the-scenes work is akin to another private sphere in which women can work but not hold any real positions of power. While individual Catholic parishes and believers may hold more progressive social views (Martínez, Rodríguez-Entrena, \& Rodríguez-Entrena, 2012; The Pew Forum on Religion and Public Life, 2008), the highest Catholic leaders, including the Pope, institutionalize a traditional and complementarian gender ideology in the Church's doctrine and beliefs. More recently, Pope Francis wrote that "women make [an indispensable contribution] to society through the sensitivity, intuition and other distinctive skill sets which they, more than men, tend to possess" yet continued to affirm that "the reservation of the priesthood to males...is not a question open to discussion" (Francis,

\footnotetext{
${ }^{2}$ As cited in Butler (2007), prior to the 1940's women's equal worth to men was never explicitly addressed by Catholic teachings, although they did extol women's place in the private sphere of family life (Harahan, 1983). After Pope Pius XII (pontificate: 1939 - 1958) and the Second Vatican Council (1962 - 1965), Catholic and papal teachings responded to the growing feminist movement by specifically addressing and reaffirming women's unique contribution to the Church and society as wives and mothers. This praise of women's role as leaders of the private sphere of family life was then coupled with the assertion that although men and women are designed for leadership in different spaces, they are equal in dignity and worth as human beings (Harahan, 1983; Ruether, 2008).
} 
2013). Pope Francis continues to commend women for their "God-given" femininity which he sees as a gift to the Church, but continues to espouse that the highest and most powerful positions of leadership in the Catholic Church are only intended for men (D'Emilio, 2014).

Protestant denominations espouse more varying gender ideologies. At one end of the continuium, prominent right-wing Evangelical and Baptist theologians interpret Biblical verses as infallible evidence for complementarianism (Grudem, 1994, pp. 454 - 471; Grudem, 1996; Piper \& Grudem, 1991; MacArthur, 2011; Driscoll \& Driscoll, 2012). However, at the other end, beginning in the 1970's new Biblical scholars began putting forth dissenting (i.e., egalitarian) interpretations of the very same passages of scripture that have been used to justify a divine patriarchy through complementarianism (Pierce \& Groothuis, 2004, pp. 58-60). The married team of Baptist theologian Frank Stagg and his wife, Evelyn Stagg (1978) wrote that Jesus did not in fact endorse the status-quo patriarchy of his time but, instead, "crashed through many barriers as he related to women as persons" (p. 255). Turning on its head the commonly cited evidence that Jesus must have supported patriarchal ideas of church leadership as he chose only men to be a part of his twelve disciples, Stagg and Stagg argue that just because Jesus' closest followers were male does not in and of itself mean that all Biblical teachers and pastors must always be men. After all, all of the disciples were Jewish and it would be preposterous to analogously argue that only Jewish men could be Christian pastors today. They further conclude that what is of critical importance is that Jesus "affirmed" women and all who were disenfranchised in his day "with the fullest right to identity, freedom, and responsibility" (Stagg \& Stagg, 1978, pp. 123-125).

Retired New Testament professor Carroll D. Osburn (2001) also maintains that a more egalitarian view of gender and gender roles is better aligned with Christian ideals. In Women in 
the Church: Reclaiming the Ideal, he concluded, "maintaining restrictions [on women] in the areas of church and home has no biblical basis" (Osburn, 2001, p. 266). Similarly, New Testament scholar and retired Anglican Bishop N. T. Wright has endorsed egalitarian gender roles in arguing that women should be allowed to assume church leadership positions typically reserved for men (Wright, 2004; 2009). Wright further notes that scripture makes it clear that Jesus was constantly challenging the gender paradigm of his day in teaching women and allowing them to embody male (i.e., privileged) spaces (Wright, 2004).

While an increasing number of Protestant pastors and individual churches may have begun to move away from advocating complementarian notions of gender, it remains the case that in many Protestant and non-denominational churches today (e.g., Southern Baptist Convention, Lutheran Church - Missouri Synod, Presbyterian Church in America, and Sovereign Grace Ministries), complementarianism is still institutionalized (Grudem, 2006, p. 286). Drawing upon personal experience, while many Christian churches are beginning to espouse more egalitarian views of gender, the norm for many American Christian churches is still some variation of complementarianism even if it is presented as egalitarian (e.g., women may be allowed to lead musical worship, but are still not allowed to preach from the pulpit). As such, individual beliefs are still largely informed by traditional values that accentuate the prescribed role differences between men and women. It is no surprise that research reveals Christian beliefs and traditional gender role attitudes are related. For example, among women, religious devoutness (defined as frequency of participating in religious activities, reading the Bible, and experiencing religious feelings) has been linked to traditional gender role attitudes (Morgan, 1987), and among a sample of mostly Protestant (62.4\%) and Catholic (26.3\%) men and women, stronger religiosity has been found to be significantly and positively correlated with more 
traditional attitudes towards working women (Harville \& Rienzi, 2000). In one study using data from a worldwide survey sampling from over 90 countries and regions, Seguino (2011) found stronger religiosity (i.e., personal importance and frequency of attending religious services) was associated with significantly more gender inequitable attitudes in Catholicism and multiple other Protestant denominations. With a link established between Christian faith and traditional gender role attitudes, a question remains as to whether such attitudes translate into actual sexist behaviors. Berdahl (2007) concluded that contexts which "emphasize the superiority of one sex over another and distinctions between the sexes" are more susceptible to occurrences of sexbased harassment (p. 653). Conservative Christian churches which endorse complementarianism and stress the innate differences between men and women may be more at risk for creating and perpetuating a culture that actively encourages gender harassment.

\section{Benevolent Sexism}

Some Christians might contest any notion that traditional gender role attitudes are sexist since women are in fact highly valued for their femininity, an important attribute which complements men's masculinity. In other words, these Christians do not see their complementarian gender ideologies as problematic because they still value and honor women as wives and mothers (Driscoll \& Driscoll, 2012). The issue with this notion of women's roles, however, is that a gender ideology that in any way limits how a woman can identify herself or reduces her worth to how well she can enable male dominance is oppressive. While conservative Christians may value women for traditional femininity, many women who step outside of their prescribed private sphere roles of wives and mothers are met with disdain, disapproval, and suffer for it (Congregation for the Doctrine of Faith, 2007; Ingersoll, 2003). The same can be said for Christian men who assume roles in designated female terrain such as full-time spouse 
and primary caregiver of the children. While overt sexism against women, such as sexual violence, is easy to identify as problematic, covert sexism against women operating under the guise of equality presents a more ubiquitous and challenging problem.

Glick and Fiske (1997) analyzed the seemingly unproblematic gender ideologies that some men hold regarding women to develop their theory of ambivalent sexism, and the different forms it takes. The authors found that both hostile sexism and benevolent sexism (i.e., seemingly affectionate attitudes towards women based on notions of protective paternalism, complementarian gender role beliefs, and romanticized views of heteronormative sexual relationships between men and women) serve to justify and reproduce patriarchies and traditional gender roles (Glick \& Fiske, 1997). While hostile and benevolent sexism may differ in the valence of attitudes towards women, both still serve to promote male dominance, traditional gender role ideologies, and patriarchal social structures. Those who hold benevolent sexist views may believe they endorse a positive gender ideology of equality with regards to the value they place on men and women, but they still reinforce specific, gendered roles within a power imbalance: Those who endorse benevolent sexist attitudes may applaud women for their inherent femininity, but underlying their praise is the notion that women are inferior to and dependent on men.

\section{Benevolent Sexism and Religion}

Benevolent sexist attitudes linked to religiosity may serve to motivate gender harassment. A study by Burn and Busso (2005) found in their sample of mostly White Christians (Catholics being the most represented) that scriptural literalism (i.e., how closely you follow a literal and traditional interpretation of a Bible verse) was positively correlated with benevolent sexism, but 
not hostile sexism. Additionally, both intrinsic (internally motivated religion characterized by personal faith) and extrinsic religiosities (motivated by "social acceptance, friends, and God's protection") were positively correlated with benevolent sexism, but not hostile sexism (Burn \& Busso, 2005). Similarly, Glick, Lameiras, and Castro (2002) found that Catholic religiosity predicted more benevolent sexism, but not hostile sexism for both men and women. Taşdemir and Sakall1-Uğurlu (2010) concluded that in Western Christian cultures, religiosity is significantly correlated with benevolent sexism, but not hostile sexism. Bryant (2006) found evidence that the gender-role attitudes held by college students in an Evangelical Christian campus ministry were rooted in a complementarian gender ideology that states men and women are equal in worth but designed for different roles that complement one another in which men have authority over women. These prescribed gender-roles may value women for their femininity, but they limit the choices women have in life to transcend traditional roles (Bryant, 2006).

\section{Religious-Based Harassment}

Considering the dearth of scholarship focusing solely on gender harassment outside of the conceptualization of sexual harassment, it should come as no surprise that there is a scarcity of research focusing on the moderating role of religious attribution on the negative experiences of gender harassment. There is however, an abundance of research to support the use of Christian beliefs for other salient forms of harassment and divine discrimination, most notably homophobic beliefs and anti-gay discrimination. Christian-motivated harassment against women may operate in more subtle ways compared to anti-gay discrimination but the same mechanisms underlie the impact of religious justification for minority oppression: divine discrimination transcends gender harassment and operates across various modes of identities. 
The majority of recent reports regarding lesbian, gay, and bisexual (LGB) ${ }^{3}$ issues show that attitudes have shifted towards tolerance, most notably regarding marriage equality. Today a majority of Americans favor same-sex marriage (Public Religion Research Institute, 2014). Major religious groups fall on either side the debate: a majority of White mainline Protestants (62\%) and Hispanic Catholics (56\%) support same-sex marriage while $69 \%$ of White Evangelical Protestants and 59\% of Black Protestants oppose it. Catholics who regularly attend mass are split on the issue (50\% favor, $45 \%$ oppose) (Public Religion Research Institute, 2014, pp. 1-3).

While marriage equality has seen an overwhelming amount of increased support in the last 10 years even in the church, homophobic attitudes regarding LGB individuals still linger. A national report from 2003 found that a 55\% majority of Americans believed that it is a sin to engage in homosexual behavior, and that view was stronger among those with high religious commitment (The Pew Forum on Religion and Public Life, 2003). Additionally, it was found that highly religious Americans are much more likely to hold negative views of gay men and lesbians (The Pew Forum on Religion and Public Life, 2003), although those opinions may fluctuate depending on whether the person endorsing the view is able to make a person-behavior distinction (Rosik, Griffith, \& Cruz, 2007). A more recent report found that a majority of White Evangelical Protestants, Black Protestants, Hispanic Protestants, and Catholics agree that samesex marriage is incongruent with their religion and that a majority of Americans believe homosexual activity between consenting adults is morally wrong (Public Religion Research Institute, 2014).

\footnotetext{
${ }^{3}$ I purposely do not include the " $\mathrm{T}$ " for transgender individuals in this acronym. Gender minority individuals experience unique discrimination that differs from sexual minority individuals. While issues of gender and sexuality are irrevocably linked and all LGBT individuals experience discrimination from the Christian church, issues of homosexuality and same-sex marriage are more salient and relevant issues for lesbian, gay, and bisexual people.
} 
These homophobic judgments and attitudes have translated into structural barriers in the form of official policies within churches that discriminate against LGB individuals: the Catholic Church considers the "inclination of the homosexual person...as an objective disorder" and Pope Francis maintains that same-sex marriage is illegitimate (Congregation for the Doctrine of the Faith, 1986; Pentin, 2014). ${ }^{4}$ The Southern Baptist Convention passed a resolution at their 2005 annual convention that encourages parents to take action against their child's public school if it promotes tolerance and acceptance of homosexuality (Human Rights Campaign, 2014). These moral convictions, as deemed by some conservative Christians, frequently translate into institutionalized prejudices against sexual minorities. Wolff and Himes (2010) report that out of a random sample of 20 members of the Council for Christian Colleges and Universities (CCCU), $75 \%$ of the universities list expulsion/dismissal in their code of conduct/student handbook as the consequence of violating policies prohibiting homosexual behavior (pp. 445-445).

Given the overt nature of discrimination that Christian institutions and Christians themselves engage in against LGB individuals, it follows that these same institutions and people may engage in similar discrimination and harassment of women. The incentive to do harm to the LGB community is rooted in the idea that homosexuality is not an acceptable expression of sexuality: The Southern Baptist Convention holds that "homosexuality is not a normal lifestyle and is an abomination in the eyes of God" (The Southern Baptist Convention, 1988). And yet how different are those disdainful positions on gays and lesbians from the Catholic Church's view of denying women priesthood because for them to assume such a public role is not acceptable female gender behavior? Or how different is gay prejudice from gender harassment

\footnotetext{
${ }^{4}$ In July 2013, Pope Francis told reporters, "A gay person who is seeking God, who is of good will -- well, who am I to judge him" (Wooden, 2013)? While this is an encouraging statement from the Pope, he still maintains that "the family is also threatened by growing efforts on the part of some to redefine the very institution of marriage" (Rocca, 2015).
} 
when Protestant theologians assert that men have inherent authority over women? Discerning the role of Christian justification for discrimination, whether against lesbian, gay, bisexual people, or women, deserves more attention.

In one of the few studies conducted in the area of Christian motivation for gender harassment, Hall, Christerson, and Cunningham (2010) explored how gender harassment was experienced by faculty members at an Evangelical Christian university. The researchers found evidence that experiences of harassment were affected by the gender ideology prevalent in the Evangelical Christian context in which the participants worked: when harassment frequency was low, high attribution to a Christian belief system actually ameliorated the negative effects of harassment on both levels of institutional climate (defined as sense of influence and perceived access to information) compared to low attribution to a Christian belief system. However, when harassment was highly attributed to a Christian belief system, the negative effects of harassment on institutional climate were potentiated or intensified as the frequency of harassment increased. In contrast, when harassment was less attributed to a Christian belief system, the effect on institutional climate did not significantly change based on the frequency of harassment. In other words, low levels of harassment highly attributed to a Christian belief system were associated with more positive levels of organizational climate than low levels of harassment less attributed to a Christian belief system. Additionally, increased harassment highly attributed to a Christian belief system resulted in a significant decrease in both levels of organizational climate. This same effect was not seen for harassment less attributed to a Christian belief (2010, pp. 184-185).

In another study, Eliason, Hall, and Anderson (2012) explored the experiences of sexual and gender harassment in an Evangelical Christian university female student population. The study specifically looked at the frequency of harassment, kind of harassment, and the effects it 
had on female students' perceptions of campus climate and college satisfaction. Findings indicated low reports of sexual harassment, but that gender harassment was experienced by $97 \%$ of participants (Eliason, Hall, \& Anderson, 2012, p. 349). While the attribution of the harassment to Christian belief was not found to have a significant moderating effect on the experience as was the case in the previously discussed study, the researchers did identify that gender harassment independently contributed to negative campus climate and poor college adjustment (Eliason, Hall, \& Anderson, 2012).

While the two aforementioned studies used respondents from Christian universities for reasons of availability and convenience, the populations were primarily white. It would be helpful to have a more diverse sample in order to better understand the interlocking systems of oppression that affect people in different ways.

Only one study was found that looked at gender harassment through a lens of race at a Christian university. Using a phenomenological approach, Kim, Anderson, Hall, and Willingham (2010) found that Asian/Asian-American female faculty members at Christian universities across the country were discriminated against not just for being women, but for being Asian women. Due to the lack of racial and ethnic diversity among the faculty and students, the participants were met with naiveté and denial regarding their experienced discrimination and racism among their Christian counterparts (Kim, Anderson, Hall, \& Willingham, 2010, pp. 460-462). In the social sphere of the White, conservative, Evangelical faculty, stress on individualism was found to be so strong that individuals in that group held onto a worldview that did not allow for structural explanations for negative personal experiences to exist, meaning they were blind to the reality and consequences of institutionalized racism within their own Christian work place and society as a whole (Kim, Anderson, Hall, \& Willingham, 2010, p. 461). In addition, the 
participants were met with a "missionary mentality" from White Christians: the idea that White Christians tend to view non-White people or non-Americans as members of a non-Western group who still need to be colonized, Westernized, and converted (Kim, Anderson, Hall, \& Willingham, 2010, p. 462).

All of the aforementioned research has looked at religiosity rooted in Protestant denominations. There is a lack of research that analyzes the effects of gender harassment attributed to Christian/Catholic belief in a Catholic university student population. To that end, DePaul University presented an interesting population to explore as it is the largest Catholic university in the country (DePaul University, 2014), and is rooted in Vincentian values, which foster social justice and respect for diverse populations (DePaul University, 2010). Additionally, it is located in the large, diverse, urban City of Chicago. A quantitative and qualitative analysis of DePaul students' experiences of Christian-motivated gender harassment shed light on a pervasive form of sex-based harassment in a yet-to-be explored Catholic student population.

\section{Present Study}

The present study explored the different effects gender ideologies prescribed by Christian doctrine might have on women. This study employed a mixed-methods approach utilizing both quantitative and qualitative research methods. While this study is rooted in feminist theoretical perspectives, an interdisciplinary lens was used to achieve study aims. The first method quantitatively assessed through self-report scales the effects of gender harassment on female (female-identified) DePaul University students. Consistent with studies reviewed here, I hypothesized that gender harassment would negatively predict levels of college adjustment, and that this effect would be intensified when that harassment was attributed to a Christian belief. 
The second method qualitatively analyzed descriptions of gender harassment by those participants who perceive that their experiences of harassment were motivated by the perpetrator's Christian belief. These responses allow for a deeper investigation into the lived experiences of participants and their own voices to be heard. Additionally, these qualitative descriptions help illustrate how Christian gender ideologies are used in the expression of "divine discrimination."

As a study rooted in feminist theological perspectives, it is important to address the use of quantitative methods for this project. Traditionally, the use of quantitative methods has been heavily criticized by feminist researchers citing issues with the kinds of measures used, the samples most often engaged in research, the level of analysis, and the complicated statistics used to analyze the data (Sprague, 2005). Additionally, quantitative methods are typically used to establish the cause-and-effect relationship between two variables "isolated" from "real world" conditions; there is no exploration into why the phenomena occurs or what societal conditions precipitate the relationship (Fonow \& Cook, 1991). Many criticisms, however, center on the interpretation of quantitative data as absolute truth: feminist researchers adamantly critique the idea that "the numbers don't lie." Finally, feminist researchers argue against the use of quantitative methods as they were birthed from patriarchal structures that are entrenched within oppressive power dynamics: some see quantitative methods as the "master's tools."

Beyond the actual use of quantitative methods, many feminist researchers critique their heavy use in research stemming from the scientific method. These types of projects are heavily rooted in Enlightenment values that claim all truth can be discovered if hypotheses are systematically examined. Often times this type of research stems from positivists' views that claim the only discernable, objective, and valid truths are those that can be interrogated through 
heavily controlled research methods isolated form "real world" conditions. Qualitative methods such as structured interviews are relegated as biased.

While the criticisms of certain uses of quantitative methods are valid points, I agree with Sprague that "many of the criticisms of quantitative methods are actually criticisms of how positivists do quantitative" research (2005, p. 81). Additionally, these criticisms also touch on epistemological themes that delve deeper into the discourse of how we approach and use the knowledges created by the use of our research methods (Fonow \& Cook, 1991). Given that there is no one correct way to do feminist methodology, I argue that this means we cannot fully dismiss the validity of quantitative methods: Quantitative methods are not inherently antifeminist; it is the epistemological stance evident in an overall problematic research methodology that positions quantitative methods as the only objective and valid method through which to discover all truth that is anti-feminist.

This study uses quantitative methods within an overall feminist-based project as evidenced in addressing some of the criticisms brought forth by Sprague (2005) regarding the use of quantitative methods. First and foremost, this project is grounded in my own interests and personal experience as a heterosexual, cisgendered, Christian, White, feminist woman. While I utilize a privileged study sample, I am actively interested in the experiences of college women at DePaul University and the results will not be generalized to the public. The instruments used to collect data regarding gender harassment and sexuality policing were both developed by women, for women. Additionally, the GEQ measure was revised for specific use with a student population. The statistical tests through which I analyzed my data are not overly complicated and are easy to understand and recreate. Moreover, this project aims to go deeper into analyzing institutional powers by shedding light on how the most powerful religious institution in our 
country plays a moderating role in young women experiencing gender harassment: Beyond simply finding a causal relationship between gender harassment and an outcome, this project enriches the discourse in recognizing the powerful role religion plays in the systematic oppression of women. Finally, and perhaps most importantly, this project does not utilize a positivist lens regarding the outcome of the quantitative data analysis. I recognize that numbers can only tell us part of the story.

\section{Method}

\section{Participants and Design}

A statistical power analysis was performed for sample size estimation, based on data from Hall, Christerson, and Cunningham (2010) $(\mathrm{N}=138)$, a study investigating Christian attribution as a moderator of gender harassment on institutional climate as a faculty member of a university. The effect size in this study for perception of being informed was .05 (model $1 \mathrm{R}^{2}=$ .140 , model $2 \mathrm{R}^{2}=.182$ ), considered to be small. With an alpha $=.05$ and power $=.80$, the projected sample size needed with this effect size is approximately $\mathrm{N}=158$. To account for the differences in populations and outcome variables between Hall, Christerson, and Cunningham (2010) and the current study, a sample of 244 undergraduate female/female-identified students attending a large Catholic university in an urban city were enrolled (target enrollment: $\mathrm{N}=250$ ) between September 2014 and March 2015. While people of all genders experience various forms of gender harassment, it is well documented that the majority of sex-based harassment is disproportionately directed towards women and girls (The White House Council on Women and Girls, 2014) Participants were recruited from the university’s psychology research participant pool, a network of potential study participants comprised of students enrolled in various DePaul 
University psychology courses. Participants were awarded class credit or extra credit for participating in the study. Twenty-one (21) participants were administratively withdrawn from the study for having incomplete data that could not be analyzed or for not providing a valid subject pool code at the end of the study which was needed for awarding credit. Thus, a sample of $\mathrm{N}=223$ participants was analyzed. The age range of participants was $18-57$, mean age 20.5 (SD: 3.67) and most were first- and second-year undergraduate students (52\%). While this university is known to be ethnically and racially diverse, a majority of participants identified as White $(59.2 \%)$ which is consistent with current enrollment statistics for this university (College Data, 2014; Forbes, LLC, 2014).

This two-part study was an online survey. The first part utilized a quantitative, crosssectional, correlational research design. Consistent with past research on gender harassment, a correlational design was used to (1) understand the lived experiences of gender harassment and the negative effects it has on participants and (2) understand the predictive nature of gender harassment on college adjustment, and the extent to which this relationship is influenced by Christian attribution for harassment. The second part of this study was a qualitative content analysis of participant's descriptions of Christian-motivated harassment. This study was approved by the DePaul University Institutional Review Board (IRB) (protocol number AM061814LAS).

\section{Procedure}

Upon signing up for the study through the psychology department's experiment managing system, potential participants were re-directed to the online survey for completion. It is important to note that deception was used in this study. The study was described to be 
evaluating students' (of all genders) general college experiences. It is possible that if participants knew the study's true purpose before data collection, they may not have honestly reported incidences of gender harassment due to the stigmatization of labeling those experiences as such. It is also possible that participants who knew that we were examining the moderating role of Christian attribution for harassment may have purposely or inadvertently changed their responses to the questionnaire. Additionally, if participants were made aware that only female participants were included, they may have been primed to think of gender or why the researchers' were only concerned about the experiences of women during the study.

The survey was deployed using Qualtrics, a web-based data software tool utilizing SSLencryption protection to ensure the confidentiality of data and the privacy of participants. Given the online consent process which occurred without an in-person interaction between the participant and researcher and the deceptive language used in the consent form masking the true purpose of the study, a waiver of documentation of consent and alteration of the consent process was granted by DePaul's IRB.

An online self-administered survey consisting of both closed- and open-ended questions was used to collect data. While an online study presents many challenges to the research process such as a loss of control over the context in which data are collected, this method also offered many advantages including reduced costs, increased sample size, and increased convenience for participants. Closed-ended items, such as scaled responses were used as they are more specific in assessing a certain aspect of a construct and were easily coded for quantitative analysis. Openended items, such as free-response questions were also used to center the experiences of the participant and gain a deeper understanding of their thoughts and feelings beyond closed-ended 
items. The survey took on average 19.5 minutes to complete, range $5.92-68.27$ (excluding 5 participants who took over two hours to complete the study and are considered outliers).

First, participants read a consent statement that explained the general deceptive purpose (i.e., evaluating students' college experiences), procedure, and risks of the study. At the end of the consent document, in order to proceed to the next screen the participant was forced to answer the following question, "I have read the above information. I have had all my questions and concerns answered. By clicking below, I indicate my consent to be in the research.” The participant had to choose, "I consent to be in the study, please click on this button to take me to the survey," or, "No. I DO NOT consent to be in the research." If the participant chose the former, the study proceeded. If the participant chose the latter, the participant was given my contact information to answer any questions they had and the study ended. All participants analyzed consented to enrolling in the study. In order to address the issue of impaired control over the context of survey administration, participants were instructed to find a quiet place to complete the survey free of noise, people, and other distractions. Additionally, participants were instructed to complete the survey in one-sitting to receive credit; they were not allowed to save their responses and finish the study at a later time.

After participants completed the survey, they were shown a debriefing sheet that explained the true purpose of the study and why it was being conducted. My contact information as well as the contact information of the faculty sponsor, Dr. Kimberly Quinn, was also provided.

\section{Measures}


Gender harassment. First, participants completed the 20-item Gender Experiences Questionnaire (GEQ) (Leskinen \& Cortina, 2014), a newly developed tool for measuring gender harassment isolated from sexual harassment (Appendix A). This instrument captures the multiple dimensions of gender harassment and allows for a nuanced analysis of this construct. Behaviors targeted by this instrument include, "Talked to you as if you were a small child instead of speaking to you like an adult" and "Made sexist jokes in your presence." The subscales and overall measure have good reliability, with coefficient alphas ranging from .78 to .93 (Leskinen \& Cortina, 2014, p. 115). Correlations among the five subscales range from .39 to .61, averaging .50 (Leskinen \& Cortina, 2014, p. 115). This measure demonstrates good content validity as it was specifically designed to capture an exhaustive list of the dimensions of gender harassment (for a detailed analysis regarding this instrument's creation and validation, see Leskinen and Cortina, 2014). The GEQ also demonstrates excellent convergent validity as it correlates with measures of sexual-advance harassment and heterosexist harassment (Leskinen \& Cortina, 2014, pp. 115 - 117). Participants responded to each item asking if they had ever experienced that facet of gender harassment on a 5-point scale ranging from 1 (never) to 5 (many times). This instrument does not use the phrase "gender harassment" in its item descriptions or directions as that may influence how a participant responds to the questions. While this tool was developed for use in professional settings, the authors encourage the use of the tool in different environments (Leskinen \& Cortina, 2014, p. 118). As such, the instrument was modified for administration in a university setting by changing the stem of the question from, "'During the PAST YEAR, has anyone associated with your WORK (e.g., supervisors, coworkers, clients/customers, collaborators at other companies..." to "During the PAST YEAR, has anyone associated with DEPAUL UNIVERSITY (e.g., professors, classmates/peers, faculty/staff, friends who attend 
DePaul)...” Additionally, six items that measure the policing of women's sexuality were administered with this instrument using the same question stem and response scale (Appendix B). In the current sample, the subscales and overall measure have good reliability, with coefficient alphas ranging from .73 to .95 . Correlations among the six subscales range from .44 to .66. The sexuality policing items held together and had an alpha of .91. The sexuality policing subscale positively and significantly correlated with the other subscales of the GEQ within the moderate-to-strong range (.55 to .66) (Table 1). This suggests that the sexuality policing dimension represents a unique and discrete dimension of gender harassment not already covered by the GEQ. Therefore, the modified GEQ score used for analysis was calculated by averaging across all 26 items present in the questionnaire: the original 20 -items created by Leskinen and Cortina (2014) and the 6-items created.

Table 1. Intercorrelations Among Gender Harassment Subscales and Sexuality Policing Scale $(\mathrm{N}=223)$

\begin{tabular}{lcccccccc}
\hline Variable & $\mathrm{M}$ & $\mathrm{SD}$ & 1 & 2 & 3 & 4 & 5 & 6 \\
\hline 1. Sexist Remarks & 2.02 & 1.02 & $(.91)$ & & & & & \\
2. Sexually Crude/Offensive Behavior & 1.49 & 0.69 & $0.66^{*}$ & $(.84)$ & & & & \\
3. Infantalization & 1.76 & 0.81 & $0.54^{*}$ & $0.55^{*}$ & $(.80)$ & & & \\
4. Work/Family Policing & 1.36 & 0.57 & $0.58^{*}$ & $0.53^{*}$ & $0.55^{*}$ & $(.81)$ & & \\
5. Gender Policing & 1.28 & 0.51 & $0.44^{*}$ & $0.53^{*}$ & $0.50^{*}$ & $0.47^{*}$ & $(.73)$ & \\
6. Sexuality Policing & 2.18 & 1.08 & $0.64^{*}$ & $0.66^{*}$ & $0.57^{*}$ & $0.56^{*}$ & $0.55^{*}$ & $(.91)$ \\
\hline Note. M = mean; SD = standard deviation. Coefficient $\alpha$ as are reported in parentheses along the diagonal of the correlational matrix & & & \\
* p $<.001$ & & & & & & & &
\end{tabular}

Religious attribution. An adapted procedure from Hall, Christerson, and Cunningham (2010) and Eliason, Hall and Anderson (2012) was used to capture data regarding Christian attribution for harassment: if the participant reported any level of harassment (i.e., a response other than "Never" for any of the GEQ items), participants were asked, "Do you perceive that those who engaged in the behavior were motivated by their Christian/Catholic beliefs?" 
Participants responded using a 5-point scale ranging from 1 (not at all motivated by

Christian/Catholic beliefs) to 5 (motivated entirely by Christian/Catholic beliefs). Christian attribution scores were created by averaging the total number of Christian Attribution items answered. Scores ranged from 1 to 4.6, higher scores indicating higher attribution of gender harassment to the Christian/Catholic beliefs of the perpetrator. Participants reporting a Christian motivation (i.e., a response other than "not at all motivated by Christian/Catholic beliefs") were then asked to briefly explain the situation in an open-ended free response. Participants were encouraged to describe the context of the event, who was involved, what was said or done, why they believe the perpetrator was motivated by a Christian belief, and the thoughts and feelings they experienced as a result (Appendix C). Out of 223 participants, 95 (42.6\%) participants reported experiencing Christian/Catholic motivated gender harassment and were invited to write about their experiences.

College adjustment. Next, participants completed the Student Adaptation to College Questionnaire (SACQ), which is a 67-item measure of college adjustment (Baker \& Siryk, 1989). This is one of the most frequently used instruments in assessing college adjustment and measures its four dimensions: (1) academic adjustment, meaning how well the student is coping with the academic demands of college; (2) social adjustment, which is defined as how well the student is dealing with the "interpersonal-societal" demands of the collegiate environment; (3) personal-emotional adjustment, which assesses any general psychological distress and somatic symptoms experienced by the student; and (4) institutional attachment, meaning how dedicated a student is to their own educational goals and how attached they are to the university that have chosen for college (in this study meaning DePaul University) (Baker \& Siryk, 1999, pp. 14 - 15). Items include, "I really haven't had much motivation for studying lately" and "I feel I have good 
control over my life situation at college."5 Participants assessed how well each of the statements applied to themselves using a response scale ranging from 1 (applies very closely to me) to 9 (doesn't apply to me at all). This measure demonstrates high predictive validity regarding college grades and college retention and correlates with relevant social outcome measures including coping skills and social support demonstrating its concurrent validity (Credé \& Niehorster, 2012). Meta-analytic results indicate subscale true-score correlations range from .53 to .96 (Credé \& Niehorster, 2012, p. 146) and the internal reliability for each subscale and full scale ranges from .77 to .95 (Baker \& Siryk, 1999, p. 34). In the current sample, the subscales and overall measure have good reliability, with coefficient alphas ranging from .79 to .93 and correlations among the six subscales range from .34 to .76 (Table 2).

Table 2. Intercorrelations Among Student Adaptation to College Questionnaire Subscales $(\mathrm{N}=223)$

\begin{tabular}{|c|c|c|c|c|c|c|}
\hline Variable & $\mathrm{M}$ & SD & 1 & 2 & 3 & 4 \\
\hline 1. Academic (R: $24-216)$ & 149 & 27.56 & $(.88)$ & & & \\
\hline 2. Social (R: 20 - 180) & 116 & 27.67 & $0.34 *$ & $(.87)$ & & \\
\hline 3. Emotional (R: 15 - 135) & 75 & 22.43 & $0.64^{*}$ & $0.39 *$ & $(.85)$ & \\
\hline 4. Institutional Attachment (R: 15 - 135) & 99 & 18.35 & $0.51 *$ & $0.76^{*}$ & $0.50 *$ & $(.79)$ \\
\hline
\end{tabular}

The creators of this instrument, Baker and Siryk caution against simply using the overall college adjustment score when trying to fully understand how well a student is coping with the challenges of attending a university. They encourage the use of each subscale score as well as the overall adjustment score in gaining a nuanced understanding of how well a student is adjusting to

\footnotetext{
${ }^{5}$ Sample items of the $S A C Q$ copyright @ 1989, 1999, by Western Psychological Services. Reprinted by permission of the publisher, Western Psychological Services, 625 Alaska Avenue, Torrance, California, 90503, U.S.A. Not to be reprinted in whole or in part for any additional purpose without the expressed, written permission of the publisher (rights@wpspublish.com). All rights reserved.
} 
college. As stated in the manual, "using the full scale score alone also sacrifices a considerable amount of information about a student's pattern of adjustment to college and thus may lead to erroneous conclusions" (Baker \& Siryk, 1999, p. 14). As such, each subscale score as well as the overall adjustment score will be used as a dependent variable in the final analysis.

Demographics. Finally, participants completed a demographic information sheet which captured data regarding the participant's age, sex assigned at birth, gender identity, race, ethnicity, political affiliation, sexual orientation, year in school, and religious affiliation (Table 3). All participants reported a birth/biological sex and gender identity of female except two: One (1) participant reported a male birth/biological sex and female gender identity and one (1) participant reported a female birth/biological sex and gender neutral/nonconforming gender identity. These two participants are being kept in the data for analysis for two reasons: (1) All participants were required to complete a prescreening questionnaire before enrollment which restricted access to female identified students, meaning these two participants reported a female gender in a separate survey prior to enrollment and (2) the enrollment criteria for this study was defined as female/female-identified students which encompasses both participants to a degree. Table 3 contains detailed information regarding participant demographic characteristics. (Appendix D). 
Table 3. Demographic Characteristics $(\mathrm{N}=223)$

\begin{tabular}{|c|c|c|}
\hline Variable & $\mathrm{n}$ & $\%$ \\
\hline \multicolumn{3}{|l|}{ Race } \\
\hline Black/African American & 19 & $8.5 \%$ \\
\hline White & 132 & $59.2 \%$ \\
\hline Spanish/Hispanic/Latino/a & 39 & $17.5 \%$ \\
\hline Asian & 18 & $8.1 \%$ \\
\hline Native Hawaiian/Pacific Islander & 1 & $0.4 \%$ \\
\hline Other & 14 & $6.3 \%$ \\
\hline \multicolumn{3}{|l|}{ Student Status } \\
\hline First- or second-year student & 116 & $52.0 \%$ \\
\hline Third- or fourth-year student & 98 & $44.0 \%$ \\
\hline Other & 9 & $4.0 \%$ \\
\hline \multicolumn{3}{|l|}{ Current Sexual Orientation } \\
\hline Lesbian & 2 & $0.9 \%$ \\
\hline Bisexual & 16 & $7.2 \%$ \\
\hline Heterosexual & 202 & $90.6 \%$ \\
\hline Other & 3 & $1.3 \%$ \\
\hline \multicolumn{3}{|l|}{ Religious Affiliation } \\
\hline Catholic & 86 & $38.6 \%$ \\
\hline Atheist & 12 & $5.4 \%$ \\
\hline Agnostic & 22 & $9.9 \%$ \\
\hline Protestant & 14 & $6.3 \%$ \\
\hline Nondenominational Christian & 19 & $8.5 \%$ \\
\hline Unitarian/Spiritual & 10 & $4.5 \%$ \\
\hline Muslim & 11 & $4.9 \%$ \\
\hline Other $^{\mathrm{a}}$ & 49 & $21.9 \%$ \\
\hline \multicolumn{3}{|c|}{ Religious Service Attendance (prior 12 months) } \\
\hline Never & 73 & $32.7 \%$ \\
\hline Rarely & 82 & $36.8 \%$ \\
\hline At least once a month & 22 & $9.9 \%$ \\
\hline At least 2 to 3 times a month & 25 & $11.2 \%$ \\
\hline Once a week or more & 21 & $9.4 \%$ \\
\hline \multicolumn{3}{|l|}{ Importance of Faith } \\
\hline Not at all important & 30 & $13.5 \%$ \\
\hline Somewhat unimportant & 23 & $10.3 \%$ \\
\hline Neither important nor unimportant & 36 & $16.1 \%$ \\
\hline Somewhat important & 69 & $30.9 \%$ \\
\hline Very important & 65 & $29.1 \%$ \\
\hline
\end{tabular}




\section{Results}

\section{Quantitative Data Preparation}

Quality assurance. All quantitative data preparation and analysis were conducted using SPSS, Version 22 (IBM Corp., 2013). First, a quality control check of the data was implemented to assess for missing values, incomplete responses, as well as to establish the psychometric properties of the instruments used. The subscale correlations and reliability alphas for the GEQ and SACQ were reported above. Out of the 223 respondents analyzed, one participant had one missing item on the GEQ and an imputed score was created by averaging across the total number of items answered for the subscale on which the missing item appeared. Across all 223 participants, 163 missing items on the SACQ were prorated based on the scoring instructions provided in the SACQ Manual (after necessary items were reversed scored, see below) (Baker \& Siryk, 1999). It is important to note that two items addressed the participant's roommates and college dormitory which were to be omitted if the participant did not have roommates or live in a college dormitory, respectively. In fact, 155 of the missing items prorated were for missing values for these two items. As such, the number of missing items of the SACQ and subsequent number of prorated items calculated was not unexpected.

Variable preparation. Continuous scores were created for each construct: gender harassment, Christian attribution, and college adjustment. GEQ subscale scores and overall construct scores were calculated by averaging across the total number of items answered to achieve a score between 1 and 5, higher scores indicating higher frequency of gender harassment. Christian attribution scores were calculated by averaging across the total number of attribution items answered resulting in a score between 1 and 5, higher scores indicating higher levels of attribution to a Christian/Catholic belief for harassment. Christian attribution scores 
were created for the overall GEQ measure and for the sexuality policing subscale. Out of 223 participants, $204(91.5 \%)$ reported experiencing gender harassment and obtained a Christian attribution score. The SACQ subscale scores and full scale score were created by first reverse scoring 33 items and prorating values for the missing items. Items were then summed to create subscale scores and an overall construct score, higher scores indicating better college adjustment. It should be noted that some SACQ items appear on more than one subscale, meaning subscale scores cannot be summed to create an overall college adjustment score.

Normality. Normality was assessed for all instruments. While there is no "golden standard" for establishing the normal distribution for a data set, there are a number of subjective and objective methods that can be used including calculating and analyzing skewness and kurtosis z-scores, running the Shapiro-Wilk test for normality, and visually inspecting histograms and normal Q-Q plots. For a medium sized sample $(50<\mathrm{n}<300)$ employed here, two methods (one objective and one subjective) were used to determine normality: kurtosis and skewness z-scores and visual inspection of normal Q-Q plots. The cutoff for skewness and kurtosis z-scores followed the rule suggested by Kim (2013): the null hypothesis (i.e., the assumption that the data has a normal distribution) was rejected "at absolute z-value over 3.29, which corresponds with an alpha level 0.05 , and conclude[d] the distribution of the sample is non-normal" (p. 53). In other words, if the absolute value of the kurtosis and skewness z-scores were under 3.29 , I would accept the null hypothesis that the data had a normal distribution as $\mathrm{p} \geq$ .05 .

$\boldsymbol{G E Q}$. First, normality was established for the GEQ overall scale score and sexuality policing subscale score. As evident in Table 4, the raw data were non-normal for both GEQ scores with positive skews. It should be noted that the sexuality policing subscale had a 
somewhat normal Q-Q plot. While the hierarchical regression requires that the residuals of all independent variables and dependent variables be normally distributed (which will be further explored in the regression analysis), the non-normal scores of the GEQ will be used in the regression for two reasons: (1) regression analyses are fairly robust to non-normal data distributions and (2) a data transformation would complicate the interpretation of the results.

Christian attribution. Next, the Christian attribution scores for sexuality policing and overall gender harassment were explored. Similar to the GEQ scores, both Christian attribution scores had strong positive skews as evident by their z-scores which were confirmed upon visual inspection of the normal Q-Q plots.

$\boldsymbol{S A C Q}$. Finally, the SACQ subscale and full scale scores were explored. All of the subscale and full scale scores had kurtosis and skewness z-scores below absolute 3.29 indicating that all of the scores had a normal distribution. This was confirmed upon visual inspection of all normal Q-Q plots.

Table 4. Normality Assessment: Z-Scores

\begin{tabular}{cccc}
\hline Scale & & Kurtosis & Skewness \\
\hline GEQ & & \\
& Sexuality Policing Subscale & -1.74 & $4.42^{*}$ \\
& GEQ Full Scale (26 items) & $5.11^{*}$ & $7.61^{*}$ \\
Christian Attribution Scores & & \\
$\quad$ Christian Att for Sexuality Policing & $23.09^{*}$ & $15.46^{*}$ \\
$\quad$ Christian Att for GEQ Full Scale & $15.15^{*}$ & $11.66^{*}$ \\
SACQ Scores & & \\
$\quad$ Academic Subscale & -0.99 & -0.34 \\
$\quad$ Social Subscale & -1.34 & -1.79 \\
$\quad$ Emotional Subscale & -0.69 & 0.28 \\
Attachment Subscale & -0.94 & -2.36 \\
$\quad$ SACQ Full Scale & -0.32 & -0.01 \\
\hline * $<<.05 \quad$ & &
\end{tabular}




\section{Qualitative Data Preparation}

All qualitative data preparation was conducted in both SPSS and Excel while all qualitative data analysis was conducted using QSR International's NVivo 10 qualitative data analysis software (QSR International Pty Ltd., 2012). Participants who reported experiencing Christian/Catholic motivated harassment were invited to write about their experiences, including who engaged in the harassing behavior and why the participant believed it was motivated by the Christian/Catholic belief of the perpetrator. A total of 270 responses were submitted in the study. Response length ranged from one word to multiple paragraphs with most responses consisting of a few sentences.

First, a quality control check of the qualitative data was implemented to confirm that only participants who reported Christian motivated harassment were asked to write about their experiences. This was conducted by verifying within Qualtrics that only participants who reported experiencing harassment and submitted attributional responses other than "not at all motivated by Christian/Catholic beliefs" were invited to write about their experiences. Additionally, the data were checked to confirm that open-ended responses were only completed when the participant indicated they experienced Christian-motivated harassment. Finally, all open-ended responses were read multiple times in SPSS and in NVivo in order to become familiar with the data. While some responses were abstract thoughts distally related to the prompt, no responses were clear deviations from the survey question.

\section{Quantitative Data Analysis}

It was hypothesized that (1) gender harassment would be predictive of impaired levels of college adjustment and (2) Christian attribution for harassment would moderate and potentiate 
the negative impact of harassment on college adjustment. In other words, increased frequency of gender harassment would be associated with decreased scores of adjustment to college as evident by a negative regression of college adjustment on gender harassment; this effect on college adjustment would be worse (i.e., college adjustment scores will be lower) when the harassment is perceived to have been motivated by the Christian/Catholic belief of the perpetrator. These hypotheses were tested for the overall gender harassment scale score on each of the four dimensional scores of college adjustment as well as the overall college adjustment score, meaning five hierarchical regressions were conducted to test both hypotheses. The multiple hierarchical regression test was chosen for the final analysis, as it allows for determining the independent impact of each independent variable on the dependent variable and test for any moderation effects.

For each regression, the gender harassment score and Christian attribution score were first centered in order to reduce issues of multicollinearity and because scores of zero are meaningful for each variable (i.e., it is possible to experience zero/no gender harassment or perceive that the event of harassment was not at all motivated by a Christian belief). Centering was accomplished by subtracting the mean score for the variable from each independent score. Next, a centered interaction term was calculated by multiplying the centered gender harassment score by the centered Christian attribution score.

Each regression was conducted with two models. In the first model, the centered Christian attribution score and centered gender harassment score were entered. In the second model, the centered interaction term was entered. The appropriate college adjustment score was the dependent variable for both models. While the main focus on this analysis lies in the second model, the first model determined if gender harassment and Christian attribution each combined 
to predict levels of college adjustment. The second model determined whether the appropriate interaction term (the only variable entered in this model) increased the model's capacity for predicting levels of college adjustment over and above the independent variable and moderator variable. In other words, the second model detected whether Christian attribution moderated the impact of gender harassment on college adjustment. If Christian attribution moderated this relationship, the addition of the appropriate centered interaction term in the second model led to a statistically significant increase of $\Delta \mathrm{R}^{2}$ as well as was a unique predictor of college adjustment as evident by a significant beta coefficient. The independent effects of the independent variable and moderator variable in the second model do not add any practical information to the analysis. ${ }^{6}$

For each of the regressions performed, the following 6 assumptions were checked: 1) the Durbin-Watson statistic to check for independence of residuals was close to the value 2 (at least between one and three), 2) a visual inspection of the scatterplot of the studentized residuals against the unstandardized predicted values showed an overall linear relationship between the dependent variable and independent variables, 3) a visual inspection of the scatterplot of the studentized residuals against the unstandardized predicted values showed acceptable homoscedasticity, 4) all VIF values were less than 10 indicating no issues of multicollinearity, 5) all standardized residuals and studentized deleted residuals were within \pm 3 standard deviations indicating no outliers, all cases had leverage values of less than 0.35 indicating safe to moderately risky levels of leverage for each case, all cases had Cook's Distance values of less than 1 indicating acceptable influence for each case, and 6) a visual inspection of all histograms

\footnotetext{
${ }^{6}$ In the second model, if the interaction term is a statistically significant predictor of college adjustment, then we can accept our alternative hypothesis that Christian attribution moderates the relationship between gender harassment and college adjustment. It does not matter if Christian attribution and/or gender harassment are independently unique predictors of college adjustment in the second model as it is not practically important. Even if gender harassment has a main effect on college adjustment, if the interaction term is statistically significant, we know the relationship between gender harassment and college adjustment is moderated regardless. If the interaction term is not found to be significant, any potential main effects of gender harassment will be noted.
} 
and normal P-P plots of the standardized residuals generated by each regression showed that the residuals were normally distributed. All regressions met these assumptions except where noted.

For information regarding the correlations between the regression variables, see Tables 5 and 6. Note the subscale correlations of the SACQ were previously reported in Table 2.

Table 5. Correlations for Overall GEQ Regression Variables.

\begin{tabular}{llc}
\hline Variable & 1 & 2 \\
\hline 1. GEQ Overall Score & & \\
2. Christian Attribution & .049 & \\
3. Academic (R: $24-216)$ & $-.238^{* *}$ & -.052 \\
4. Social (R: $20-180)$ & .071 & .075 \\
5. Emotional (R: $15-135)$ & $-.226^{* *}$ & -.024 \\
6. Attachment (R: $15-135)$ & $-.169^{*}$ & -.003 \\
7. SACQ Overall Score & $-.186^{* *}$ & -.012 \\
\hline * $\mathrm{p}<.05, * * \mathrm{p}<.01$ & &
\end{tabular}

Table 6. Correlations for Sexuality Policing Regression Variables.

\begin{tabular}{lcc}
\hline Variable & 1 & 2 \\
\hline 1. Sexuality Policing Score & & \\
2. Christian Attribution & $.208^{* *}$ & \\
3. Academic (R: $24-216)$ & -.119 & .001 \\
4. Social (R: $20-180)$ & .120 & -.003 \\
5. Emotional (R: $15-135)$ & $-.179 * *$ & -.015 \\
6. Attachment (R: $15-135)$ & -.107 & -.084 \\
7. SACQ Overall Score & -.094 & -.018 \\
\hline$* * \mathrm{p}<.01$ & &
\end{tabular}

Overall gender harassment and academic adjustment. In the first model, the separate contributions of overall gender harassment and Christian attribution combined explained a statistically significant $5.8 \%\left(\mathrm{R}^{2}=.058\right)$ of the variance in academic adjustment $(F(2,201)=$ 
$6.211, \mathrm{p}=.002$ ). Additionally, overall gender harassment was a unique predictor of decreased levels of academic adjustment $(b=-10.021, \mathrm{SE}=2.912), \mathrm{p}=.001$.

In the second model when the interaction term was added, results indicate that Christian attribution did not moderate the relationship between overall gender harassment and academic adjustment, as evidenced by an increase in the total variance explained of $1.4 \%\left(\Delta \mathrm{R}^{2}=.014\right)$, which was not statistically significant $(F(1,200)=3.077, \mathrm{p}=.081)$. Additionally, the interaction term was not a unique predictor of decreased levels of academic adjustment $(b=19.808, \mathrm{SE}=$ 11.292), $\mathrm{p}=.081$. Overall gender harassment however, continued to independently be associated with decreased levels of academic adjustment $(b=-10.277, \mathrm{SE}=2.900), \mathrm{p}<.001$. In other words, there was a significant main effect of overall gender harassment predicting decreased academic adjustment, but Christian attribution did not moderate this relationship (Table 7).

Table 7: Hierarchical Regression Analysis: Gender Harassment and Academic Adjustment

\begin{tabular}{llcccc}
\hline \multicolumn{1}{c}{ Model } & \multicolumn{1}{c}{ Variable } & $\beta$ & $p$ & $\mathrm{R}^{2}$ & $\Delta \mathrm{R}^{2}$ \\
\hline Model 1 & & & & .058 & .058 \\
& Gender Harassment & -.236 & .001 & & \\
Model 2** & Christian Attribution & -.040 & .556 & & \\
& & & & .072 & $.014 *$ \\
& Gender Harassment & -.242 & $<.001$ & & \\
& Christian Attribution & .014 & .851 & & \\
& Interaction Term & .131 & .081 & & \\
${ }^{*} \mathrm{~F}(1,200)=3.077, \mathrm{p}=.081$ & & & & \\
$* * \mathrm{~F}(3,200)=5.209, \mathrm{p}=.002$ & & & &
\end{tabular}

It should be noted that in one case there was a standardized residual of -3.106 and a studentized deleted residual of -3.191 (all other cases were within the \pm 3 range). Additionally, one case had a leverage value of .619 which is considered high (all other leverage values were less than .17). Both cases were kept in the final analysis. 
Overall gender harassment and institutional attachment. In the first model, results indicate that overall gender harassment and Christian attribution combined did not explain $2.9 \%$ $\left(\mathrm{R}^{2}=.029\right)$ of the variance in institutional attachment $(F(2,201)=2.974, \mathrm{p}=.053)$. Overall however, gender harassment was a unique predictor of decreased levels of institutional attachment $(b=-4.802, \mathrm{SE}=1.969), \mathrm{p}=.016$.

When the interaction term was added to the second model, results indicate that Christian attribution did not moderate the relationship between overall gender harassment and institutional attachment, as evidenced by no increase in the total variation explained $\left(\Delta \mathrm{R}^{2}=.000\right)$, which was not statistically significant $(F(1,200)=.037, \mathrm{p}=.847)$. Additionally, the interaction term was not a unique predictor of decreased levels of institutional harassment $(b=1.490, \mathrm{SE}=7.694), \mathrm{p}$ $=.847$. Overall gender harassment continued to independently predict decreased levels of institutional attachment $(b=-4.821, \mathrm{SE}=1.976), \mathrm{p}=.016$. In other words, there was a significant main effect of overall gender harassment predicting decreased institutional attachment, but Christian attribution did not moderate this relationship (Table 8).

Table 8: Hierarchical Regression Analysis: Gender Harassment and Institutional Attachment

\begin{tabular}{llrrrr}
\hline \multicolumn{1}{c}{ Model } & Variable & $\beta$ & $p$ & $\mathrm{R}^{2}$ & $\Delta \mathrm{R}^{2}$ \\
\hline Model 1 & Gender Harassment & -.170 & .016 & & .029 \\
& Christian Attribution & .005 & .944 & & \\
Model 2** & & & & .029 & $.000^{*}$ \\
& Gender Harassment & -.170 & .016 & & \\
& Christian Attribution & .011 & .886 & & \\
& Interaction Term & .015 & .847 & & \\
\hline
\end{tabular}

${ }^{*} \mathrm{~F}(1,200)=.037, \mathrm{p}=.847$

** $\mathrm{F}(3,200)=1.986, \mathrm{p}=.117$

It should be noted that in one case there was a leverage value of .619 which is considered high (all other leverage values were less than .17). This case was kept in the final analysis. 
Overall gender harassment and personal-emotional adjustment. In the first model, the unique contributions of overall gender harassment and Christian attribution combined explained a statistically significant $5.1 \%\left(\mathrm{R}^{2}=.051\right)$ of the variance in personal-emotional adjustment $(F(2,201)=5.436, \mathrm{p}=.005)$. Additionally, overall gender harassment was a unique predictor of decreased levels of personal-emotional adjustment $(b=-7.799, \mathrm{SE}=2.378), \mathrm{p}=$ .001 .

In the second model in which only the interaction term was added, results indicate that Christian attribution did not moderate the relationship between overall gender harassment and personal-emotional adjustment, as evidenced by an increase in the total variation explained of $1.3 \%\left(\Delta \mathrm{R}^{2}=.013\right)$, which was not statistically significant $(F(1,200)=2.810, \mathrm{p}=.095)$. Additionally, the interaction term was not a unique predictor of decreased levels of personalemotional adjustment $(b=15.472, \mathrm{SE}=9.230), \mathrm{p}=.095$. Gender harassment, however, continued to independently be associated with decreased levels of personal-emotional adjustment $(b=-7.999, \mathrm{SE}=2.371), \mathrm{p}=.001$. To summarize, there was a significant main effect of overall gender harassment predicting decreased personal-emotional adjustment, but Christian attribution did not moderate this relationship (Table 9).

Table 9: Hierarchical Regression Analysis: Gender Harassment and Personal-Emotional Adjustment

\begin{tabular}{llcccc}
\hline \multicolumn{1}{c}{ Model } & Variable & $\beta$ & $p$ & $\mathrm{R}^{2}$ & $\Delta \mathrm{R}^{2}$ \\
\hline Model 1 & & & & .051 & .051 \\
& Gender Harassment & -.226 & .001 & & \\
Model 2** & Christian Attribution & -.013 & .853 & & \\
& & & & .064 & $.013^{*}$ \\
& Gender Harassment & -.231 & .001 & & \\
& Christian Attribution & .040 & .600 & & \\
& Interaction Term & .126 & .095 & & \\
\hline
\end{tabular}

$* \mathrm{~F}(1,200)=2.810, \mathrm{p}=.095$

$* * \mathrm{~F}(3,200)=4.593, \mathrm{p}=.004$ 
It should be noted that one of the cases had a leverage value of .619 which is considered high (all other leverage values were less than .17). This case was kept in the final analysis.

Overall gender harassment and social adjustment. In the first model, results indicate that the independent contributions of overall gender harassment and Christian attribution combined did not explain a statistically significant amount of variance $\left(\mathrm{R}^{2}=.010\right)$ in social adjustment $(F(2,201)=1.032, \mathrm{p}=.358)$. Additionally, gender harassment was not a unique predictor of social adjustment $(b=2.895, \mathrm{SE}=2.997), \mathrm{p}=.335$.

When the interaction term was added in the second model, results indicate that Christian attribution did not moderate the relationship between overall gender harassment and social adjustment, as evidenced by an increase in the total variance explained of $0.1 \%\left(\Delta R^{2}=.001\right)$, which was not statistically significant $(F(1,200)=.167, \mathrm{p}=.684)$. Additionally, the interaction term was not a unique predictor of decreased levels of social adjustment $(b=-4.778, \mathrm{SE}=$ $11.707), \mathrm{p}=.684$. Overall gender harassment again was not found to be a unique predictor of social adjustment $(b=2.956, \mathrm{SE}=3.007), \mathrm{p}=.327$. That is to say there was not a significant main effect between overall gender harassment and social adjustment nor did Christian attribution moderate this relationship (Table 10).

Table 10: Hierarchical Regression Analysis: Gender Harassment and Social Adjustment

\begin{tabular}{llcccc}
\hline \multicolumn{1}{c}{ Model } & Variable & $\beta$ & $p$ & $\mathrm{R}^{2}$ & $\Delta \mathrm{R}^{2}$ \\
\hline Model 1 & Gender Harassment & .068 & .335 & & .010 \\
& Christian Attribution & .071 & .311 & & \\
Model 2** & Gender Harassment & .069 & .327 & & \\
& Christian Attribution & .058 & .453 & & \\
& Interaction Term & -.032 & .684 & & \\
& & & & \\
& & & & & \\
& &
\end{tabular}

${ }^{*} \mathrm{~F}(1,200)=.167, \mathrm{p}=.684$

$* * \mathrm{~F}(3,200)=.741, \mathrm{p}=.529$ 
It is important to note that upon visual inspection of the scatterplot of the studentized residuals against the unstandardized predicted values, the assumption of homoscedasticity may have been violated. This should be kept in mind when interpreting the results of this regression. Additionally, one case had a leverage value of .619 which is considered high (all other leverage values were less than .17). This case was kept in the final analysis.

Overall gender harassment and overall college adjustment. The first model was statistically significant indicating that the combined contributions of overall gender harassment and Christian attribution explained $3.5 \%\left(\mathrm{R}^{2}=.035\right)$ of the variance in overall college adjustment $(F(2,201)=3.614, \mathrm{p}=.029)$. Additionally, overall gender harassment was a unique predictor of decreased levels of overall college adjustment $(b=-19.783, \mathrm{SE}=7.374), \mathrm{p}=.008$.

In the second model when only the interaction term was added, results indicate that Christian attribution did not moderate the relationship between overall gender harassment and overall college adjustment, as evidenced by an increase in the total variation explained of $0.7 \%$ $\left(\Delta \mathrm{R}^{2}=.007\right)$, which was not statistically significant $(F(1,200)=1.385, \mathrm{p}=.241)$. Additionally, the interaction term was not a unique predictor of decreased levels of overall college adjustment $(b=33.789, \mathrm{SE}=28.715), \mathrm{p}=.241$. Gender harassment continued to independently predict decreased levels of overall college attachment $(b=-20.281, \mathrm{SE}=7.376), \mathrm{p}=.007$. In short, here was a significant main effect of overall gender harassment predicting decreased overall college adjustment, but Christian attribution did not moderate this relationship (Table 11). 
Table 11: Hierarchical Regression Analysis: Gender Harassment and Overall College Adjustment

\begin{tabular}{llcccc}
\hline \multicolumn{1}{c}{ Model } & \multicolumn{1}{c}{ Variable } & $\beta$ & $p$ & $\mathrm{R}^{2}$ & $\Delta \mathrm{R}^{2}$ \\
\hline Model 1 & & & & .035 & .035 \\
& Gender Harassment & -.186 & .008 & & \\
Model 2** & Christian Attribution & -.003 & .966 & & \\
& & & & .041 & $.007^{*}$ \\
& Gender Harassment & -.190 & .007 & & \\
& Christian Attribution & .034 & .654 & & \\
& Interaction Term & .090 & .241 & & \\
\hline
\end{tabular}

${ }^{*} \mathrm{~F}(1,200)=1.385, \mathrm{p}=.241$

$* * \mathrm{~F}(3,200)=2.876, \mathrm{p}=.037$

It should be noted one case had a studentized deleted residual of -3.013 (all other cases were within the \pm 3 range). Additionally, one case had a leverage value of .619 which is considered high (all other leverage values were less than .17). Both cases were kept in the final analysis.

In sum, Christian attribution did not moderate the relationship between gender harassment and any college adjustment score, although some main effects of gender harassment predicting decreased levels of college adjustment were detected. While the GEQ measure covers five dimensions of gender harassment as experienced by women, it is possible this measure (initially created for use in the workplace) does not detect the kinds of Christian-motivated gender harassment college women are experiencing. In other words, college women who are in a different social context and developmental stage than working women may be experiencing forms of Christian-motivated gender harassment not detected by the GEQ. Running the above regressions with the sexuality policing measure collapsed into an overall GEQ score may be downplaying the experiences of sexuality policing reported by the sample. Considering that women ages 18-24 have the highest rate of sexual assault compared to women in all other age 
groups (Sinozich \& Langton, 2014), gender harassment as experienced through the policing of women's bodies and sexuality may be a more salient form of gender harassment for this student sample. Additionally, in citing my own experiences, sex and sexuality are major tools through which the Christian church attempts to control and police individuals - especially young adults who are often engaging in sexual activities for the first time. In order to better understand these differences, hierarchical regressions were conducted to test the moderating effect of Christian attribution between sexuality policing (isolated from the rest of the GEQ) and college adjustment. These regressions were conducted using the same procedures and checking the same assumptions as outlined above.

Sexuality policing and academic adjustment. In the first model, the results indicate that the combined contributions of sexuality policing and Christian attribution did not explain $1.5 \%$ $\left(\mathrm{R}^{2}=.015\right)$ of the variance in academic adjustment $(F(2,182)=1.368, \mathrm{p}=.257)$. Additionally, sexuality policing was a not a unique predictor of decreased levels of academic adjustment $(b=-$ 3.185, $\mathrm{SE}=1.926), \mathrm{p}=.100$.

The second model, which only included the addition of the interaction term was statistically significant indicating that sexuality policing, Christian attribution, and the interaction term combined predicted participants' academic adjustment, $(F(3,181)=2.775, \mathrm{p}=.043)$. Additionally, the interaction term was an independent predictor of academic adjustment above sexuality policing and Christian attribution, as evidenced by a statistically significant increase in the total variance of academic adjustment explained of $2.9 \%\left(\Delta \mathrm{R}^{2}=.029\right),(F(1,181)=5.520, \mathrm{p}$ $=.020)(b=13.381, \mathrm{SE}=5.695)$. In other words, attribution to Christian beliefs was a significant moderator of the relationship between sexuality policing and academic adjustment (Table 12). 
Table 12: Hierarchical Regression Analysis: Sexuality Policing and Academic Adjustment

\begin{tabular}{llcccc}
\hline \multicolumn{1}{c}{ Model } & \multicolumn{1}{c}{ Variable } & $\beta$ & $p$ & $\mathrm{R}^{2}$ & $\Delta \mathrm{R}^{2}$ \\
\hline Model 1 & & & & .015 & .015 \\
& Sexuality Policing & -.124 & .100 & & \\
Model 2** & Christian Attribution & .027 & .718 & & \\
& & & & .044 & $.029 *$ \\
& Sexuality Policing & -.129 & .085 & & \\
& Christian Attribution & -.082 & .353 & & \\
& Interaction Term & .203 & .020 & & \\
\hline
\end{tabular}

$* \mathrm{~F}(1,181)=5.520, \mathrm{p}=.020$

** $\mathrm{F}(3,181)=2.775, \mathrm{p}=.043$

It should again be pointed out that one case had a studentized deleted residual of -3.084 (all other cases were within the \pm 3 range). This case was retained in the final analysis.

Sexuality policing and institutional attachment. In the first model, the results indicate that the unique contributions of sexuality policing and Christian attribution failed to explain $1.5 \%\left(\mathrm{R}^{2}=.015\right)$ of the variance in institutional attachment $(F(2,182)=1.423, \mathrm{p}=.244)$. Additionally, sexuality policing was a not a unique predictor of decreased levels of institutional attachment $(b=-1.586, \mathrm{SE}=1.282), \mathrm{p}=.218$.

The addition of the interaction term in the second model was statistically significant, indicating that sexuality policing, Christian attribution, and the interaction term predicted participants' institutional attachment $(F(3,181)=3.065, \mathrm{p}=.029)$. The interaction term was a statistically significant independent predictor of institutional attachment, as evidenced by an increase in the total variance of institutional attachment explained of $3.3 \%\left(\Delta \mathrm{R}^{2}=.033\right),(F(1$, $181)=6.266, \mathrm{p}=.013)(b=9.472, \mathrm{SE}=3.784)$. In other words, attribution to Christian beliefs was a significant moderator of the relationship between sexuality policing and institutional attachment (Table 13). 
Table 13: Hierarchical Regression Analysis: Sexuality Policing and Institutional Attachment

\begin{tabular}{llcccc}
\hline \multicolumn{1}{c}{ Model } & \multicolumn{1}{c}{ Variable } & $\beta$ & $p$ & $\mathrm{R}^{2}$ & $\Delta \mathrm{R}^{2}$ \\
\hline Model 1 & & & & .015 & .015 \\
& Sexuality Policing & -.093 & .218 & & \\
Model 2** & Christian Attribution & -.065 & .389 & & \\
& & & & .048 & $.033^{*}$ \\
& Sexuality Policing & -.098 & .189 & & \\
& Christian Attribution & -.181 & .040 & & \\
& Interaction Term & .216 & .013 & & \\
\hline
\end{tabular}

$* \mathrm{~F}(1,181)=6.266, \mathrm{p}=.013$

$* * \mathrm{~F}(3,181)=3.065, \mathrm{p}=.029$

Sexuality policing and personal-emotional adjustment. In the first model, the marginally significant results indicate that the specific contributions of sexuality policing and Christian attribution combined explained $3.2 \%\left(\mathrm{R}^{2}=.032\right)$ of the variance in personal-emotional adjustment $(F(2,182)=3.052, \mathrm{p}=.050)$. Additionally, sexuality policing was a unique predictor of decreased levels of personal-emotional adjustment $(b=-3.824, \mathrm{SE}=1.553), \mathrm{p}=.015$.

The addition of the interaction term in the second model was statistically significant indicating that sexuality policing, Christian attribution, and the interaction term predicted participants' personal-emotional adjustment, $(F(3,181)=4.313, \mathrm{p}=.006)$. The interaction term was an independent predictor of personal-emotional adjustment, as evidenced by an increase in the total variance of personal-emotional adjustment explained of $3.4 \%\left(\Delta \mathrm{R}^{2}=.034\right),(F(1,181)=$ $6.647, \mathrm{p}=.011)(b=11.807, \mathrm{SE}=4.580)$. In other words, attribution to Christian beliefs was a significant moderator of the relationship between sexuality policing and personal-emotional adjustment (Table 14). 
Table 14: Hierarchical Regression Analysis: Sexuality Policing and Personal-Emotional Adjustment

\begin{tabular}{llrrrr}
\hline \multicolumn{1}{c}{ Model } & \multicolumn{1}{c}{ Variable } & $\beta$ & $p$ & $\mathrm{R}^{2}$ & $\Delta \mathrm{R}^{2}$ \\
\hline Model 1 & & & & .032 & .032 \\
& Sexuality Policing & -.184 & .015 & & \\
Model 2** & Christian Attribution & .024 & .753 & & \\
& & & & .067 & $.034^{*}$ \\
& Sexuality Policing & -.188 & .011 & & \\
& Christian Attribution & -.094 & .277 & & \\
& Interaction Term & .220 & .011 & & \\
\hline
\end{tabular}

* $\mathrm{F}(1,181)=6.647, \mathrm{p}=.011$

$* * \mathrm{~F}(3,181)=4.313, \mathrm{p}=.006$

Sexuality policing and social adjustment. In the first model, results indicate that sexuality policing and Christian attribution combined did not explain a statistically significant amount of variance $\left(\mathrm{R}^{2}=.015\right)$ in social adjustment $(F(2,182)=1.404, \mathrm{p}=.248)$. Additionally, sexuality policing was not a unique predictor of social adjustment $(b=3.238, \mathrm{SE}=1.933), \mathrm{p}=$ .096 .

With the addition of the interaction term in the second model, results indicate that Christian attribution did not moderate the relationship between sexuality policing and social adjustment, as evidenced by an increase in the total variation explained of $1.6 \%\left(\Delta \mathrm{R}^{2}=.016\right)$, which was not statistically significant $(F(1,181)=2.899, \mathrm{p}=.090)$. Additionally, the interaction term was not a unique predictor of decreased levels of social adjustment $(b=9.804, \mathrm{SE}=5.757)$, $\mathrm{p}=.090$. Sexuality policing again was not found to be a unique predictor of social adjustment $(b$ $=3.154, \mathrm{SE}=1.924), \mathrm{p}=.103$. In other words, Christian attribution did not moderate the relationship between sexuality policing and social adjustment (Table 15). 
Table 15: Hierarchical Regression Analysis: Sexuality Policing and Social Adjustment

\begin{tabular}{llcccc}
\hline \multicolumn{1}{c}{ Model } & \multicolumn{1}{c}{ Variable } & $\beta$ & $p$ & $\mathrm{R}^{2}$ & $\Delta \mathrm{R}^{2}$ \\
\hline Model 1 & & & & .015 & .015 \\
& Sexuality Policing & .126 & .096 & & \\
Model 2** & Christian Attribution & -.029 & .702 & & \\
& & & & .031 & $.016^{*}$ \\
& Sexuality Policing & .123 & .103 & & \\
& Christian Attribution & -.108 & .221 & & \\
& Interaction Term & .148 & .090 & & \\
\hline
\end{tabular}

* $\mathrm{F}(1,181)=2.899, \mathrm{p}=.090$

$* * \mathrm{~F}(3,181)=1.912, \mathrm{p}=.129$

It is important to note that upon visual inspection of the scatterplot of the studentized residuals against the unstandardized predicted values, the assumption of homoscedasticity may have been violated. This should be kept in mind when interpreting the results of this regression.

Sexuality policing and overall college adjustment. In the first model, the results indicate that sexuality policing and Christian attribution combined did not explain $0.9 \%\left(\mathrm{R}^{2}=\right.$ $.009)$ of the variance in overall college adjustment $(F(2,182)=.805, \mathrm{p}=.449)$. Additionally, sexuality policing was a not a unique predictor of decreased levels of overall college adjustment, $(b=-6.019, \mathrm{SE}=4.831), \mathrm{p}=.214$.

The second model which included only the addition of the interaction term was statistically significant indicating that sexuality policing, Christian attribution, and the interaction term combined predicted participants' overall college adjustment, $(F(3,181)=3.191, \mathrm{p}=.025)$. The interaction term between sexuality policing and Christian attribution was an independent predictor of overall college adjustment, as evidenced by an increase in the total variation of overall college adjustment explained of $4.1 \%\left(\Delta \mathrm{R}^{2}=.041\right),(F(1,181)=7.902, \mathrm{p}=.005)(b=$ 39.913, SE $=14.199)$. In other words, attribution to Christian beliefs was a significant moderator of the relationship between sexuality policing and overall college adjustment (Table 16). 
Table 16: Hierarchical Regression Analysis: Sexuality Policing and Overall College Adjustment

\begin{tabular}{llcccc}
\hline \multicolumn{1}{c}{ Model } & \multicolumn{1}{c}{ Variable } & $\beta$ & $p$ & $\mathrm{R}^{2}$ & $\Delta \mathrm{R}^{2}$ \\
\hline Model 1 & & & & .009 & .009 \\
& Sexuality Policing & -.094 & .214 & & \\
Model 2** & Christian Attribution & .002 & .981 & & \\
& & & & .050 & $.041^{*}$ \\
& Sexuality Policing & -.099 & .182 & & \\
& Christian Attribution & -.128 & .144 & & \\
& Interaction Term & .242 & .005 & & \\
\hline
\end{tabular}

$* \mathrm{~F}(1,181)=7.902, \mathrm{p}=.005$

** $\mathrm{F}(3,181)=3.191, \mathrm{p}=.025$

As similarly indicated above, one case had a studentized deleted residual of -3.045 (all other cases were within the \pm 3 range) but was kept in the final analysis.

Post hoc: simple slopes analysis. As recommended by Aiken \& West (1991), simple slopes for each regression with a significant interaction term were plotted in order to gain a better understanding of the data. Sexuality policing was plotted on the x-axis and college adjustment on the y-axis. Two slopes were calculated based on two different Christian attribution scores: "Low Christian Attribution" meaning one standard deviation below the mean of Christian attribution and "High Christian Attribution" representing one standard deviation above the mean of Christian attribution. These slopes were plotted at "Low Sexuality Policing" (again, one standard deviation below the mean of sexuality policing) and at "High Sexuality Policing" (one standard deviation above the mean of sexuality policing). Figure 1,2,3, and 4 each show two simple slopes of harassment predicting levels of adjustment, one slope at one standard deviation below the mean of Christian attribution (Low Christian Attribution) and one slope at one standard deviation above the mean (High Christian Attribution). Post hoc simple slopes t-tests were conducted to determine if the slope of each regression line (one at Low Christian Attribution and 
one at High Christian Attribution) was different from zero. If the slope was not significantly different from zero, college adjustment scores did not significantly change as frequency of harassment increased at that specific value of Christian attribution (Table 17).

Table 17: Post Hoc Simple Slopes T-Tests for Sexuality Policing and College Adjustment

\begin{tabular}{llrrr}
\hline \multicolumn{1}{c}{ Outcome } & $\begin{array}{c}\text { Level of } \\
\text { Moderation }\end{array}$ & Gradient & t-value & $\mathrm{p}$ \\
\hline Academic Adjustment & & & & \\
& Low Attribution & -7.923 & -2.858 & $.005^{*}$ \\
& High Attribution & 1.323 & .490 & .625 \\
& & & & \\
Institutional Attachment & Low Attribution & -4.940 & -2.682 & $.008^{*}$ \\
& High Attribution & 1.606 & .894 & .372 \\
& & & & \\
Personal-Emotional Adjustment & Low Attribution & -8.005 & -3.591 & $<.001^{* *}$ \\
& High Attribution & .153 & .071 & .944 \\
Overall College Adjustment & & & & \\
& Low Attribution & -20.152 & -2.916 & $.004 *$ \\
& High Attribution & 7.428 & 1.103 & .271 \\
\hline
\end{tabular}

$* * \mathrm{p}<.001 ; * \mathrm{p}<.01$ 
Academic adjustment. When Christian attribution was high, academic adjustment scores did not significantly change as frequency of harassment increased, $t(219)=.490, p=.625$. When Christian attribution was low, however, academic adjustment scores significantly decreased as frequency of harassment increased, $\mathrm{t}(219)=-2.858, \mathrm{p}=.005$. In other words, the negative regression of academic adjustment on sexuality policing at low Christian attribution was confirmed while the regression of academic adjustment on sexuality policing at high Christian attribution did not differ from zero (Figure 1).



Figure 1. Simple slopes of sexuality policing predicting levels of academic adjustment for low Christian attribution and high Christian attribution. 
Institutional attachment. Institutional attachment scores did not significantly change as frequency of harassment increased when Christian attribution was high, $\mathrm{t}(219)=.894, \mathrm{p}=.372$. When Christian attribution was low, however, institutional attachment scores significantly decreased as frequency of harassment increased, $t(219)=-2.682, p=.008$. In other words, the negative regression of institutional attachment on sexuality policing at low Christian attribution was confirmed while the regression of institutional attachment on sexuality policing at high Christian attribution did not differ from zero (Figure 2).

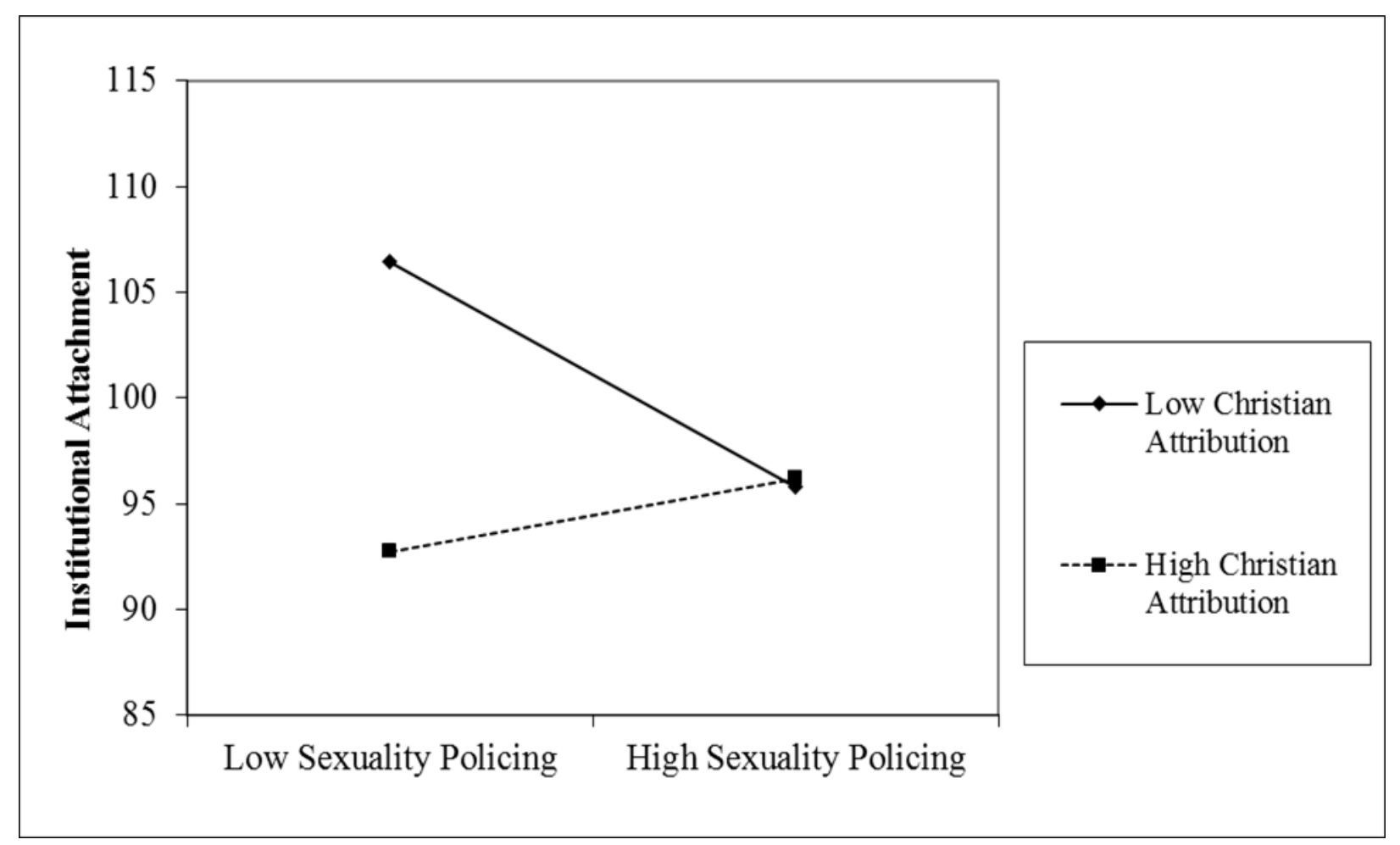

Figure 2. Simple slopes of sexuality policing predicting levels of institutional attachment for low Christian attribution and high Christian attribution. 
Personal-Emotional adjustment. The regression line for high Christian attribution did not significantly change as frequency of harassment increased, $t(219)=.071, p=.944$. The slope of low Christian attribution, however, shows that personal-emotional adjustment scores significantly decreased as frequency of harassment increased, $\mathrm{t}(219)=-3.591, \mathrm{p}<.001$. In other words, the negative regression of personal-emotional adjustment on sexuality policing at low Christian attribution was confirmed while the regression of personal-emotional adjustment on sexuality policing at high Christian attribution did not differ from zero (Figure 3).

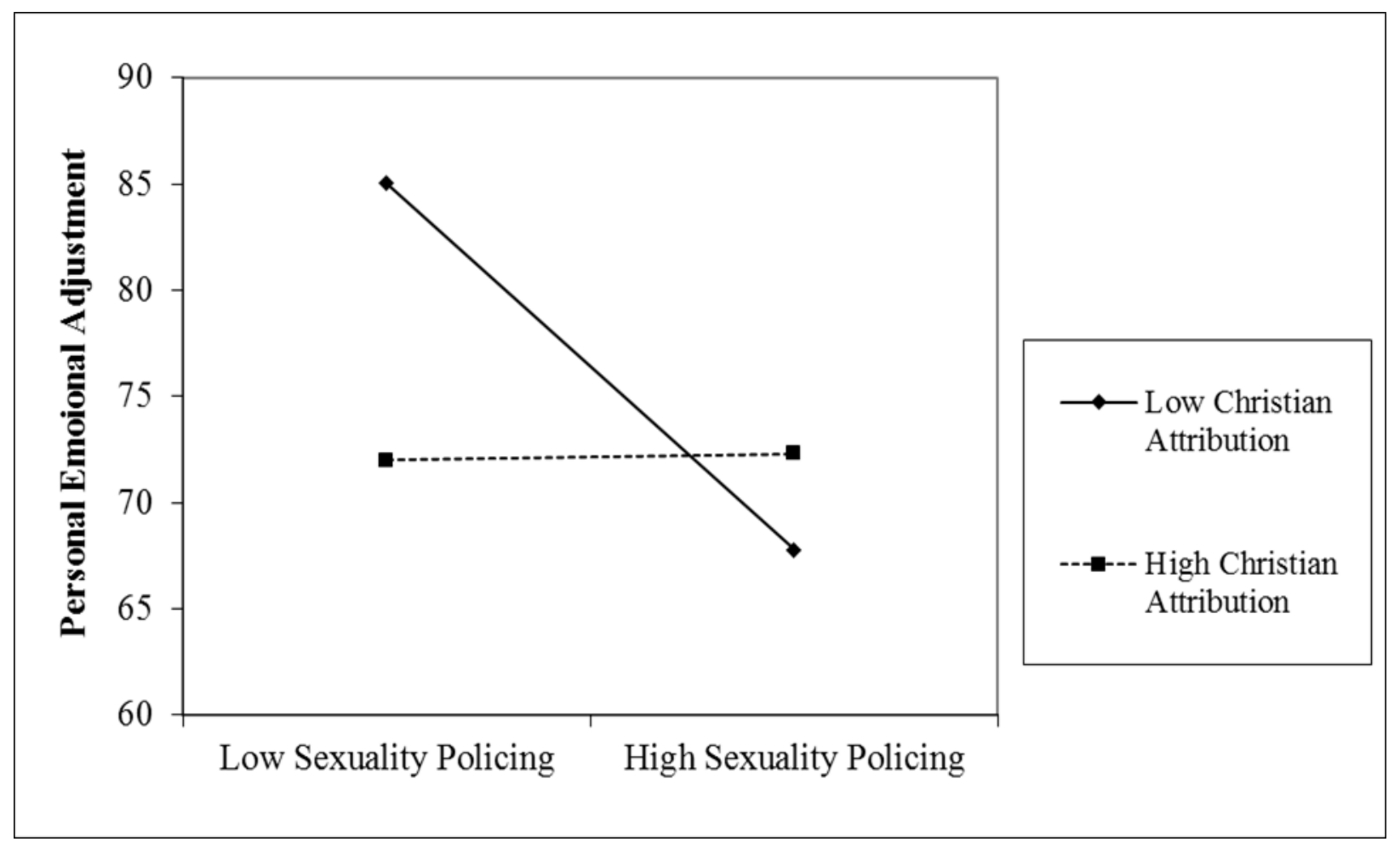

Figure 3. Simple slopes of sexuality policing predicting levels of personal-emotional adjustment for low Christian attribution and high Christian attribution. 
Overall college adjustment. When Christian attribution was high, overall college adjustment scores did not significantly change as frequency of harassment increased, $\mathrm{t}(219)=$ $1.103, \mathrm{p}=.271$. When Christian attribution was low, however, overall college adjustment scores significantly decreased as frequency of harassment increased, $\mathrm{t}(219)=-2.916, \mathrm{p}=.004$. In other words, the negative regression of overall college adjustment on sexuality policing at low Christian attribution was confirmed while the regression of overall college adjustment on sexuality policing at high Christian attribution did not differ from zero (Figure 4).

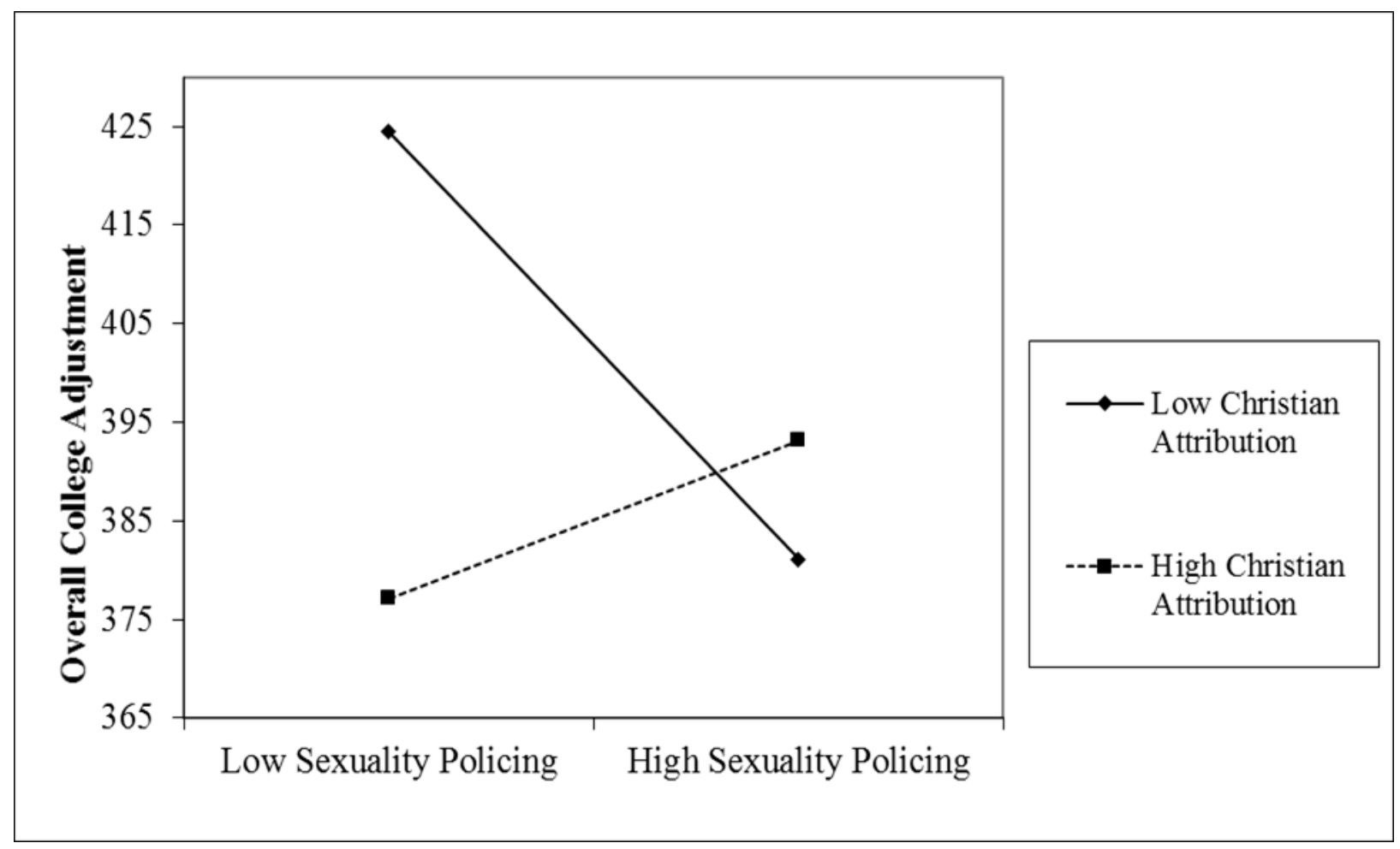

Figure 4. Simple slopes of sexuality policing predicting levels of overall college adjustment for low Christian attribution and high Christian attribution. 


\section{Qualitative Data Analysis}

For the open-ended responses, an automatic broad-brush analysis was implemented first by running an automatic word frequency query on the data set to get a better feel for the data. This NVivo feature scanned the entire data set and compiled a list of the most frequently used words (exact match only); see Table 18 for results. Unfortunately, the list of generated words did not elicit any specific themes or coding categories through which to organize the data.

\begin{tabular}{cc} 
Table 18: Word Frequency Chart Generated by \\
NVivo (Exact Match Only) \\
\hline Word & Count \\
\hline women & 175 \\
believe & 140 \\
religious & 124 \\
god & 100 \\
power & 98 \\
higher & 97 \\
Catholic & 84 \\
people & 82 \\
think & 66 \\
men & 54
\end{tabular}

Next, the responses were re-read, organized, and coded into two nodes (the organizational unit defined by NVivo where you place source documents of similar themes) identified by the researcher while reading the data: (1) the identity of the perpetrator(s) in relation to the participant and (2) the reason the participant made the attribution to a Christian motivation. While only one researcher coded the responses, meaning inter-rater reliability cannot be calculated, the researcher thoroughly coded the data two times and randomly selected $10 \%$ of the responses to be fully coded a third time. Each of the three coding sessions took place during a different day over the course of two weeks. This was done to ensure that the coding process and 
determination was consistent across time. The coding process utilized a hierarchal organization of "parent" nodes with nested "child" nodes. Responses could be coded to multiple child nodes within the same parent node if applicable (e.g. "students and teachers...”). The following coding scheme was used:

\section{(1) Parent Node: Perpetrator}

- $\quad$ Child Node: Professor/Faculty/Staff - the participant identified the perpetrator as a staff member or someone in a position of authority within the university

- Child Node: Classmate/Peer - this category includes roommates, people in extracurricular activities/groups with the participant (e.g., a sorority, a cappella group), or other students. Responses mentioning individuals the participant was at a party with or another social activity where it is likely that the individuals were in the same age bracket as the participant were coded to this category as well.

- $\quad$ Child Node: Friends - this child node includes friends, boyfriends/girlfriends, and ex-boyfriends/ex-girlfriends. This node designates that the person(s) who engaged in the behavior had a more intimate relationship with the participant than just being a classmate or a peer.

- Child Node: Other - Responses which did not specify the person(s) engaging in the behavior (e.g., "some guy" or "people") and could not be coded to another node were coded to this category.

\section{(2) Parent Node: Reason for Christian Attribution}

- Child Node: Known Christian - This node contains responses in which the perpetrator may not have used an explicit Christian belief or Biblical reference when engaging in the behavior, but they are known to be a Christian or were 
known to be raised in a Christian/Catholic family. For this reason, the participant attributes the harassing behavior to the Christian/Catholic faith of the perpetrator.

- $\quad$ Child Node: Faith-Informed Reason - Responses including a reference to Christian/Catholic-informed beliefs about something were coded to this node. Only responses that alluded to a Christian/Catholic belief for why a conservative remark was stated were coded to this category. For example, the statement "women are more nurturing" would not be coded to this node, but statements such as "women are more nurturing because God made them that way" would be. Additionally, if the response mentions that the perpetrator brings up sin or morality when making the remark (e.g., "women are more nurturing and if they do not stay at home with their kids it is a sin"), it is coded to this category as well. In summary, the perpetrator may not have referenced a specific Biblical passage for their belief, but their justification for engaging in gender harassment was motivated by beliefs associated with/informed by their Christian/Catholic faith.

- $\quad$ Child Node: Bible or Text - Responses that indicated an explicit reference to the Bible or another religious text was used to justify the Christian motivated gender harassment were coded to this node.

- Child Node: Assuming a Christian Motivation or Indirectly Associating the Behavior with Christianity - Responses were coded to this node when the participant made a Christian attribution because the behavior/remark was considered conservative, which the participant assumed was due to the Christian/Catholic beliefs of the perpetrator(s). The perpetrator(s) did not say or do anything that explicitly referenced a Christian belief, but because the behavior 
was deemed evident of traditional ideologies, the participant assumed it must have stemmed from the perpetrator's conservative (i.e., Christian/Catholic) faith. In other words, because the behavior was deemed representative of sexist and conservative values, the participant assumed it must have been indirectly motivated by a Christian or Catholic belief.

- Child Node: Unsure about the Religious Motivation - Responses were coded to this child node when the participant expressed that they were unsure whether/how Christian beliefs motivated the behavior. Something to note is that all participants who wrote about their experiences previously indicated that the behavior was at least partially motivated by the Christian/Catholic belief of the perpetrator via the closed-ended response.

Perpetrator. A total of 222 responses were coded to the Perpetrator parent node.

Professor/Faculty/Staff. Of those responses, 27 (12.2\%) were coded to the Professor/Faculty/Staff node. The majority of these responses identify a professor who made remarks or engaged in behaviors that insulted women, sometimes causing serious negative consequences. One participant wrote:

I have had about 3 male professors at [DePaul $]^{7}$ who have made comments about women that I would not necessarily deem appropriate. One instance that still irks me today is a Professor who made a comment telling me I was too pretty to do [such] stressful and [strenuous] [work] and that I would probably be better off putting my skills to other uses[.] I kind [of] just brushed it off and laughed about it with him. But he continued making such jokes throughout the quarter...At first I did not mind the remark, but by the

\footnotetext{
${ }^{7}$ Any revisions to the original text submitted by participants are noted within brackets. Revisions ranged from correcting a misspelled word, to adding in an apostrophe, to adding in a linking verb such as "and" in order for the text to read correctly.
} 
end of the quarter I felt very inferior and belittled which resulted in me often skipping the class and doing poorly as a result.

One theme present in many responses regarding professors is the idea that the collegiate environment is not a place for women. This idea is expressed through professors talking down to the participants, stating that women should focus more on private sphere skills as opposed to gaining skills for work outside of the home, or claiming women are not as good (or do not need to be as good) as men in professional fields. In these responses, the public sphere of the university and the workplace are deemed appropriate for men while women are othered. One participant wrote:

Many professors and students have made disparaging remarks against women studying at the College of Digital Media. I have heard things such as, "The marketing class is across the hall - this is a PROGRAMMING class" to, "Women don't need to do well to get job in information technology, they just need to be women!" These are comments that students and professors make daily, and it is just a part of the atmosphere at DePaul's CDM

This same participant wrote about seeking information from an employee of DePaul University regarding her access to a sexual health clinic:

I asked [where] the sexual health clinic was at [DePaul's] campus. A professional member scoffed and said "Only sluts would be concerned with getting a free pass and not suffering with the consequences of pregnancy." I know this person was Catholic and I [believe] his comment was primarily driven by Catholic ideology because he said "Thank God this is a Catholic university - I [wouldn't] be able to live with myself if my employer funded abortions for whores."

Classmate/Peer. A total of 103 (46.4\%) of the Perpetrator nodes were coded to the Classmate/Peer child node, the most popular Perpetrator child node. While a few participants stated that sexism is low in frequency at DePaul, many students recognized the pervasive 
prejudice embedded in the atmosphere of the student body. Some cited classroom discussions

where women's roles are relegated to the private sphere:

Well when I was in class, we were talking about how our cultural beliefs affect our family dynamics and a student stated that they felt that women shouldn't be working. They are more feminine and loving thus children need that. The student stated that he [is] Catholic and was raised to believe this.

Participants also wrote about experiencing gender harassment through jokes among their peers:

Students often make casual sexist jokes such as "Get back in the kitchen!" or "Go make me a sandwich, bitch!" Obviously these remarks are hurtful and brutish - it is awful that these comments are ALLOWED in a professional environment, and even [encouraged thanks] to the Catholic affiliation of DePaul. The religious affiliation of these people is Christian - while not especially devout themselves, they come from particularly involved families.

Multiple students reported peers engaging in the policing of women's sexuality:

Girls talking about other girls who slept around, religiously immoral, made them "dirty whores"

Another student wrote:

A few men on campus, who looked like students were talking about a group of girls they were with over the weekend and were talking about how "slutty" one of them was dressed and were saying sexual things about her...

Other interesting subthemes to note in this child node are that participants wrote about being "cat-called" on or around campus, how students (both male and female) would degrade other female students for dressing "inappropriately," and how students would harass women who are doing the "walk of shame." 
Friend. A total of 34 responses $(15.3 \%)$ were coded to the Friend node. Many of these responses noted joking as the conduit through which gender harassment occurred. Their friends would make jokes that insulted women or derived their humor from sexist stereotypes. One participant wrote:

One joke that is used often in my group of friends is the "That's what she said" joke. It is never meant to be offensive to me or any of my girlfriends, and it never bothers us. We understand it is just a silly joke, and is often actually fairly funny, [we admit].

Another wrote:

The sexist comments made by either professors or friends were just off-hand comments said in a joking manner, like saying that women can't drive or can't operate as well in the workplace.

Multiple students reported not feeling hurt or angry when their friends made such jokes, and in fact played along and found them funny. One student wrote about her male friend making a negative comment about a woman driver:

I was not that uncomfortable because even though he was probably somewhat serious I was also aggravated by the driver so I found his comment funny.

Other participants noted the slut-shaming that occurred among their friend group. The remarks were not usually aimed at the participant:

Like I said in previous responses, I have observed women being slut-shamed on a number of occasions. Even my own friends will occasionally make negative comments about girls based on their sexual experience, such as "She's really easy" or "I heard she f**ed the whole basketball team." 
While these comments may not be directed towards the participant, these kinds of statements still negatively impact the women hearing them. The same participant wrote:

Even among my own group of friends here, male and female students alike often talk about girls who are "fat" or "ugly" and regard them as if they are somehow worth less as people for being unattractive. Such comments often make me feel bad about myself, [and] influence me to compare myself to other girls and judge my own worth based on my appearance.

Other. A total of $58(26.1 \%)$ responses were coded to the Other child node of the Perpetrator parent node. As would be expected with a category like this, the content of the responses ranged in content. Some participants noted blatant slut-shaming:

Catholic guy said women should not entice men with slutty clothes

Other participants wrote about situations where others espoused stereotypical ideas of women's roles:

In one of these instances, the individual had suggested that women, as the bearers of children, are responsible for household maintenance and childcare.

Reason for attribution. A total of 161 responses were coded to the Reason for Attribution parent node. Something to note is that many participants did not include a reason for making the Christian attribution they did in their open-ended response.

Known Christian/Catholic. Of the participants that did explain why they made the Christian attribution they did, the most common reason was that the participant knew the perpetrator(s) to be a Christian/Catholic. A total of $52(32.3 \%)$ responses were coded to this category. Many participants noted that while the perpetrator(s) did not explicitly reference a Catholic/Christian belief for the behavior, the participant interpreted the motivation for the 
behavior as being related to a Christian/Catholic belief as the participant knew the perpetrator(s)'

religious affiliation. One participant wrote:

Professionals and students at DePaul have occasionally made remarks that women here are just looking for a husband to have children with and that this is the prime function of women. I know the people who have made these remarks are staunch Catholics. It [is] upsetting that bigots such as that are at a higher institution of learning and that DePaul as an employer sees no issue with employing and promoting these values. Catholicism is inherently sexist, so it is why I think their Catholic beliefs contribute [to] their opinions on women's rights.

Some participants acknowledged the attributional ambiguity in trying to determine why they experienced the Christian-motivated harassment they did. Some participants took note of the Christian/Catholic identity of the perpetrator and recognized that it may have influenced the behavior some, but not fully. One participant wrote:

...I just know these peers happen to be Catholic and the reason for the sexist remarks may be due to this or just how they were brought up in their household. They just made very stereotypical remarks about women always crying and only wanting [to get] married for money so they can shop, etc. I hated hearing the words come out of this peer's mouth.

Faith-Informed Reason. A total of 37 (23.0\%) responses were coded to the Faith-

Informed Reason child node. Most of these responses centered on experiences of participants being given religious reasons as to why women should dress "appropriately" and refrain from sexual activity or why women are better suited for roles in the private domain. The religious reasons are derived from both religious scripture and commonly held beliefs in traditional Christian culture. One student wrote:

Girls talking about other girls who slept around...religiously immoral...made them "dirty whores" 
Another student wrote:

Once again, I was involved in a discussion with peers about women in the work place. Several of my peers all agreed that women should stay home with the children and [perform] domestic duties, while the man works away from the home. Religion was brought up [once] or twice as backing for their beliefs on this issue. Other peers stated it was due to women's character. I felt nauseated during and after this discussion.

Beyond using faith-informed arguments, multiple students wrote about others attempting to police their actions and bodies through the authority of God. In these situations, perpetrators used their belief and convictions of what God would approve of in order to regulate their peers. One student (the same student who wrote about the "dirty whores" comment above) wrote:

Boys in my dorm said [women] should make babies and sandwiches because [that's] what Jesus said to do.

Another student wrote:

A comment was made saying that I should wear longer shorts because god would not approve.

In these situations, those engaging in the harassing behavior do not present their statement as a negotiable opinion, but state with conviction that it is not they who disapprove, but God. In continuing to situate myself in this research, these experiences speak the most to my own experiences while in college: perpetrators employing a narrative through which they claim to speak for God, who would disapprove of their actions.

Bible/Text. Only 4 (2.5\%) responses were identified and coded to the Bible/Text child node in which the perpetrator made an explicit reference to the Bible for engaging in gender harassment. Three of the four center on women's sexuality and the policing of their body. 
Something to note is that one participant wrote three of the four responses coded to the

Bible/Text node, and this participant reported being an atheist who never attends worship

services. One of the responses from this participant was about a discussion in which women's

roles were debated:

Peers of mine were discussing how they believe that women should stay home and [perform] domestic duties (cleaning, cooking, [etc.]) while her husband works outside of the home and provides for his family. The people engaged in this discussion stated several [times] throughout, that they believed for this to be the way God intended women to behave. Quoting Bible passages about Eve and the sin women bear in consequence to her disobedience. I was shocked, disgusted, and further turned off to the idea of [Christianity].

This same participant later wrote:

This was stated by a friend of a friend who also attends DePaul University. She stated that she thinks it is inappropriate for women to dress a certain way. I asked her why she cared what other people wore and she spoke about what it said about their [character], she also mentioned how women are supposed to act with relevance to how women are described and spoken about in The Bible. She is an outspoken Christian. I felt very angry and annoyed after the conversation. After holding a conversation with her I [thought] a lot about sexism in the Christian religion.

Assuming Christian motivation. One of the more difficult categories to code was the Assuming Christian Motivation or Indirect Association with Christianity child node. A total of $38(23.6 \%)$ responses were coded to this category. These responses highlight an interesting phenomenon: participants experiencing gender harassment as a result of conservative beliefs may assume those beliefs are tied to Christianity/Catholicism because they consider these faiths to be ontologically conservative. In other words, participants may attribute general conservative attitudes to a Christian ideology even with no other evidence. One participant wrote: 
I was talking with a student and I was telling him I like to run and I would like to travel before I begin a family. The male told me that females nowadays are extremely selfish. The person was a white male so I assumed he was catholic or Christian. I [believe] this person was religiously motivated because he objected to my independent female lifestyle. I was shocked by the bluntness of his comments.

Some students took note that while the actual harassing statement or behavior may not have been motivated by a Christian/Catholic belief, they recognize the power of Christianity in influencing larger culture in prescribing traditional gender attitudes. One participant wrote:

Sometimes in settings such as parties, I have seen male students make extremely [inappropriate] sexual comments to girls, such as chanting "Tits out for the boys!" repeatedly to one very uncomfortable looking large-breasted young woman, or looking me up [and] down while passing me on the sidewalk and suggestively saying "I like what I see." I don't think these kinds of behaviors are directly motivated by Christian/Catholic beliefs but like I said before, such beliefs often feed into a culture that make men [feel] entitled to women and their bodies.

Unsure about the religious motivation. The most interesting category to emerge was the Unsure about the Religious Motivation child node. A total of 30 (18.6\%) were coded to this category. While this grouping may seem contradictory given the fact that in order for participants to write about their experiences they needed to make at least a partial attribution to a

Christian/Catholic belief for why the behavior occurred, this category is better understood as highlighting the ambiguity present when making such attributions. Sometimes participants made it clear they did not believe the perpetrator was motivated by their Christian beliefs at all:

A classmate of mine raised his opinion on women in the health field. He insisted that although time[s] are changing, women belong at home not working in hospitals and [that the] day women [outnumber] men is the day the world is in trouble. No I [do] not believe [this person] was motivated by his religious beliefs. I felt degraded and belittled. 
It is important to note that the above participant reported that they believed the person engaging in the above mentioned behavior was "Slightly motivated by Christian/Catholic beliefs" in the closed-ended response. While some participants stated they did not believe the behavior was motivated a Christian/Catholic belief, others mentioned that they are simply unsure about the perpetrator(s)’ religious affiliation. One participant wrote:

I was walking down the hallway with a few of my friends \& we heard a professor say that it was a girl, who did the worst on the test to another professor $\&$ then he proceeded to say that it was obvious that it was a girl. I do not know if this person has Catholic background.

Another participant wrote:

Just today, in one of my classes, a male student said to another male student "dude, that bitch that I was talking about? She has a boyfriend!" The other student said "seriously?!" and the first male said "Yeah! Like don't smile at me and talk to me [every day] during class if you have a boyfriend!" and the other guy said "Sluts, man." I have absolutely no idea what either of the boys' religious affiliations are but I was blown away by the obvious deeply-rooted lack of respect that they both had for women.

Given that these participants still reported the behaviors were at least partially motivated by a Christian/Catholic belief in the closed-ended responses, they may recognize that the behavior is evident of a conservative Christian ideology but aware that they are unsure as to the exact religious affiliation of the perpetrator.

\section{Discussion}

This study explored Christian-motivated gender harassment, a form of divine discrimination. Specifically, this study had two hypotheses: (1) gender harassment, determined by scores on the self-administered Gender Experiences Questionnaire (GEQ) along with a sexuality policing 
measure developed for this project, would negatively predict college adjustment, as assessed by the Student Adaptation to College Questionnaire (SACQ), and (2) this effect would be moderated (i.e., intensified) by Christian attribution in that when harassing behavior was attributed to the Christian belief of the perpetrator, as measured by a self-report item assessing perceived Christian motivation for the harassing behavior, college adjustment would be even lower. Overall gender harassment was found to significantly and negatively predict levels of academic adjustment, institutional attachment, personal-emotional adjustment, and overall college adjustment. In fact, for every increase in one point on the 5-point scale of overall gender harassment scale (e.g., "never" to "once or twice" in the 12 months prior), overall college adjustment scores dropped around 20 points. However, Christian attribution did not moderate any of these relationships, meaning that the relationship between gender harassment and college adjustment did not change significantly depending on whether the target attributed the harassing behavior to the perpetrator's Christian belief or not. However, sexuality policing was more fully explored, as this form of gender harassment may be more salient for college women given their social context and developmental stage. As such, evidence of divine discrimination was found: Christian attribution was found to moderate the relationship between sexuality policing and academic adjustment, institutional attachment, personal-emotional adjustment, and overall college adjustment. No significant relationships were found among gender harassment, sexuality policing, and social adjustment. This is the first study to my knowledge that has found a significant moderating effect of Christian attribution on gender harassment in a college student sample.

Simple slope t-tests revealed that for all of the significant interactions, the negative regression of the appropriate adjustment score on sexuality policing at low Christian attribution 
was confirmed while the regression of the appropriate adjustment score on sexuality policing at high Christian attribution did not differ from zero. This means when sexuality policing was highly attributed to the Christian belief of the perpetrator, adjustment scores did not significantly change as frequency of harassment increased; when sexuality policing was slightly attributed to the Christian beliefs of the perpetrator, however, adjustment scores significantly decreased as harassment frequency increased

It is important to note that the simple slopes t-tests only tell us whether college adjustment scores significantly change as frequency of harassment increases for a value of Christian attribution; it does not negate the moderating effect of Christian attribution overall. For example, Figure 3 depicts the simple slopes for personal-emotional adjustment regressed unto sexuality policing at two levels of Christian attribution: high and low. The negative slope of low attribution is visually apparent (when harassment is slightly attributed to Christian beliefs personal-emotional adjustment scores decrease as gender harassment increases), but there seems to be no change in personal-emotional adjustment as frequency of harassment increases for high attribution.

Several conclusions can be drawn from interrogating all four of the simple slopes graphs. When harassment is somewhat attributed to the Christian belief of the perpetrator, college adjustment decreases significantly as frequency of harassment increases. In other words, the negative effects of slightly attributing harassment to the Christian belief of the perpetrator are ameliorated when harassment is low. Additionally, when harassment is highly attributed to the Christian belief of the perpetrator, college adjustment scores are diminished for all frequency levels of harassment. Meaning, regardless of the amount of sexuality policing one experiences, college adjustment is diminished when it is highly attributed to the Christian belief of the 
perpetrator. Upon visual inspection of these figures, it is apparent that all college adjustment plot points seem to be similar in value except for low frequency with low attribution: those experiencing infrequent episodes of harassment which are only slightly attributed to the Christian belief of the perpetrator fair better than those experiencing frequent episodes of harassment which are only slightly attributed to a Christian belief or those experiencing any level of harassment when it is highly attributed to the Christian belief of the perpetrator.

In interrogating Figure 2 depicting the moderating role of Christian attribution on sexuality policing predicting institutional attachment, the low harassment/high attribution adjustment score is 92.8 , the high harassment/high attribution adjustment score is 96.2 , and the high harassment/low attribution adjustment score is 95.8. These scores are close in value (within 3.5 points). Additionally, the adjustment scores associated with high harassment for both low and high attribution are practically identical (the plot points are on top of each other). Moreover, the slope of the high attribution line is not statistically different from zero, indicating that all scores for high attribution stay the same regardless of harassment frequency. In other words, from both a statistics and practical standpoint, these three adjustment scores are very similar. The low harassment/low attribution score, however, is 106.4 , over 10 points higher (i.e., better) than the next closest score. The only combination of factors that seems to protect an individual is low harassment/low attribution. This begs the question, why does high Christian attribution have the same negative impact regardless of harassment frequency? Or put another way, why does the amount of Christian attribution only seem to have any importance when sexuality policing is low in frequency?

\section{Normative Behavior and Perceived Injustice.}


Mikula's (1993) attribution-of-blame model of judgments of injustice may provide a possible explanation. As frequency of sexuality policing increases, subjects may no longer experience it as an unjust event but as part of the normative environment. If the episodes of gender harassment are no longer considered unjust, it is possible that the specific effects stemming from the kinds of attributions made for the behavior fluctuate. Gender harassment regardless of frequency may still have a main negative effect on college adjustment, but Christian attributions for gender harassment may potentiate the negative effects of harassment only when it is perceived as an unjust event (i.e., gender harassment is low in frequency). In other words, it may not be just an attribution of Christian motivation that moderates the effect of gender harassment on college adjustment, but a specific kind of attribution of Christian motivation relating to an experience of injustice: an attribution of blame and responsibility. The experience of injustice may operate as a function of frequency of gender harassment.

As noted by Hlavka (2014), compulsory heterosexuality and heteronormativity can normalize the presence of sexual and gender harassment. Compulsory heterosexuality, as popularized by Adrienne Rich in 1980, deems the assumption of all social subjects as heterosexual a "political institution" which reinforces heterosexuality within a complex of male domination. The assumed passive nature of women's heterosexuality complements men's domineering heterosexuality, which erases and others lesbianism and women's erotic desire for other women. This assumed and forced system of heterosexuality (re)creates social scripts and societal norms which accept and excuse the abuse of women by men: these acts of sexual violence are a "normal" part of the heterosexual culture. Hence, compulsory heterosexuality is a subliminally forced institutional power masked as normative through which the patriarchy is created and reproduced (Rich, 1980). 
Similarly, heteronormativity describes the "view that institutionalized heterosexuality constitutes the standard for legitimate and prescriptive sociosexual arrangements" (Ingraham, 1994, p. 204). This forced institutionalization of a culture of heterosexuality is rooted in static understandings of gender identity, gender expression, and sexual orientation: every person is a cisman or ciswoman, all men are traditionally masculine and all women are traditionally feminine in order to fulfill complementarian roles, all people are heterosexual and only engage in monogamous heterosexual sexual activities, and these relationships are legitimized and prescribed as normal through political institutions such as marriage, the idea of the normative nuclear family, and social rituals such as Valentine's Day (Farrell, Gupta, \& Queen, 2004). As such, heteronormativity as a regime of social control can be thought of as a consequence of compulsory heterosexuality that is constantly being reinforced as normative culture. Part of this system of heteronormativity is the socialization of traditional sexual scripts which depict men as having insatiable sexual drives and women as sexually reluctant (for a review of traditional sexual scripts, see Byers, 1996, pp. 8 - 11). Masters, Casey, Wells, and Morrison (2013) found that in their sample of young men and women, intra- and interpersonal sexual scripts often times conformed to traditional cultural-level gendered scripts. Although they noted participants who also engaged in "exception-finding" and "transforming" styles with regards to their own gendered rules for dating and sex, the conformity to traditional cultural-level gendered scripts was the most represented category in their analysis (Masters et al., 2013).

It is through this myriad of social relations entrenched in patriarchal understandings of sexuality that Hlavka argues that "heteronormative discourses have allowed for men's limited accountability for aggressive, harassing, and criminal sexual conduct" (Hlavka, 2014, pp. 339 340). Men's aggressive sexual behavior is deemed a natural part of the male sexual drive; 
therefore it is no longer an abnormal occurrence or characteristic of a pathological personality, but simply a typical aspect of the heteronormative sexual landscape. As such, episodes of sexual harassment become normalized as a part of culture (Hlavka, 2014). The data from this study support the notion that for some, gender harassment may also be considered a normative behavior.

In this study, gender harassment was reported by $91.5 \%$ of the sample with $83 \%$ reporting having experienced some form of sexuality policing perpetrated by someone at DePaul University at least once in the prior 12 months. While sexuality policing is not considered severe in terms of frequency in this sample, it is considered pervasive in terms of how many participants have experienced it. Additionally, the qualitative responses indicate that for some, gender harassment is such a ubiquitous occurrence that it is considered a normal part of life at DePaul University:

Unfortunately, sexism is prominent everywhere- DePaul included.

Like I said, I have heard women referred to as "sluts" or "whores" before...

It is said all the time by men and women of all religious affiliations, some who are motivated by Christian and Catholic beliefs, and some who aren't. Because of [its] prevalence it doesn't really bother me.

Additionally, the qualitative data from this study revealed that one of the more popular methods through which classmates, peers, and friends expressed gender harassment to the participant was through jokes and humor. Even when participants noted the jokes did not necessarily hurt them, they acknowledged a culture where sexist jokes are considered acceptable. Research shows that sexist jokes and humor are associated with actual sexist beliefs and 
behavioral intentions. Ryan and Kanjorski (1998) found that for men, the enjoyment of sexist jokes was associated with rape-supportive beliefs, likelihood of committing rape, and sexual, physical, and psychological aggression. Beyond sexist humor being associated with real sexist thoughts and actions, research shows that sexist humor can actually promote a perception that sexism and gender-based prejudice are acceptable.

In a particularly interesting study, Ford, Boxer, Armstrong, and Edel (2008) found that upon exposure to sexist jokes (as compared to neutral jokes or nonhumorous sexist statements), greater hostile sexism was associated with men's decreased willingness to help a women's organization. Additionally, the researchers found that upon exposure to sexist comedy sketches (as opposed to non-sexist comedy sketches), greater hostile sexism was associated with men's actual sexist behavior as defined as the percentage of budget cuts allocated to a women's organization (greater hostile sexism was associated with higher cuts) (Ford et al., 2008). Sexist humor acted as a tool of trivialization regarding sexism: making light of gender-based prejudice communicated that sexism was acceptable behavior. Treating the sexism as a joke actually communicated to subjects that they are free to "release" their internal sexist thoughts and feelings. As stated by the researchers, "sexist humor created a realization of two separate and conflicting norms of appropriate conduct toward women: a general, nonprejudiced norm and a local, prejudiced norm - a norm more tolerant of sexism" (Ford et al., 2008, p. 168). It is possible that the ubiquitous nature of sexist and gender-prejudice jokes at DePaul contribute to establishing a normative environment in which gender harassment is trivialized and tolerated. Even though some female participants indicated that the sexist humor espoused by their friends and classmates did not bother them (and that they often found the jokes humorous as well), it still may be contributing the overall normalization of gender harassment at DePaul University. 
All of this evidence lends supports to the notion that as frequency of gender harassment increases (especially when its conduit is through humor); the more it may be considered a part of the normative environment of the university. As such, gender harassment may no longer be perceived as an unjust event but more of a typical (although still negative) behavior. Cohen argues that "perceptions of justice are based fundamentally on attributions of cause and responsibility" (1982, p. 119). Actors who engage in behaviors which fall within the normative range of what is acceptable do not elicit attributional thinking from targets regarding responsibility: There is no need to attribute responsibility for the behavior as it is already considered socially acceptable conduct. The behavior is seen less as the result of internalized forces from an actor but more the result of external forces such as conformity to social norms. (Cohen, 1982). Recall that Mikula (2003) argues that judgements of injustice are conceived as particular instances of blaming an agent who is seen as responsible for a violation of entitlement. As such, behaviors which are deemed normative may not result in attributions of blame and responsibility. Consequently, "if no one is to blame, there is no social injustice" (Folger \& Cropanzano, 2001, p. 1).

The failure to see gender harassment as an unjust event has implications for the kinds of attributions made for the behavior. This means that participants still engage in attributional thinking regarding their experiences of gender harassment and may attribute their experiences to the Christian/Catholic belief of the perpetrator, but those attributions may not be attributions of blame or responsibility which dictate whether or not the behavior is considered unjust. As such, the Christian attributions made for the behavior may not necessarily moderate the impact of gender harassment on college adjustment if the behavior is not perceived as unjust and those attributions do not regard responsibility and blame. Research shows that perceptions of justice 
can play an important role regarding health outcomes (Jashaswini, 2011). In relation to this study, the lack of naming these experiences of gender harassment as unjust may play a role in the effect of the kinds of Christian attributions made. The data from the current study support this argument, as when sexuality policing is high in frequency (i.e., it is more likely to be considered part of the normative gendered heterosexual landscape), there is no practical difference in college adjustment scores at varying levels of Christian attribution: it is possible these experiences are deemed normative and, as such, Christian attribution does not moderate the relationship as these attributions are not regarding acts of injustices.

Deviations from the range of normative behaviors, however, are more likely to evoke attributional thinking regarding responsibility and blame as there is a discrepancy between the expected behavior and the behavior that actually occurred (Cohen, 1982). In keeping consistent with Mikula's attribution-of-blame model of judgments of injustice, subjects will perceive more injustice the more they attribute responsibility and blame to an actor for causing a violation of entitlement (2003, p. 795). As such, when sexuality policing is low in frequency, college women are more likely to perceive incidents of gender harassment as non-normative behavior, or behavior that is outside of socially acceptable conduct. Consequently, these women may be more likely to engage in attributional thinking regarding responsibility and blame. College women may perceive that their gender harassment was not just motivated by their perpetrator's Christian/Catholic belief, but these attributions of responsibility and blame are likely to lead to a judgment that the behavior was unjust. Meaning, making a Christian attribution is not just an explanation for a negative behavior with its own moderating effect; it is a "moral accusation" against someone for violating their entitlements which in turn can mediate the impact of these attributions on outcomes (Mikula, 2003, p 795). The data support this, as when sexuality policing 
is low (and episodes of sexuality policing are more likely to be considered nonnormative behaviors); higher Christian attribution is associated with significantly lower college adjustment as compared to lower Christian attribution. Higher attributions to Christian beliefs may also be higher attributions of blame, indicating greater injustice perceived.

In summary, it is possible that an important element in understanding the moderating role of Christian attribution is to determine whether the behavior is considered unjust in the eyes of the target. It is possible that the power of using Christian/Catholic beliefs to harm individuals only matters if the behavior is deemed an act of injustice by the subject experiencing the harassment. Christian attribution may moderate the relationship between gender harassment and college adjustment, but the moderating effect may be mediated by judgements of injustice as judged by the target. Judgements of injustice are influenced by multiple factors, including whether or not the behavior is considered normative conduct.

Practically speaking, this makes sense in a real world scenario: if two targets, one a conservative Christian and the other a liberal atheist, are told by an actor that women have no place in the workplace as God designed them to be the primary caretaker of the home, each target may attribute the cause of the behavior to the Christian belief of the perpetrator, which moderates the impact of the behavior on an outcome. This moderation, however, is mediated by interpretations of the behavior as unjust. The conservative Christian may agree with the harassing statement as it aligns with her own values, beliefs, and convictions. She may spend time in communities where an actor making this sort of statement is considered normative behavior. As such, while she attributes the statement to the Christian/Catholic belief of the perpetrator, it most likely is not an attribution of blame resulting from feeling as though her entitlements have been violated. Consequently, she may not deem this behavior as unjust, 
although there still may be a negative main effect of harassing behavior on outcomes. On the other hand, a liberal atheist may spend more time in communities where nontraditional gender ideologies are espoused; therefore she would interpret the Christian-motivated statement as a deviation from the social norm and attribute blame to the actor for engaging in an act of social injustice. As such, the moderating effect of Christian attribution intensifies the effect of this episode of harassment on an outcome.

While it is difficult to expand upon the relationship between acts of perceived injustice and Christian attributions in the given study beyond abstract theorizing, more research should focus on how attributions of blame and labeling acts as unjust interact to moderate the effect of such attributions on an outcome. In other words, how do attributions as a function of perceived injustice differ in moderating the relationship between gender harassment and college adjustment? I have suggested that perceptions of injustice mediate the moderating impact of Christian attribution, but more research needs to be done to test this model. It is possible that Christian attribution may not play as important a role as perceived injustice associated with that attribution. Meaning, maybe the important element in this model is not the effects of different kinds of attributions made as a result of perceived injustice, but that the event was perceived as unjust at all. I maintain however, that Christianity/Catholicism are such powerful institutions of social control and regimes which influence hegemonic social, cultural, and political ideals that the specific attribution of perceiving an unjust event as motivated by Christianity will have a significant impact over and above perceiving an event as simply unjust. More research needs to be done however, to test this notion.

\section{Sexuality Policing: Adolescent Development and Christian Control}


Another interesting result to emerge from this study was that sexuality policing was the only form of gender harassment to be moderated by Christian attribution in its impact on college adjustment. No evidence was found to support the claim that sexist remarks, sexually crude/offensive behavior, infantilization, work/family policing, gender policing, or the overall GEQ were significantly moderated by Christian attribution in their impact on college adjustment. There are several possibilities as to why the findings emerged this way.

It was stated earlier that Leskinen and Cortina (2014) developed the GEQ for more professional environments rather than other settings stating, "the stem of our GEQ is specifically tailored to workplace contexts, but it could be adapted for use in classrooms, courtrooms....and any other organized contexts where gender may be devalued" (p. 118). While the directions of the GEQ can be revised so that it can be administered in different settings, it is possible that it does not detect the kinds of gender harassment younger women (i.e., college-aged women) experience. For example, the Work/Family Policing dimension taps into harassment stemming from traditionally held sexist beliefs regarding women in the workplace. As discussed in the literature review, sexist ideas regarding women's place in and out of the home are often times justified using a religious argument or reasoning based in religious thought. While these sexist ideologies regarding women in the public sphere may have a significant negative impact on working women, including inspiring cold working climates and sexist corporate policies such as inadequate maternity leave (Valenti, 2014), issues of gender harassment specific to workplace contexts may not be the most relevant kinds of Christian-motivated gender harassment as experienced by women who have not yet entered the workforce.

College women being told that "women are better suited for raising children than being in the workplace" due to the religious belief of the perpetrator may not have as nuanced an effect 
on them because the traditional thought being espoused does not impact their life in a meaningful way given their current life stage (Leskinen \& Cortina, 2014, p. 114). In other words, being told that women are better suited for raising children than being in the workforce for religious reasons may not have a nuanced impact when you are currently a woman who is less likely to be a parent or working full-time. A cursory glance at the GEQ data from this study corroborates the results from Eliason, Hall, and Anderson (2012), suggesting that college women do not experience pervasive significant Christian-motivated gender harassment. However, upon closer examination we see that college women $d o$ experience significant Christian-motivated harassment; it is just a different kind of Christian-motivated harassment unique to their social and developmental contexts.

The current study sample had a low average age of 20.5 years, with 214 (96.0\%) participants reporting being between the ages of 18 and 25. As such, the vast majority of participants fall into the developmental stage of "emerging adulthood" (Arnett, 2000), sometimes referred to as late adolescence. This culturally specific developmental period is marked by increased identity exploration at a time when one feels as though one is no longer an adolescent, but neither a full adult, typically from ages 18 to 25 (Arnett, 2000). During this time of identity formation and exploration, sexuality and sexual expression change in significant ways.

Dating moves from being simply a recreational activity to something more meaningful through which one develops deeper emotional connections and physical intimacy with romantic partners (Arnett, 2000). Similarly, emerging adulthood is often the time when young adults take part in a variety of sexual experiences due to decreased adult surveillance often coupled with living out of the home (Arnett, 2000). Additionally, while it is difficult to predict how one individual youth will develop their sexual identity, most people will engage in sexual intercourse 
by 20 years old (Advocates for Youth, 2007). Moreover, college is a time when sexual risk behaviors increase (Conklin, 2012). As such, the experiences of gender harassment in the form of sexuality policing may be the most relevant form of gender harassment college women experience. This form of gender harassment regarding aspects of their identity and behavior rooted in their specific social and developmental context may elicit a more nuanced impact that is moderated by the various attributions one makes for why they experience the harassing behavior.

Beyond the fact that this form of gender harassment may be a more salient and relevant form of harassment college women experience, it is a common critique of the Christian church and especially of Catholicism that sexuality and sexual behavior are used as tools of social control, especially for women. The policing of women's sexuality further reproduces patriarchal control. As author and journalist Mona Eltahawy states, "All religions, if you shrink them down, are all about controlling women's sexuality..." (Day, 2015). The Christian church prescribes normative and "good" sexual practices and behaviors which are juxtaposed against a set of deviant sexual practices. More important is that these ideas of sex and sexuality are linked to morality: to be a good person is to follow the rules regarding "moral" sexual behavior.

Speaking from my own experience in college, I felt as though the main "sin" my Evangelical campus ministry always addressed was sexual sin (e.g., premarital sex, viewing pornography, masturbating, etc... anything other than monogamous heterosexual sex within the confines of marriage). Looking back at these experiences now, my spiritual health was solely defined by measuring up against whether or not I was staying “pure:” In situating those experiences now, I see that I was taught to define my entire spiritual sense of self through my sexual behavior (or better yet, lack thereof). It felt that if I failed to stay "pure" sexually, then my 
entire existence as a Christian woman was worthless. My identity as a woman and as a Christian was inextricably linked to my sexual identity and behaviors. This is not an uncommon experience.

The Catholic Church throughout history has disseminated conservative rules and regulations regarding expressions of sexuality. Catholic Catechism, "a text which contains the fundamental Christian truths formulated in a way that facilitates their understanding" (United States Conference of Catholic Bishops, 2015), holds that all who are baptized into the Church are called to chastity (Catechism of the Catholic Church, 1993). Offenses against chastity include lust, masturbation, fornication (defined as "carnal union between an unmarried man and an unmarried woman"), pornography, prostitution, and rape (Catechism of the Catholic Church, 1993). Additionally, people who experience "an exclusive or predominant sexual attraction toward persons of the same sex" are called to refrain from engaging in sexual activity (Catechism of the Catholic Church, 1993). In summary, the Catholic Church espouses that "sexual pleasure is morally disordered when sought for itself, isolated from its procreative and unitive purposes" within a monogamous and heterosexual marriage (Catechism of the Catholic Church, 1993). Any sort of desire for sexual behavior outside of the institution of heterosexual marriage should be not be entertained but controlled.

While there is great variability among Protestant beliefs, many denominations espouse similar sexual mores. The Southern Baptist Convention's Baptist Faith and Message (their statement of faith) reads that "Christians should oppose....all forms of sexual immorality, including adultery, homosexuality, and pornography" and that a marriage between one man and one woman is the "channel of sexual expression according to biblical standards" (The Southern Baptist Convention, 2000). Respected evangelical theologian Wayne A. Grudem writes in his 
seminal book, Systematic Theology: An Introduction to Biblical Doctrine, "sexual union with someone other than one's own wife or husband is a specially offensive kind of sin against one's own body" (1994, p. 455). It should be noted, however, that some progressive Christian churches hold more liberal views on sex and sexuality and may not necessarily police these behaviors with such vigor as other churches. However, my own experiences in the Evangelical and nondenominational Christian church have been marked by the recurring themes of sexual purity and modesty. Even within more liberal Christian spaces which affirm non-heterosexual sexual orientations and non-gender binary gender identities, sexual behavior is still considered amoral unless it is within a monogamous relationship between two committed/married people. Once again, these prescriptions regarding sexual behavior are not just discussed in terms of what is normal and atypical, but in terms of what is moral and deviant.

Research supports the notion that religion and sexuality are linked. Lefkowitz, Gillen, Shearer, and Boone (2004) found that for those in the emerging adulthood developmental stage who adhered to their religion's prescriptions regarding sexual behaviors and whose religion was an important part of their daily life also held more conservative sexual attitudes. Post-hoc tests revealed that Protestants (comprised mostly of Baptists, Presbyterians, and Methodists) were more conservative than nonbelievers (comprised of agnostics, atheists, and those who reported they had no religion), but Catholics did not differ from either (Lefkowitz, Gillen, Shearer, \& Boone, 2004). A study by Mahoney (2008) using semi-structured interviews with 10 White women, all of whom were raised in Christian homes (seven were Roman Catholic and the other three Protestant), revealed that a conflict between sexuality and spirituality emerged in adolescence. This conflict was rooted in the realization that "their sexual behavior was inconsistent with their Christian religious traditions" (Mahoney, 2008, p. 95). While the 
participants in this study were often times more concerned with not becoming pregnant, they still suffered from the psychological dissonance of what they were being told to do and what they were actually doing (Mahoney, 2008)

Beyond evidence that there is a link between religiosity and conservative sexual attitudes which impact young people's lives; religiosity plays a role in controlling sexual behavior. Vazsonyi and Jenkins (2010) found that religiosity (as defined by frequency of religious service attendance, prayer, reading of religious texts, and religious importance) and self-control each independently contributed to the likelihood of staying a virgin (as operationalized as never having engaged in sexual intercourse) and delaying oral sex for a sample of college-age participants from a major university in the "Bible Belt." Evidence was also found to support selfcontrol as a partial mediator of religiosity on virginity status (for males) and oral sex (for males and females) (Vazsonyi \& Jenkins, 2010).

Given that Christian religiosity is linked with both conservative sexual attitudes and behaviors, it follows that expressions of sexuality that depart from these prescribed sexual behaviors may elicit both external and internal negative reactions. Sharma (2008) found that for Protestant women (Anglican, Baptist, Methodist, and interdenominational) during the emerging adulthood stage of their life, sexual expression was characterized through communal accountability. The participants felt as though they were under a microscope, being monitored and judged by others when it came to their sexuality (Sharma, 2008). In fact, one major theme to emerge was that sex was a community decision: sex is only permissible through marriage (a ceremony facilitated and celebrated by the community) so many participants felt as though their sense of sexual selves belonged to their faith community. In this way, there was an assumed accountability between the women and the church regarding their sexual behaviors in which they 
felt obligated to divulge their sexual activities (Sharma, 2008). Given the pervasive idea that marriage was the only legitimate channel through which to engage in sex, some participants did not confide in their church community if they were engaging in premarital sexual activities due to intense feelings of guilt and for fear of being judged and rejected. While the open sense of community regarding sexual accountability fostered feelings of empowerment for some women, the gendered negotiations accompanying any premarital sexual activity also led to general sexual oppression (Sharma, 2008).

As evidence in Sharma's (2008) study, some Christian communities are characterized by assumed accountability for sexual actions and feelings of pervasive guilt and fear for transgressing the prescribed sexual norms. As such, Christians may feel entitled to policing women's sexuality regardless of their target's beliefs through their own convictions regarding sexual accountability. Additionally, considering the weight some Christians place on adhering to conservative sexual regulations (especially for women); it is possible that perceived Christian motivation for experiencing sexuality policing may intensify any negative result. Even if the target of the policing is not a Christian or does not believe in the same conservative sexual attitudes or beliefs as their perpetrator, the victims of the Christian-motivated harassment may still suffer from more intense consequences given the power and weight of the harassment. Meaning, women experiencing Christian-motivated sexuality policing may sense the serious moral implications from their perpetrator which intensify the negative reactions, even if they themselves do not subscribe to those beliefs. The particularly negative consequences may stem from knowing their perpetrator links their sexual expression so heavily to ideas of morality through their Christian beliefs. 
In summary, there are a few possibilities as to why sexuality policing was the only form of gender harassment where Christian attribution for the behavior moderated the impact of harassment on college adjustment. It may be because sex and sexuality play integral roles in the psychological and social development of people in emerging adulthood, a life stage the vast majority of the current study sample falls into. As such, this dimension of gender harassment may be a more salient form of gender harassment and have a more nuanced and complex impact on outcomes given the different kinds of attributions made for why they experienced that behavior. Additionally, given the conservative prescriptions of sexual behaviors espoused by both Catholic and Protestant churches, as well as the evidence that religiosity is at odds with sexual expression outside of marriage, experiences of sexuality policing thought to be motivated by Christian beliefs may be particularly harmful to women. These experiences may tap into larger understandings of morality (and recognition of the use of sexual oppression as a form of social control) which may cause greater harm to young women.

\section{Social Adjustment: Potential Protection}

Overall gender harassment was found to significantly and negatively predict levels of academic adjustment, institutional attachment, personal-emotional adjustment, and overall college adjustment, although Christian attribution was not found to moderate these relationships. Christian attribution, however, was found to moderate the relationship between sexuality policing and academic adjustment, institutional attachment, personal-emotional adjustment, and overall college adjustment. These findings have serious implications for women experiencing gender harassment and Christian-motivated sexuality policing. Women experiencing these harmful episodes of harassment may result in their decreased academic performance, diminished psychological and physical health, and decreased satisfaction with being in college or 
specifically being enrolled at DePaul University (Baker \& Siryk, 1999). These results also provide evidence that experiences of gender harassment result in a myriad of negative consequences: not only might an increase in frequency of harassment negatively impact women's psychological health, it may impact their academic standing and overall satisfaction with being college as well. While this study does not test for causation, therefore a causal effect of harassment on college adjustment cannot be determined; the results from these data provide a foundation for theorizing about the many negative effects for college women experiencing gender harassment, especially when sexuality policing is perceived to have been motivated by the perpetrator's Christian belief. In summary, gender harassment should be examined with the same seriousness as sexual harassment given its negative associations with multiple dimensions of college adjustment in college women.

As stated previously, no significant relationships were found among overall gender harassment, sexuality policing, and social adjustment. Additionally, Christian attribution was not found to moderate the impact of either overall gender harassment or sexuality policing on social adjustment. Recall that social adjustment in this study measured the success in coping with the interpersonal-societal demands while at college (Baker \& Siryk, 1999). Baker and Siryk (1999) identified four item clusters or factors of this dimension of college adjustment: (1) general, meaning general social functioning; (2) other people, as evidenced by interpersonal relationships with others on campus; (3) nostalgia, or adjusting to the social relocation often accompanied with moving away to college; and (4) social environment, meaning satisfaction with the social activities as experienced in college (p. 15). Some noted correlates of increased social adjustment include participation in social activities, social support, and decreased loneliness (Baker \& Siryk, 1999, p. 15). 
It seems counterintuitive that no significant relationships were found between gender harassment and sexuality policing (as experienced through interpersonal relationships) and social adjustment. What is even more peculiar is that to an extent a relationship was found, it was in the positive direction, indicating that increased frequency of gender harassment and sexuality policing was associated with increased social adjustment. One possible explanation is that occurrences of gender harassment and sexuality policing may be evidence of increased social interactions: one must socially engage with others in order to experience episodes of harassing behaviors. It is possible that increased involvement with social activities and relationships with other classmates incur more episodes of gender harassment, but that this increased socialization associated with the university protects the students from any negative social effects of harassment indirectly. Mounts, Valentiner, Anderson, and Boswell (2006) found that participants reporting lower levels of sociability in relation to the transition to college also reported higher levels of loneliness. It is possible that increased social adjustment to college may positively influence factors such as loneliness, which buffer against the negative social effects of gender harassment. These mediators may not have the same protective effect when it comes to academic adjustment, personal-emotional adjustment, and institutional attachment.

\section{Limitations and Future Directions}

Several limitations of this study should be noted. Firstly, all data were collected via selfreports from the participants. While the agency of each participant should be awarded and recognized, there are several biases associated with using self-report measures exclusively, including social desirability bias. As a result, it is possible that participants were able to gauge what each instrument was measuring and report in a way consistent with how they wanted to be 
viewed or what lines up with their personal beliefs. For instance, while the GEQ does not use the term "gender harassment" in the instrument, which accounts for subjective interpretations of what one would consider gender harassment, the first item assessed the frequency of persons making "sexist remarks about people of your gender" (Leskinen \& Cortina, 2014). As such, participants who did not want to be seen as feminist or caring about issues relating to sexism may have reported decreased episodes even though they experience people making sexist remarks. Future studies should employ other methods of measuring gender harassment, such as asking more general questions relating to college experiences to reduce focus on gender-specific questions.

Another limitation is that the GEQ asks about experiences of gender harassment in the past 12 months. For future studies relating to the study of gender harassment in college environments, I suggest trimming down the recall period to something shorter, such as 3 or 4 months. Given the fact that college is typically four years and students are normally only enrolled $9-10$ months out of the year, it makes more sense to truncate the recall period to something more conducive to a student's timeline while enrolled in college. Additionally, given that social contexts, such as living arrangements, friend groups, and social activities may vary from semester or quarter, participants may experience a fluctuating frequency of gender harassment given whatever temporary social environment they are in. As such, asking about overall frequency of an event over the course of 12 months may be a recall period that is too long and provides too much variability in relation to how frequently they experienced a certain behavior.

Additionally, participants were asked to write about all of their experiences of Christianmotivated harassment. While this provided a plethora of qualitative responses, it may have also 
de-incentivized participants from reporting Christian-motivated harassment. While participants were not forced to write about their experiences, it is possible that they caught on to the survey logic where they would be asked to write a narrative if they attributed their harassment to Christian beliefs. As such, to avoid being asked to write and move through the survey quicker, participants may have failed to report Christian motivation on purpose. Additionally, often times the narrative responses were short or did not fully answer the question provided. Future research should employ smaller, but more meaningful, qualitative studies utilizing semi-structured interviews. These kinds of studies would provide richer detail as to how participants experience Christian-motivated harassment. Nuanced themes and more complex theorizing regarding this form of sex-based harassment could be gleaned from studies using a smaller sample but more indepth interviews. One interesting direction to take the research would be to interview members of a parachurch or campus ministry alongside a more secular/less religious student organization; that way experiences between subpopulations of a student sample could be explored.

Another limitation is that this sample was mostly White (59.2\%). As such, these results do not take into account the nuances of racial/ethnic discrimination intersecting with gender discrimination. It is important to keep in mind that these results are not able to be generalized to all of women's experiences. While this study provides a good first step in assessing the overall effects of gender harassment on college adjustment, future research should directly sample nonWhite participants in order to detect the nuanced effects of gender harassment intersecting with other axes of identity.

Additionally, another limitation to note is that the power differential among the different types of perpetrators identified in the qualitative portion of this study and the participants was not addressed. It is very possible that given the power dynamic present when a professor, faculty 
member, or staff member of DePaul University harasses a student, there would be specific and more harmful consequences that would occur. Taking into consideration the position of power that a professor holds over the student (one not present when the harassment stems from a friend or peer), gender harassment occurring in this top-down relationship aimed at the student might result in further or more negative consequences for the victim. Future research should take this into account when attempting to understand the nuanced impact of gender harassment. It is important to identify the perceived power differential between the victim and the perpetrator(s) in understanding how perceived power imbalances may moderate and intensify the impact of the gender harassment experienced.

Finally, a limitation is that this study is correlational and cannot determine causality. This means that this data cannot provide any insights as to whether gender harassment influences college adjustment, college adjustment influences gender harassment, or if other variables mediate or moderate the relationship between the independent variable, the moderator, and the dependent variable. However, when it comes to gender and sexual harassment, measuring the correlations of real-life experiences is one of the best methods of capturing data. It goes without saying that manipulating frequency of gender harassment for women in an experimental setting is wildly unethical, and assessments of hypothetical reactions to imagined harassment may not be a suitable comparison. As such, the present study is still a valid addition to the gender harassment literature.

Future research should continue to assess the impact of gender harassment in college women. This study provided evidence that increased frequency of harassment is associated with decreased levels in multiple dimensions of college adjustment. As such, future research should attempt to replicate this study and corroborate these results. Additionally, Christian-motivated 
episodes of gender harassment deserve to be more fully explored. As mentioned earlier, this is the first study to my knowledge that found a significant moderating effect of Christian attribution on gender harassment predicting college adjustment. As such, these relationships need to be assessed more. Some specific recommendations for future research include understanding how this effect differs in a secular university, whether the effect differs for people with various religious affiliations or levels of religiosity, how judgements of injustice mediate the moderating effect of Christian attribution, and whether Christian attribution for different forms of gender harassment change over time, with relevance to the developmental and social contexts of the targets.

\section{Concluding Remarks}

I have not yet worked through the pain I experienced as a result of membership in my college campus ministry. There were both wonderful and destructive experiences that I have yet to reconcile. Did the overwhelming silencing of my politics, knowledges, and experiences erase the nights I stayed up late sharing my soul with my friends? Did the weekend retreats full of laughter, hugs, and tears dismiss the fact that no one seemed to care that I was no longer affiliated with the ministry by the beginning of my senior year because I could not stand their sexist, transphobic, and homophobic policies? Even today, I can feel the joy and pain in my chest - swirling around, looking for some peace but finding none. I look at old photographs or videos from days before the tensions arose and I think of how happy I was to be a part of God's family. I think to today, with how much it angers me when those same people still engage in behaviors that cause visceral harm to the communities I work with - and in the name of God no less. While the campus minister's wife and I have seemed to move past our differences, I can still feel the 
overwhelming sense of defeat when I think of the Christian-motivated harassment I experienced while affiliated with that organization. While these seemingly contradictory feelings still exist, I have found solace in knowing that my identity as both a feminist and Christian are not at odds. In fact, these identities have allowed me to see and articulate the very experiences of divine discrimination that led me to this project. I look forward to my continued research in this field, knowing that while the experiences I had in that college ministry may have been difficult, they also have brought about a transformative passion in me for understanding divine discrimination. 


\section{References}

Advocates for Youth. (2007). Sexual Development through the Life Cycle. Retrieved May 13, 2015, from Advocates for Youth: http://www.advocatesforyouth.org/publications/201lessons

Aiken, L. S., \& West, S. G. (1991). Multiple Regression: Testing and Interpreting Interactions. Newbury Park, CA: Sage Publications, Inc.

Arnett, J. (2000). Emerging adulthood: A theory of development from the late teens through the twenties. American Psychologist, 55(5), 469-480.

Baker, R. W., \& Siryk, B. (1989). SACQ: Student Adaptation to College Questionnaire Manual. Los Angeles, CA: Western Psychological Services.

Baker, R. W., \& Siryk, B. (1999). SACQ: Student Adaptation to College Questionnaire Manual (Second Printing). Los Angeles, CA: Western Psychological Services.

Berdahl, J. L. (2007). Harassment Based on Sex: Protecting Social Status in the Context of Gender Hierarchy. The Academy of Management Review, 32(2), 641-658.

Bryant, A. N. (2006). Assessing the Gender Climate of an Evangelical Student Subculture in the United States. Gender and Education, 18(6), 613-634.

Burn, S. M., \& Busso, J. (2005). Ambivalent Sexism, Scripturalism Literalism, and Religiosity. Psychology of Women Quarterly, 29, 412-418.

Butler, S. (2007). The Catholic Priesthood and Women: A Guide to the Teaching of the Church. Chicago/Mundelein, IL: Hillenbrand Books. 
Byers, E. S. (1996). How Well Does the Traditional Sexual Script Explain Sexual Coercion? Review of a Program of Research. Journal of Psychology \& Human Sexuality, 8(1-2), 7 25.

Catechism of the Catholic Church. (1993). CATECHISM OF THE CATHOLIC CHURCH, II. The Vocation to Chastity. Retrieved May 14, 2015, from The Vatican: http://www.vatican.va/archive/ENG0015/_P85.HTM

Cohen, R. L. (1982). Perceiving justice: An attributional perspective. In J. Greenberg, \& R. L. Cohen (Eds.), Equity and justice in social behavior (pp. 119 - 160). New York: Academic Press.

College Data. (2013). College Profile: DePaul University. Retrieved November 08, 2014, from College Data: http://www.collegedata.com/cs/data/college/college_pg01_tmpl.jhtml?schoolId=350

Congregation for the Doctrine of Faith. (2007, December 19). General Decree regarding the delict of attempted sacred ordination of a woman. Retrieved from Vatican.va: http://www.doctrinafidei.va/documents/rc_con_cfaith_doc_20071219_attentata-orddonna_en.html

Congregation for the Doctrine of the Faith. (1986, October 1). On the Pastoral Care of Homosexual Persons. Retrieved from Vatican.va: http://www.vatican.va/roman_curia/congregations/cfaith/documents/rc_con_cfaith_doc_1 9861001_homosexual-persons_en.html 
Conklin, K. (2012). Adolescent Sexual Behavior. Retrieved May 13, 2015, from Advocates for Youth: http://www.advocatesforyouth.org/publications/publications-a-z/413-adolescentsexual-behavior-i-demographics

Connors, G. J., Tonigan, J. S., \& Miller, W. R. (1996). A Measure of Religious Background and Behavior for Use in Behavior Change Research. Psychology of Addictive Behaviors, 10(2), $90-96$.

Credé, M., \& Niehorster, S. (2012). Adjustment to College as Measured by the Student Adaptation to College Questionnaire: A Quantitative Review of its Structure and Relationships with Correlates and Consequences. Educational Psychology Review, 24(1), 133-165.

Day, E. (2015). Mona Eltahawy: 'All religions are obsessed with my vagina'. Retrieved May 14, 2015, from The Guardian: http://www.theguardian.com/world/2015/may/10/monaeltahawy-interview-religions-obsessed-vagina-headscarves-and-hymens

D'Emilio, F. (2014, January 25). Pope Francis Says Women Should Have Bigger Presence, But Not A Lead Church. Retrieved from The Huffington Post: http://www.huffingtonpost.com/2014/01/25/pope-francis-women-_n_4664868.html

DePaul University. (2010). Vincentian Identity. Retrieved November 08, 2014, from DePaul University: Office of Mission \& Values: https://mission.depaul.edu/VINCENTIANIDENTITY/Pages/default.aspx

DePaul University. (2014). About DePaul. Retrieved November 08, 2014, from DePaul University: http://www.depaul.edu/about/Pages/default.aspx 
Driscoll, M., \& Driscoll, G. (2012). Real Marriage: The Truth about Sex, Friendship, and Life Together. Nashville, TN: Thomas Nelson, Inc.

Eliason, K., Hall, M. L., \& Anderson, T. L. (2012). Because God Said So: Religious Facets of Sexual and Gender Harassment in Christian Academia. Journal of Psychology and Theology, 40(1), 345-355.

Farrell, K., Gupta, N., \& Queen, M. (Eds.). (2004). Interrupting Heteronormativity: Lesbian, Gay, Bisexual, and Transgender Pedagogy and Responsible Teaching at Syracuse University. New York, NY: The Graduate School at Syracuse University.

Fitzgerald, L. F., Gelfand, M. J., \& Drasgow, F. (1995). Measuring Sexual Harassment: Theoretical and Psychometric Advances. Basic and Applied Social Psychology, 17(4), $425-445$.

Fitzgerald, L. F., Schullman, S. L., Bailey, N., Richards, M., Swekcer, J., Gold, Y., . . . Weitzman, L. (1988). The Incidence and Dimensions of Sexual Harassment in Academia and the Workplace. Journal of Vocational Behavior, 32(2), 152-175.

Folger, R., \& Cropanzano, R. (2001). Fairness theory: Justice as accountibility. In J. Greenberg, \& R. Cropanzano (Eds.), Advances in organizational justice (pp. 1 - 55). Stanford, CA: Stanford University Press.

Fonow, M. M., \& Cook, J. A. (Eds.). (1991). Beyond Methodology: Feminist Scholarship as Lived Research. Bloomington, IN: Indiana University Press.

Forbes, LLC. (2014). DePaul University. Retrieved November 08, 2014, from Forbes: http://www.forbes.com/colleges/depaul-university/ 
Ford, T. E., Boxer, C. F., Armstrong, J., \& Edel, J. R. (2008). More Than "Just a Joke": The Predjudice-Releasing Function of Sexist Humor. Personality and Social Psychology Bulletin, 34(2), 159 - 170.

Francis. (2013, November 24). Apostolic Exhortation: Evangelii Gaudium. Retrieved from Vatican.va: http://w2.vatican.va/content/francesco/en/apost_exhortations/documents/papafrancesco_esortazione-ap_20131124_evangelii-gaudium.html

Glick, P., \& Fiske, S. T. (1997). Hostile and Benevolent Sexism: Measuring Ambivalent Sexist Attitudes Toward Women. Psychology of Women Quarterly, 21, 119-135.

Glick, P., Lameiras, M., \& Castro, Y. R. (2002). Education and catholic religiosity as predictors of hostile and benevolent sexism toward women and men. Sex Roles, 47(9/10), 433-441.

Grudem, W. (1994). Systematic Theology: An Introduction to Biblical Doctrine. Grand Rapids, MI: Zondervan.

Grudem, W. (2006). Countering the Claims of Evangelical Feminism: Biblical Responses to the Key Questions. Colorado Springs, CO: Multnomah Publishers.

Hall, M. L., Christerson, B., \& Cunningham, S. (2010). Sanctified Sexism: Religious Beliefs and the Gender Harassment of Academic Women. Psychology of Women Quarterly, 34(2), 181-185.

Harahan, R. E. (1983). The Vocation of Woman: The Teaching of the Modern Popes from Leo XIII to Paul VI. Rome, Italy: Pontificia Universitas Lateranensis. 
Harris, K., Halpern, C., Whitsel, E., Hussey, J., Tabor, J., Entzel, P., \& Udry, J. R. (2009). The National Longitudinal Study of Adolescent to Adult Health: Wave II Codebooks. Retrieved from Carolina Population Center, University of North Carolina at Chapel Hill.: http://www.cpc.unc.edu/projects/addhealth/codebooks/wave2

Harville, M. L., \& Rienzi, B. M. (2000). Equal Worth and Gracious Submission: Judeo-Christian Attitudes Towards Employed Women. Psychology of Women Quaterly, 24, 145-147.

Hlavka, H. R. (2014). Normalizing Sexual Violence: Young Women Account for Harassment and Abuse. Gender \& Society, 28(3), 337-358.

Huerta, M., Cortina, L. M., Pang, J. S., Torges, C. M., \& Magely, V. J. (2006). Sex and Power in the Academy: Modeling Sexual Harassment in the Lives of College Women. Personality and Social Psychology Bulletin, 32(5), 616-628.

Human Rights Campaign. (2014). Stances of Faiths on LGBT Issues: Southern Baptist Convention. Retrieved May 10, 2014, from Human Rights Campaign: http://www.hrc.org/resources/entry/stances-of-faiths-on-lgbt-issues-southern-baptistconvention

IBM Corp. (Released 2013). IBM SPSS Statistics for Windows, Version 22.0. Armonk, NY: IBM Corp.

Ingersoll, J. (2003). Evangelical Christian Women : War Stories in the Gender Battles. New York, NY: New York University Press.

Ingraham, C. (1994). The Heterosexual Imaginary: Feminist Sociology and Theories of Gender. Sociological Theory, 12(2), 203 - 219. 
Jashaswini, R. (2011). Moderating Role of Justice Perception in the Relationships betwen Stressors and Strains. Master's Theses and Graduate Research at SJSU ScholarWorks.

Jensen, I. W., \& Gutek, B. A. (1982). Attributions and assignment of responsibility in sexual harassment. Journal of Social Issues, 38(4), 121-136.

John Paul II. (1988, August 15). Mulieris Dignitatem: The Dignity and Vocation of Women. Retrieved from Vatican.va: http://www.vatican.va/holy_father/john_paul_ii/apost_letters/documents/hf_jpii_apl_15081988_mulieris-dignitatem_en.html

John Paul II. (1994, May 22). Ordinatio Sacerdotalis. Retrieved from Vatican. va: http://www.vatican.va/holy_father/john_paul_ii/apost_letters/1994/documents/hf_jpii_apl_19940522_ordinatio-sacerdotalis_en.html

Kelley, H. (1967). Attribution theory in social psychology. In D. Levine (Ed.), Nebraska Symposium on Motivation (Vol. 15, pp. 192-238). Lincoln, NE: University of Nebraska Press.

Kenig, S., \& Ryan, J. (1986). Sex Differences in Levels of Tolerance and Attribution of Blame for Sexual Harassment on a University Campus. Sex Roles, 15(9/10), 535-549.

Kim, C. L., Anderson, T. L., Hall, M. L., \& Willingham, M. M. (2010). Asian and Female in the White God's World: A Qualitative Exploration of Discrimination in Christian Academia. Mental Health, Religion \& Culture, 13(5), 453-465.

Kim, H. -Y. (2013). Statistical notes for clinical researchers: assessing normal distribution (2) using skewness and kurtosis. Restorative Dentistry \& Endodontics, 38(1), 52 - 54. 
Klein, K. M., Apple, K. J., \& Kahn, A. S. (2011). Attributions of Blame and Responsibility in Sexual Harassment: Reexamining a Psychological Model. Law and Human Behavior, 35(2), $92-103$.

Lefkowitz, E. S., Gillen, M. M., Shearer, C. L., \& Boone, T. L. (2004). Religiosity, Sexual Behaviors, and Sexual Attitudes during Emerging Adulthood. The Journal of Sex Research, 41(2), 150159.

Leskinen, E. A., \& Cortina, L. M. (2014). Dimensions of Disrespect: Mapping and Measuring Gender Harassment in Organizations. Psychology of Women Quarterly, 38(1), 107-123.

Leskinen, E. A., Cortina, L. M., \& Kabat, D. B. (2011). Gender Harassment: Broadening Our Understanding of Sex-Based Harassment at Work. Law of Human Behavior, 35, 25-39.

Lim, S., \& Cortina, L. M. (2005). Interpersonal Mistreatment in the Workplace: The Interface and Impact of General Incivility and Sexual Harassment. Journal of Applied Psychology, 90(3), 483-496.

MacArthur, J. (2011). Divine Design: God's Complementary Roles for Men and Women. Colorado Springs, CO: David C. Cook.

Mahoney, A. (2008). Is it Possible for Christian Women to be Sexual? Women \& Therapy, 31(1), 89 - 106.

Martínez, J. A., Rodríguez-Entrena, M., \& Rodríguez-Entrena, M. J. (2012). The ordination of women in the Catholic Church: a survey of attitudes in Spain. Journal of Gender Studies, 21(1), 17-34. 
Masters, N. T., Casey, E., Wells, E. A., \& Morrison, D. K. (2013). Sexual Scripts among Young Heterosexually Active Men and Women: Continuity and Change. The Journal of Sex Research, 50(5), 409 - 420.

Mikula, G. (1993). On the experience of injustice. In W. Stroebe, \& M. Hewstone (Eds.), European review of social psychology (Vol. 4, pp. 223 - 244). Chichester, UK.: Wiley.

Mikula, G. (2003). Testing an attribution-of-blame model of judgements of injustice. European Journal of Social Psychology, 33, 793-811.

Mikula, G., \& Schlamberger. (1985). What people think about an unjust event: Toward a better understanding of the phenomenology of experiences of injustice. European Journal of Social Psychology, 15, 37-49.

Miller, T. D. (2001). Disrespect and the Experience of Injustice. Annual Reviews of Psychology, $52,527-553$.

Morgan, M. Y. (1987). The Impact of religion on Gender-Role Attitudes. Psychology of Women Quarterly, 11, 301-310.

Mounts, N. A., Valentiner, D. P., Anderson, K. L., \& Boswell, M. K. (2006). Shyness, Sociability, and Parental Support for the College Transition: Relation to Adolescents' Adjustment. Journal of Youth and Adolescence, 35(1), 71 - 80.

Osburn, C. D. (2001). Women in the Church: Reclaiming the Ideal. Abilene, TX: Abilene Christian University Press. 
Pentin, E. (2014). Pope Repeats that Same-Sex 'Marriage' is "Anthropological Regression". Retrieved from National Catholic Register: http://www.ncregister.com/blog/edwardpentin/pope-repeats-that-same-sex-marriage-is-anthropological-regression

Pierce, R. W., \& Groothuis, R. M. (Eds.). (2004). Discovering Biblical Equality: Complementarity without Hierarchy. Downers Grove, IL: InterVarsity Press.

Piper, J., \& Grudem, W. (Eds.). (1991). Recovering Biblical Manhood \& Womanhood: A Response to Evangelical Feminism. Wheaton, IL: Crossway Books.

Public Religion Research Institute. (2014). A Shifting Landscape: A Decade of Change in American Attitudes about Same-Sex Marriage and LGBT Issues. Washington, D.C.: Public Religion Research Institute.

QSR International Pty Ltd. (2012). NVivo qualitative data analysis software Version 10. QSR International Pty Ltd.

Raver, J. L., \& Nishii, L. H. (2010). Once, Twice, or Three Times as Harmful? Ethnic Harassment, Gender Harassment, and Generalized Workplace Harassment. Journal of Applied Psychology, 95(2), 236-254.

Rich, A. (1980). On Compulsory Heterosexuality and Lesbian Experience. Signs: Journal of Women in Culture and Society, 5, 631 - 660.

Rocca, F. X. (2015). Pope, in Philippines, says same-sex marriage threatens family. Retrieved May 19, 2015, from Catholic News Service: http://www.catholicnews.com/data/stories/cns/1500200.htm 
Rosik, C. H., Griffith, L. K., \& Cruz, Z. (2007). Homophobia and Conservative Religion: Toward a More Nuanced Understanding. American Journal of Orthopsychiatry, 77(1), 10-19.

Ruether, R. R. (2008). Women, Reproductive Rights and the Catholic Church. Feminist Theology, 16(2), 184-193.

Ryan, K. M., \& Kanjorski, J. (1998). The Enjoyment of Sexist Humor, Rape Attitudes, and Relationship Aggression in College Students. Sex Roles, 38(9/10), 743 - 756.

Sacred Congregation for the Doctrine of the Faith. (1976, October 15). Inter Insigniores. Retrieved from Vatican. va: http://www.vatican.va/roman_curia/congregations/cfaith/documents/rc_con_cfaith_doc_1 9761015_inter-insigniores_en.html

Seguino, S. (2011). Help or Hinderance? Religion's Impact of Gender Inequality in Attitudes and Outcomes. Word Development, 39(8), 1308-1321.

Sharma, A. (2008). Young Women, Sexuality and Protestant Church Community: Oppression or Empowerment? European Journal of Women's Studies, 15(4), 345 - 359.

Sinozich, S., \& Langton, L. (2014). Rape and Sexual Assault Victimization Among College-Age Females 1995 - 2013. Washington, DC: U.S. Department of Justice: Bureau of Justice Statistics.

Sprague, J. (2005). Feminist Methodologies for Critical Researchers: Bridging Differences. Walnut Creek, CA: AltaMira Press. 
St. Pierre, S. M. (1994). The Struggle to Serve: The ordination of Women in the Roman Catholic Church. Jefferson, NC: McFarland \& Company, Inc., Publishers.

Stagg, E., \& Stagg, F. (1978). Woman in the World of Jesus. Philadelphia, PA: Westminster Press.

Tang, C. S., Yik, M. S., Cheung, F. M., Choi, P. K., \& Au, K. (1995). How Do Chinese College Students Define Sexual Harassment? Journal of Interpersonal Violence, 10(4), 503-515.

Taşdemir, N., \& Sakall1-Uğurlu, N. (2010). The Relationships between Ambivalent Sexism and Religiosity among Turkish University Students. Sex Roles, 62, 420-426.

The Pew Forum on Religion and Public Life. (2003). Republicans Unified, Democrats Split on Gay Marriage: RELIGIOUS BELIEFS UNDERPIN OPPOSITION TO HOMOSEXUALITY. Washington, D.C.: The Pew Research Center.

The Pew Forum on Religion and Public Life. (2008). U. S. Religious Landscape Survey: Portrait of Catholics - Social \& Political Views. Washington, D.C.: The Pew Forum on Religion \& Public Life.

The Southern Baptist Convention. (1988). Resolution on Homosexuality. Retrieved May 10, 2014, from Southern Baptist Convention: http://www.sbc.net/resolutions/610

The Southern Baptist Convention. (2000). THE 2000 BAPTIST FAITH \& MESSAGE. Retrieved May 16, 2015, from Southern Baptist Convention: http://www.sbc.net/bfm2000/bfm2000.asp

The White House Council on Women and Girls. (2014). Rape and Sexual Assault: A Renewed Call to Action. Washington, D.C.: The White House. 
Till, F. (1980). Sexual harassment: A report on the sexual harassment of students. Washington, DC: National Advisory Council on Women's Educational Programs.

United States Conference of Catholic Bishops. (2015). Frequently Asked Questions about the Catechism of the Catholic Church. Retrieved May 16, 2015 , from United States Conference of Catholic Bishops: http://www.usccb.org/beliefs-and-teachings/what-webelieve/catechism/catechism-of-the-catholic-church/frequently-asked-questions-aboutthe-catechism-of-the-catholic-church.cfm

Valenti, J. (2014, December 3). The US is still the only developed country that doesn't guarantee paid maternity leave. Retrieved May 13, 2015, from The Guardian: http://www.theguardian.com/us-news/2014/dec/03/-sp-america-only-developed-countrypaid-maternity-leave

van Roosmalen, E., \& McDaniel, S. A. (1999). Sexual Harassment in Academia: A Hazard to Women's Health. Women and Health, 28(2), 33-54.

Vazsonyi, A. T., \& Jenkins, D. D. (2010). Religiosity, Self-Control, and Virginity Status in College Students from the "Bible Belt": A Research Note. Journal for the Scientific Study of Religion, 49(3), 561 - 568.

Wolff, J. R., \& Himes, H. L. (2010). Purposeful Exclusion of Sexual Minority Youth in Christian Higher Education: The Implications of Discrimination. Christian Higher Education, 9(5), 439-460. 
Wooden, C. (2013, July 31). 'Who am I to judge?' Pope's remarks do not change church teaching. Retrieved May 19, 2015, from Catholic News Source: http://www.catholicnews.com/data/stories/cns/1303303.htm

Wright, N. T. (2004). Women's Service in the Church: The Biblical Basis. A conference paper for the Symposium, 'Men, Women and the Church'. Durham, NC.

Wright, N. T. (2009, March 11). N.T. Wright on Controversial Issues held during the Annual Pastors Retreat for the Los Ranchos Presbytery. (T. Bolsinger, Interviewer) doi:https://www.youtube.com/watch?v=QaVVXleoAdU\&index=5\&list=PLE462DCD55 E05B03F 


\section{Appendix A}

\section{THE GENDER EXPERIENCES QUESTIONNAIRE (GEQ) DEVELOPED BY LESKINEN} AND CORTINA (2014)*

\footnotetext{
* The stem for all items reads: "During the PAST YEAR, has anyone associated with DEPAUL UNIVERSITY (e.g., professors, classmates/peers, faculty/staff, friends who attend DePaul) ${ }^{8}$ done any of the following behaviors?' Response options ranged from 1 to 5: never, once or twice, sometimes, often, many times.
}

Sexist Remarks

1. Made sexist remarks about people of your gender

2. Referred to people of your gender in insulting or offensive terms

3. Made sexist remarks or jokes about women in your presence

4. Made sexist jokes in your presence

Sexually Crude/Offensive Behavior

5. Said crude or gross sexual things in front of others or to you alone

6. E-mailed, texted, or instant messaged offensive sexual jokes to you

7. Made unwanted attempts to draw you into discussion of sexual matters

8. Told you stories of their sexual exploits when you did not want to hear them

9. Displayed or distributed dirty pictures or stories (e.g., nude pictures)

\section{Infantilization}

10. Talked to you as if you were a small child instead of speaking to you like an adult

11. Treated you as if you were stupid or incompetent

12. Publicly addressed you as if you were a child (e.g., dear, kid, etc.)

Work/Family Policing

13. Suggested women are better suited for raising children than being in the workplace

14. Suggested women belong at home, not in the workplace

15. Said employees who are mothers are less productive than other employees

16. Said employees who are mothers are less dependable than other employees

Gender Policing

17. Referred to the workplace as a "man's space"' (e.g., women do not belong here)

18. Made you feel like you were less of a woman because you had traditionally masculine interests

19. Criticized you for not behaving "like a woman should",

20. Treated you negatively because you were not "feminine enough",

\footnotetext{
${ }^{8}$ The original stem developed by Leskinen and Cortina (2014) for all GEQ items is, "During the PAST YEAR, has anyone associated with your WORK (e.g., supervisors, coworkers, clients/customers, collaborators at other companies..."
} 


\section{Appendix B}

\section{ITEMS DEVELOPED FOR ASSESSING SEXUALITY POLICING**}

* Questions use the same stem and response scale as the GEQ

1. Referred to women as "bitches" or "whores."

2. Reprimanded women need to watch their reputation.

3. Criticized women for dressing "too slutty"

4. Made derogatory remarks about a woman's body size or her lack of attractiveness.

5. Called women "dykes" if they were too masculine-acting, or had hair that was too short

6. Criticized women for being sexually active/promiscuous 


\title{
Appendix C
}

\section{ITEMS MODIFIED FROM ELIASON, HALL, AND ANDERSON (2012) AND HALL, CHRISTERSON, AND CUNNINGHAM (2010) AND DEVELOPED FOR MEASURING RELIGIOUS ATTRIBUTION*}

\begin{abstract}
*The following question is presented if the participant indicates any level of harassment (i.e., any response other than "Never" to any of the GEQ or sexuality policing items). Response options range from 1 to 5: not at all motivated by Christian/Catholic beliefs, slightly motivated by Christian/Catholic beliefs, somewhat motivated by Christian/Catholic beliefs, mostly motivated by Christian/Catholic beliefs, motivated entirely by Christian/Catholic beliefs.
\end{abstract}

1. Do you perceive that those who engaged in the behavior were motivated by their Christian/Catholic beliefs?

*The following question is presented if the participant indicates that they have experienced Christian-motivated gender harassment (i.e., any response other than "not at all motivated by Christian/Catholic beliefs" to the above question). This is an open-ended question.

2. Please use the space below to write about the behavior that you indicated you have experienced. Please provide details, including:

- Who was involved and engaged in the behavior

- What was said or done

- What you think the religious affiliation is of the person who engaged in the behavior

- Why you believe this person was motivated by a Christian/Catholic belief

- The thoughts and feelings you experienced as a result

Please do not include the names of people or organizations in your response. Nothing you write about should include information that could directly identify you or someone else. 


\section{Appendix D}

\section{DEMOGRAPHICS QUESTIONNAIRE}

DEM1.What is your age? (Numeric response. If under 18, the survey will end.)

DEM2.What is your birth/biological sex?

$$
\begin{aligned}
& 1 \text { - Male } \\
& 2 \text { - Female } \\
& 97 \text { - Other }
\end{aligned}
$$

DEM2a. If "Other," please specify. This is optional:

DEM3.How do you self-identify in terms of gender/sex?

$$
\begin{aligned}
& 1 \text { - Male } \\
& 2 \text { - Female } \\
& 97-\text { Other }
\end{aligned}
$$

DEM3a. If "Other," please specify. This is optional:

DEM4. How do you self-identify in terms of your sexual orientation?

$$
\begin{aligned}
& \text { 1-Gay/homosexual } \\
& \text { 2-Lesbian } \\
& \text { 3-Bisexual } \\
& \text { 4- Heterosexual } \\
& \text { 97- Other }
\end{aligned}
$$

DEM4a. If "Other," please specify. This is optional:

DEM5.How do you self- identify in terms of race, ethnicity, and cultural background?

$$
\begin{aligned}
& \text { 1 - White } \\
& \text { 2-Black/African American } \\
& \text { 3- Spanish/Hispanic/Latino/a } \\
& \text { 4- Asian } \\
& 5 \text { - American Indian/Alaskan Native } \\
& 6 \text { - Native Hawaiian or Other Pacific Islander } \\
& 97 \text { - Other }
\end{aligned}
$$

DEM5a. If "Other," specify:

DEM6. What is the highest degree or level of school you have completed?

1 - High School Equivalency Diploma

2 - High School Diploma

3 - Skills Training Certificate 


$$
\begin{aligned}
& \text { 4-Associate Degree } \\
& \text { 5- Bachelor's Degree } \\
& \text { 6- Master's Degree } \\
& 7 \text { - Professional Degree (J.D.) } \\
& \text { 8- Doctoral Degree }
\end{aligned}
$$

DEM7. What college/university are you currently attending?

DEM8. Which of the following best describes your student status?

$$
\begin{aligned}
& 1 \text { - First- or second-year undergraduate student } \\
& 2 \text { - Third- or fourth-year undergraduate student } \\
& 3 \text { - Fifth-year or beyond undergraduate student } \\
& 4 \text { - Graduate Student } \\
& 5 \text { - Other }
\end{aligned}
$$$$
\text { DEM8a. If "Other," specify: }
$$

DEM9. Which of the following best describes your socioeconomic status (SES) background?

$$
\begin{aligned}
& 1 \text { - Economically Disadvantaged } \\
& 2 \text { - Working Class } \\
& 3 \text { - Middle Class } \\
& 4 \text { - Professional Class } \\
& 5 \text { - Economically Advantaged }
\end{aligned}
$$

DEM10. What is your political affiliation?

$$
\begin{aligned}
& \text { 1-Democrat } \\
& \text { 2-Republican } \\
& \text { 3- Independent } \\
& \text { 4-Libertarian } \\
& \text { 5-Other }
\end{aligned}
$$

DEM9a. If "Other," specify:

DEM11. Which of the following best describes your beliefs about a god/higher power at the present time? ${ }^{9}$

$$
\begin{aligned}
& 1 \text { - I do not believe in a god/ higher power } \\
& 2 \text { - I believe we can't really know about a god/higher power } \\
& 3 \text { - I don't know what to believe about a god/higher power } \\
& 4 \text { - I believe in a god/higher power, but I'm not religious } \\
& 5 \text { - I believe in a god/higher power and consider myself religious }
\end{aligned}
$$

DEM12. What is your religious affiliation?

\footnotetext{
${ }^{9}$ Modified item taken from the Religious Background and Behavior Questionnaire (Connors, Tonigan, \& Miller, 1996)
} 


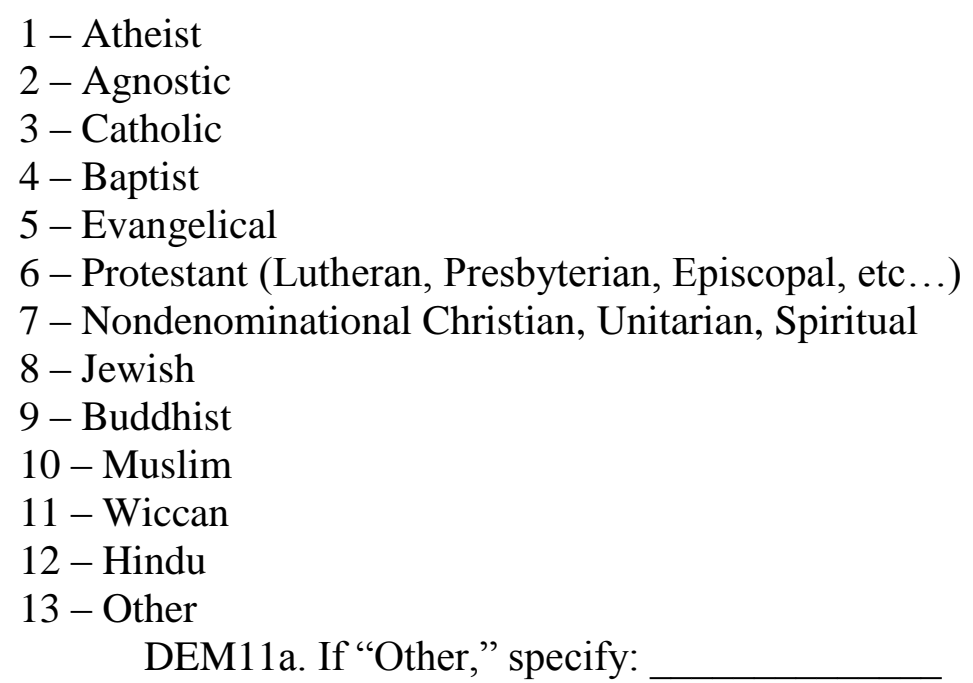

DEM13. In the past 12 months, how often did you attend religious services? ${ }^{10}$

$$
\begin{aligned}
& 1 \text { - Never } \\
& 2 \text { - Rarely } \\
& 3 \text { - At least once a month } \\
& 4 \text { - At least two or three times a month } \\
& 5 \text { - Once a week or more }
\end{aligned}
$$

DEM14. To what extent is your faith important to you?

$$
\begin{aligned}
& 1 \text { - Not important at all } \\
& 2 \text { - Somewhat unimportant } \\
& 3 \text { - Neither important nor unimportant } \\
& \text { 4- Somewhat important } \\
& \text { 5- Very important }
\end{aligned}
$$

\footnotetext{
${ }^{10}$ Modified items DEM13 and DEM14 taken from National Longitudinal Study of Adolescent Health. Wave II
} Adolescent In-Home Questionnaire. (Harris, et al., 2009) 